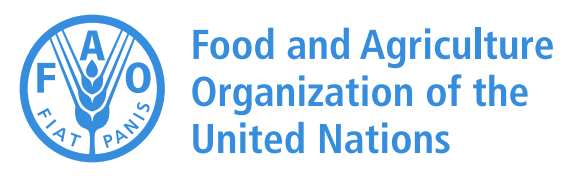

T) Columbia Center on Sustainable Investment

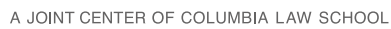
AND THE EARTH INSTITUTE, COLUMBIA UNIVERSITY

\title{
Guide on incentives for responsible investment in agriculture and food
} systems

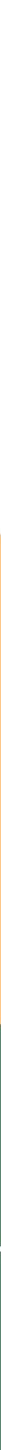





\section{Guide on incentives for}

responsible investment in agriculture and food systems

Published by

Food and Agriculture Organization of the United Nations and

Columbia Center on Sustainable Investment (CCSI)

Rome, 2021 
Bulman, A., Cordes, K.Y., Mehranvar, L., Merrill, E. and Fiedler, Y. 2021. Guide on incentives for responsible investment in agriculture and food systems. Rome, FAO and Columbia Center on Sustainable Investment. https://doi.org/10.4060/cb3933en

The designations employed and the presentation of material in this information product do not imply the expression of any opinion whatsoever on the part of the Food and Agriculture Organization of the United Nations (FAO) or Columbia University concerning the legal or development status of any country, territory, city or area or of its authorities, or concerning the delimitation of its frontiers or boundaries. The mention of specific companies or products of manufacturers, whether or not these have been patented, does not imply that these have been endorsed or recommended by FAO or Columbia University in preference to others of a similar nature that are not mentioned.

The views expressed in this information product are those of the author(s) and do not necessarily reflect the views or policies of FAO or Columbia University.

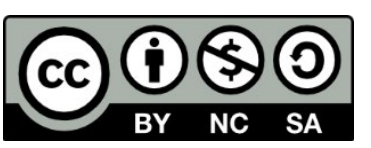

Some rights reserved. This work is made available under the Creative Commons Attribution-NonCommercial-ShareAlike 3.0 IGO licence (CC BY-NC-SA 3.0 IGO; https://creativecommons.org/licenses/by-nc-sa/3.0/igo/legalcode).

Under the terms of this licence, this work may be copied, redistributed and adapted for non-commercial purposes, provided that the work is appropriately cited. In any use of this work, there should be no suggestion that FAO or Columbia University endorses any specific organization, products or services. The use of the FAO logo and any Columbia University logo (including logos of the Columbia Center on Sustainable Investment) is not permitted. If the work is adapted, then it must be licensed under the same or equivalent Creative Commons license. If a translation of this work is created, it must include the following disclaimer along with the required citation: "This translation was not created by the Food and Agriculture Organization of the United Nations (FAO) or Columbia University. Neither FAO nor Columbia is responsible for the content or accuracy of this translation. The original English edition shall be the authoritative edition."

Disputes arising under the licence that cannot be settled amicably will be resolved by mediation and arbitration as described in Article 8 of the licence except as otherwise provided herein. The applicable mediation rules will be the mediation rules of the World Intellectual Property Organization http://www.wipo.int/amc/en/mediation/rules and any arbitration will be in accordance with the Arbitration Rules of the United Nations Commission on International Trade Law (UNCITRAL).

Third-party materials. Users wishing to reuse material from this work that is attributed to a third party, such as tables, figures or images, are responsible for determining whether permission is needed for that reuse and for obtaining permission from the copyright holder. The risk of claims resulting from infringement of any third-party-owned component in the work rests solely with the user.

Sales, rights and licensing. FAO information products are available on the FAO website (www.fao.org/publications) and can be purchased through publications-sales@fao.org. Requests for commercial use should be submitted via: www.fao.org/contact-us/licence-request. Queries regarding rights and licensing should be submitted to: copyright@fao.org. 


\section{Contents}

Foreword

Acknowledgements

Executive summary

vii

Overview of the Guide

Part I - Responsible investment in agriculture and food systems

What is responsible investment in agriculture and food systems?

Who are the key stakeholders when it comes to responsible agricultural investment?

National and sub-national government actors

Agricultural and food systems investors

Community members and civil society

Part II - Understanding investment incentives

What are investment incentives?

What are the legal and programmatic sources of incentives?

Non-institutionalised programmes and initiatives

Domestic and international laws and policies

Investor-state contracts

Common types of investment incentives

Thinking about cons and costs

Financial incentives

Technical and business support incentives

Tax (Fiscal) Incentives

Regulatory incentives 35

Other incentives

Part III - Using incentives to enhance responsible investment in agriculture and food systems: General considerations

Responsible agricultural and food systems investment is primarily determined by the 
The role of strong laws and regulation in ensuring investment is responsible

When does it make sense to use investment incentives or when is a different approach required?

Circumstances where incentives can help

Circumstances where incentives do not make sense

Incentives should be designed to support the outcomes encouraged by the CFS RAI

Reconsidering and managing incentives oriented towards large-scale foreign investors

Risks of excessive focus on large-scale foreign investors

Ways to ensure foreign large-scale investments are responsible

Regional governance and coordination are important

Attaching conditions to incentives can be essential for promoting responsible and sustainable practices beyond what is required by law

Incentives may work best as part of a package

Part IV - Planning for, designing, implementing, monitoring, and evaluating incentives for responsible agricultural and food systems investment

Planning for an appropriate intervention

Designing investment incentives

Implementing investment incentives

Monitoring, evaluation, and learning for investment incentives

Monitoring and Evaluation

Applying Learnings

Conclusion

Glossary

Annex I - Theory of change

Annex II - Designing tax incentives 


\section{Foreword}

As we write this foreword, the world is facing the worst economic crisis since the Great Depression, tied to the COVID-19 pandemic. The number of extremely poor and undernourished has increased dramatically. Millions of workers and small-scale entrepreneurs have lost their jobs and livelihoods, with women and youth hit particularly hard. Beyond triggering a recession, COVID-19 has shone a light on the deep vulnerabilities inherent in our global economic and food systems.

As countries worldwide plan for a post-pandemic recovery, we have an opportunity to design more equitable and inclusive systems. This will require concerted efforts from both public and private actors that are fully aligned with the Sustainable Development Goals in order to foster inclusive growth that is environmentally and socially sustainable.

Responsible investment in the agri-food sector holds strong potential to support realization of the SDGs. Such investment can help address some of the world's most pressing challenges, including the achievement of sustainable food security, protection and regeneration of vital ecosystems, and the creation of decent work and livelihood opportunities for those who need them most. Mechanisms that promote responsible investment in agriculture and food systems are thus critical to addressing the systemic vulnerabilities and inefficiencies COVID-19 has exposed. Such mechanisms include targeted, well-designed incentives for sustainable investment, with a particular focus on small-scale producers and small- and medium-scale enterprises.

This guide, which is a joint product of the Food and Agriculture Organization of the United Nations and the Columbia Center on Sustainable Investment, makes an important contribution in this regard. It provides policymakers and government technical staff with guidance on whether and, if so, how investment incentives can be used to enhance investment that is aligned with the Sustainable Development Goals and the Committee on World Food Security Principles for Responsible Investment in Agriculture and Food Systems.

The guide contains analytical frameworks, recommendations and good practices that can inspire new approaches to investment incentives. It builds on the extensive experience and expertise of both organizations on the trends, impacts, multidimensional challenges, and opportunities of agricultural investment in developing and emerging economies.

We hope that this guide will be of use to policy makers and technical staff in promoting and supporting the responsible investment in agriculture and food systems that is critical for more inclusive and sustainable food systems and economies.

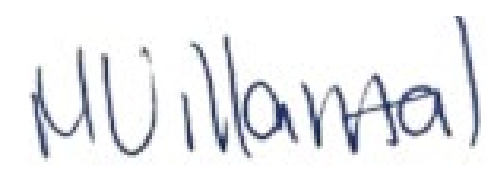

Marcela Villarreal, PhD Director

Partnerships and UN Collaboration Division Food and Agriculture Organization of the United Nations

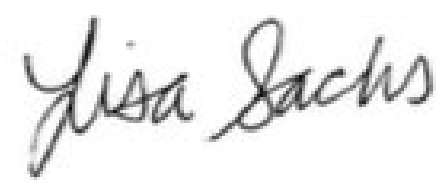

Lisa Sachs

Director

Columbia Center on Sustainable Investment 


\section{Acknowledgements}

This guide was authored by Anna Bulman, Kaitlin Y. Cordes, and Ladan Mehranvar, with contributions by Ella Merrill and Yannick Fiedler. This guide is a joint publication of the Food and Agriculture Organization of the United Nations (FAO) and the Columbia Center on Sustainable Investment (CCSI).

The project support provided by Jesse Coleman and Lisa Sachs was indispensable. The authors would also like to express their sincere gratitude to the following colleagues who provided peer reviews of all or parts of the guide: Emilie Beauchamp, David Bledsoe, Sarah Brewin, Lorenzo Cotula, Brooke Güven, Jana Herold, Lise Johnson, Jesper Karlsson, Nyaguthii Maina, Francesca Romano, Carin Smaller, Ben Stewart, Sam Szoke-Burke, Kenneth P. Thomas, Perrine Toledano, and Margret Vidar.

The authors are grateful for the excellent research support provided by Maria Jimena Rojas Mendez, Jacob Shepherd, and Abigail Edwards.

The layout and graphic design work by Carolina Saiz is gratefully acknowledged.

Finally, FAO and CCSI would like to thank Teresa Lamas Menendez for the coordination of the final editorial, layout and formatting process.

The guide was originally written in English.

\section{Suggested citation}

Bulman, Anna, Kaitlin Y. Cordes, and Ladan Mehranvar, with Ella Merrill and Yannick Fiedler. 2020. Guide on incentives for responsible investment in agriculture and food systems. Rome. Food and Agriculture Organization of the United Nations (FAO) and the Columbia Center on Sustainable Investment (CCSI). 


\section{Executive summary}

Increased investment in agriculture and food systems-from both the private and public sectors-is critical to enhance food security and nutrition, reduce poverty, and adapt to climate change. To generate sustainable benefits, this investment must be responsible.

What role should investment incentives play in encouraging such investment? This guide helps to answer that question. Specifically, the guide provides policymakers and government technical staff with guidance on how investment incentives can be used (and how they should not be used) to enhance responsible investment in agriculture and food systems.

The guide provides an overview of responsible investment in agriculture and food systems; examines common types of incentives; offers general considerations on how incentives can be used; and discusses how to plan for, design, monitor, and evaluate investment incentives for responsible investment in agriculture and food systems.

\section{Responsible investment in agriculture and food systems}

The Principles for Responsible Investment in Agriculture and Food Systems (CFS RAI) provide a framework for understanding responsible investment in agriculture and food systems. Such an investment contributes to sustainable development, enhances food security and nutrition, and respects human rights. The achievement of these objectives is supported by the incorporation of responsible investment principles into law and policy design by governments. It is also contingent on the incorporation of responsible investment principles into investor practices. Inclusive and meaningful multi-stakeholder engagement should be incorporated, by both government and investors, at all relevant stages.

Some of the principles within the CFS RAI reflect binding international human rights law, while others embody more aspirational development goals. Incentives are often not the most appropriate tool for ensuring that investments do not result in human rights abuses. By contrast, some important goals in the CFS RAI focus on achieving outcomes that are critical from a sustainability perspective, and which are aligned with but go beyond what is required by international law. In these instances, incentives are more likely to be an appropriate mechanismas one tool among many-to encourage investments that help advance such goals.

\section{Understanding Investment Incentives}

An "investment incentive" is a targeted measure provided by a government to or for the benefit of an investor (including small-scale producers) for a new or expanded investment with the goal of influencing the size, location, impact, behaviour, sector, or other character of such investment.

Investment incentives can be broadly categorised into five groups:

- Financial incentives: Non-tax-based financial supports.

- Technical or business support incentives: Can include facilitation services, technological packages, research and development, and extension services.

- Fiscal incentives (tax incentives): Tax-based measures. 
- Regulatory incentives: Derogations from national or sub-national regulations or favourable regulatory terms offered to investors.

- Other incentives: Measures that are categorised as incentives for the purposes of this guide but that do not fit into the existing established categories listed above.

The guide examines common types of incentives used in the agricultural and food systems context that fall within those categories. It provides general guidance on those incentives that are inefficient or carry an excessive risk of negative externalities (red), those that have the potential to be good or bad policy tools depending on how they are used (amber), and those that may be more likely to have positive investment outcomes if used well, albeit still with risks of negative externalities (green).

The types of incentives examined are:

Financial $\quad \begin{gathered}\text { Technical and } \\ \text { Business Support }\end{gathered}$

Grants / cash /
imput subsidies
Loans / credit
Loans guarantees
Market price
support
Income support
Concessional
insurance

\begin{tabular}{l} 
Technological \\
packages \\
\hline $\begin{array}{l}\text { Research and } \\
\text { development, and } \\
\text { extension and } \\
\text { targeted support } \\
\text { services }\end{array}$ \\
$\begin{array}{l}\text { Facilitation services: } \\
\text { Work permits, } \\
\text { immigration, } \\
\text { residence, licence } \\
\text { acquisition }\end{array}$
\end{tabular}

acquisition

\section{Fiscal}

Profit-based

Reduced rates on dividends and interest paid abroad

Tax holidays

Reduced corporate income tax rates

\section{Cost-based}

Zero-ratings and VAT exemptions

Investment tax credits

Zero or reduced tariffs

Tax deductions

Loss carry forwards

Investment allowances

Export tax exemptions

Accelerated depreciation

\section{Regulatory}

$\begin{aligned} & \text { Derogations from } \\ & \text { domestic laws and } \\ & \text { regulations }\end{aligned}$
Special land
tenure protections
for large-scale
investors

Public procurement

New, targeted infrastructure

\section{Other}

$$
\text { a }
$$




\section{Overview of the guide}

This guide aims to provide policymakers and government technical staff with guidance on how investment incentives can be used (and how they should not be used) to enhance responsible investment in agriculture and food systems.

The guide identifies key policy challenges associated with investment incentives, and offers guidance on how to design, implement, monitor, and evaluate investment incentives that are aligned with national development priorities and that contribute to the realisation of the 2030 Sustainable Development Agenda. By focusing on the full ambit of investors-domestic and foreign, small-, mid- and large-scale-the guide provides a unique contribution regarding the use of incentives for responsible investment.

The guide covers the following:

- Part I explains what responsible investment in agriculture and food systems is and who the key stakeholders are, as a starting point for understanding how incentives may be used in this context.

- Part II provides an overview of investment incentives and discusses some of the most common types of incentives used.

- Part III offers general considerations on how incentives can be used-as well as how they should not be used-to improve the quality and quantity of responsible investment in agriculture and food systems.

- Part IV discusses how to plan for, design, monitor, and evaluate investment incentives for responsible investment in agriculture and food systems.

- Separate annexes offer more specific guidance:

- Annex I provides more detail on theories of change and how they can be used for monitoring and evaluating incentives.

- Annex II discusses specific challenges of tax incentives, as well as principles that should guide the design of tax incentives.

- Annex III offers additional guidance on monitoring, evaluation, and learning (MEL) in the context of incentives. 


\section{Part I - Responsible investment in agriculture and food systems}

The agricultural sector suffers and has suffered from serious underinvestment from both the private and public sectors. Increased investment in agriculture and food systems is critical to enhance food security and nutrition, reduce poverty, and adapt to climate change. In order to generate sustainable benefits, however, it is crucial to ensure not only that more investments are made, but that more responsible investments are made.

Beyond the essential public investment that governments make in the agricultural sector, governments also play an important role in facilitating and supporting investment by smallscale producers and other private sector investors in agriculture and food systems. Strategic policy interventions, such as targeted investment incentives, can help to steer investors to invest more and in a responsible manner, with a view to promoting sustainable development and achieving the Sustainable Development Goals (SDGs). However, incentives may be ineffective, and even detrimental, if certain fundamentals are not in place. These fundamentals include factors such as strong institutions, reliable infrastructure, and laws that protect human rights and the environment.

This guide discusses the circumstances in which different types of investment incentives can be used to help to stimulate private investments that are responsible and aligned with national development priorities.

\section{What is responsible investment in agriculture and food systems?}

Investment is the commitment of capital (whether financial, physical, intellectual, or other) to something with the expectation of accumulating additional income or benefits in the future.

This guide focuses on investment made by the wide range of individuals and private sector enterprises that invest in agriculture (including livestock and pastoralism), fisheries and aquaculture, and forestry, including investments in primary agriculture as well as those in upstream or downstream activities. Investors include both domestic and foreign investors, ranging from small-scale producers and micro-enterprises to large-scale corporate investors. ${ }^{2}$

Global consensus on what constitutes responsible investment in agriculture and food systems can be found in the Principles for Responsible Investment in Agriculture and Food Systems (CFS RAI), which build on and incorporate other important guidance such as the Voluntary

\footnotetext{
${ }^{2}$ For the purposes of this guide, financial institutions are excluded from the scope of what is considered an "investor".
} 
Guidelines on the Responsible Governance of Tenure. ${ }^{3}$ According to the CFS RAI, responsible investment in agriculture and food systems contributes to sustainable development, enhances food security and nutrition, and respects human rights. The achievement of these objectives is supported by the incorporation of responsible investment principles into law and policy design by governments. It is also contingent on the incorporation of responsible investment principles into investor practices. Inclusive and meaningful multi-stakeholder engagement should be incorporated, by both government and investors, at all relevant stages.

The CFS RAI consist of 10 Principles and set out the roles and responsibilities of various stakeholders in achieving investments that are responsible and in line with the principles. Pursuant to the principles, responsible investment in agriculture and food systems achieves the following:

- Contributes to food security and nutrition (Principle 1).

- Contributes to sustainable and inclusive economic development and the eradication of poverty (Principle 2).

- Fosters gender equality and women's empowerment (Principle 3).

- Engages and empowers youth (Principle 4).

- Respects tenure of land, fisheries, and forests, and access to water (Principle 5).

- Conserves and sustainably manages natural resources, increases resilience, and reduces disaster risks (Principle 6).

- Respects cultural heritage and traditional knowledge, and supports diversity and innovation (Principle 7).

- Promotes safe and healthy agriculture and food systems (Principle 8).

- Incorporates inclusive and transparent governance structures, processes, and grievance mechanisms (Principle 9).

- Assesses and addresses impacts and promotes accountability (Principle 10).

These 10 principles can guide governments in their approach to investment in agriculture and food systems, and this approach should be incorporated into countries' national development strategies and priorities.

The CFS RAI, which were developed and negotiated using an inclusive multi-stakeholder process, take the form of a voluntary international instrument that does not, on its own, create legal obligations. Some of the principles within the CFS RAI reflect binding international

\footnotetext{
${ }^{3}$ Voluntary Guidelines on the Responsible Governance of Tenure of Land, Fisheries and Forests in the Context of National Food Security (VGGT) (FAO, 2012b).
} 
human rights law, ${ }^{4}$ while others embody more aspirational development goals. Relevant aspects of international human rights law include the right to food, the right to a remedy, and free, prior and informed consent (FPIC). Human rights law creates binding legal obligations for governments, which must: respect such rights, protect rights from infringement by third parties such as investors, and fulfil rights by taking steps to progressively realise them. In light of these obligations, incentives are often not the most appropriate tool for ensuring that investments do not result in human rights abuses.

By contrast, some important goals in the CFS RAI focus on achieving outcomes that are critical from a sustainability perspective, and which are aligned with, but go beyond, what is required by international law. These include, for example, youth empowerment, ecosystem services, and inclusive business approaches. In these instances, incentives are more likely to be an appropriate mechanism-as one tool among many-to encourage investments that help advance such goals. How incentives may do so is discussed in greater detail in Parts III and IV.

\section{Who are the key stakeholders when it comes to responsible agricultural investment?}

There are three main groups of stakeholders who have critical roles with respect to responsible agricultural and food systems investments: 5

1. National and sub-national government actors - e.g. elected or politically appointed ministry officials; ministry technical staff; elected members of legislative bodies, as well as legislative committee/technical staff; local officials and technical staff. ${ }^{6}$

2. Investors - e.g. domestic and foreign; small-, mid-, and large-scale; farmers and enterprises. ${ }^{7}$

\section{Community members affected by investments, and civil society.}

These groups may be involved in and/or affected by investment decisions and investment outcomes. Each group also has different investment-related interests and needs. These differences may be more acute at a sub-group and individual level. A participatory approach to investments and their governance-including in the design and use of incentives-can help to balance different needs, and ideally lead to outcomes that benefit all key stakeholders.

\footnotetext{
${ }^{4}$ Similarly, aspects of the CFS RAI also align with, or even incorporate, key safeguards found in other international instruments that arguably have the status of soft law, such as those contained in the Voluntary Guidelines on the Responsible Governance of Tenure of Land, Fisheries and Forests in the Context of National Food Security (VGGT) (FAO, 2012b) and the United Nations Guiding Principles on Business and Human Rights, (2011).

5 Other relevant stakeholders include donors, which support incentives programmes and other government programmes focused on agricultural and food systems investment, as well as home country governments, which incentivise their outward investors in various ways. While both can play critical roles in shaping agricultural and food systems investment, including through the use of incentives, their roles are outside the scope of this guide.

${ }^{6}$ For the purposes of this guide, certain public financial institutions are also considered to fall within the scope of "government." For one example, see below case study on the Nigeria Incentive-Based Risk Sharing System for Agricultural Lending.

${ }^{7}$ While private financial institutions are also investors in agriculture and food systems, they fall outside the scope of this guide.
} 


\section{National and sub-national government actors}

\section{Who has a general role vis-a-vis responsible agricultural investment?}

The promotion, facilitation and regulation of investment in agriculture and food systems involves a wide range of government authorities, from the national to the local level. While every country has its own specific approach to agricultural and food systems investment, and agricultural policy-making more generally, it is common for multiple ministries or agencies at the national level, as well as sub-national entities, to play a role in contributing to relevant policy, implementing investment approval processes, and/or otherwise influencing investment decision-making in this context.

At the national level, for example, issues that influence investments in agriculture and food systems may potentially be covered by a number of governmental ministries and agencies. The following table provides generalised examples of government authorities' potential roles and responsibilities; while the specifics will depend on the jurisdiction, the table gives an idea of how interrelated subjects may be parcelled out to different ministries or agencies:8

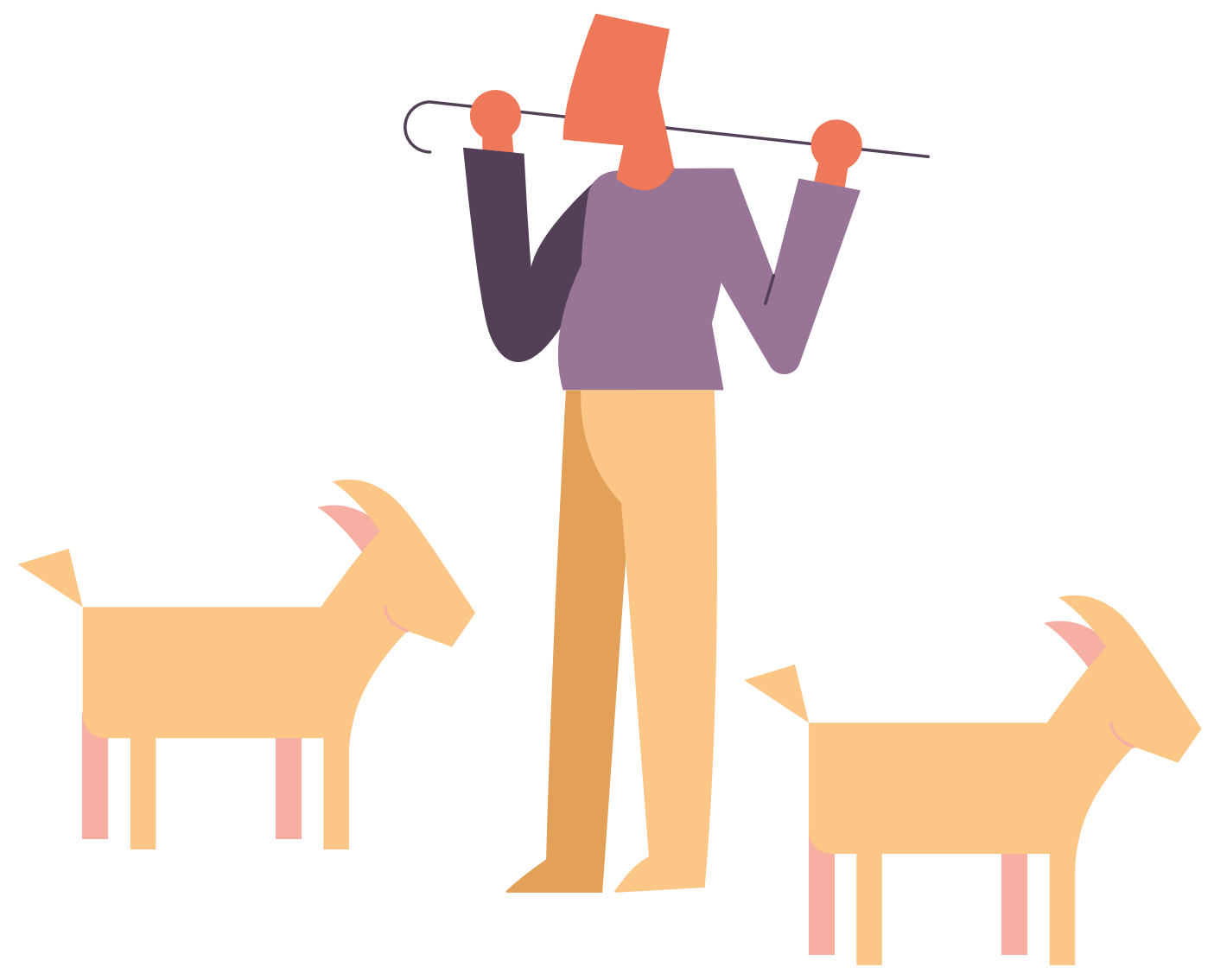

${ }^{8}$ Adapted from FAO, 2015b. 


\section{Table 1 - Subjects relevant to agricultural and food systems investment governance}

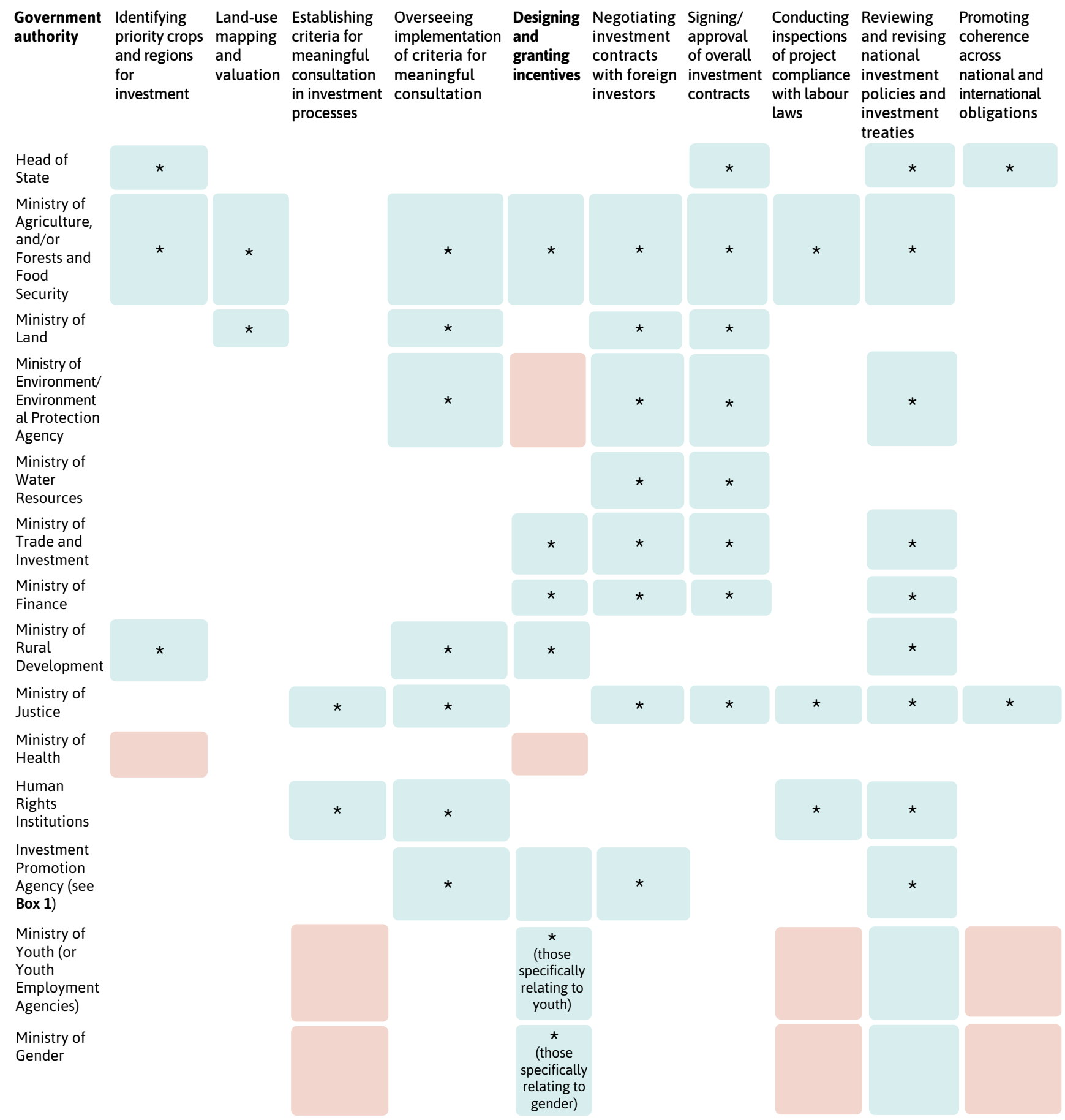

Legend

Blue shaded cells marked with a * indicate the areas where the relevant ministry or agency may have a role under mainstream practice (saying nothing of the nature or adequacy of the role).

Orange shaded cells indicate where a ministry might usefully be involved but likely is not under mainstream practice. 


\section{Government goals for responsible investment in agriculture and food systems}

Most governments have national development strategies and priorities that may influence their approach to investment in agriculture and food systems, which in turn should be aligned with the CFS RAI. For example, a government that has prioritised youth empowerment, poverty reduction, and climate change adaptation may focus on how responsible investment in agriculture and food systems can support those outcomes. Articulating the government's goals for responsible investment is an essential step when considering whether to offer investment incentives, as doing so enables policymakers and technical staff to select the best type of incentive, or another policy lever if preferable, to achieve that goal.

For foreign investment, governments often hope that investments will help to advance macroeconomic goals, such as increased revenues, job creation, technology transfer, or linkages that support additional economic growth. While these goals are sometimes achieved, they are not guaranteed. Governments and their citizens can be disappointed to realise, for example, that net livelihood loss can occur if smallholders are displaced from the land underpinning the investment (Cordes et al., 2016), that foreign corporations can use profit-shifting practices that drain anticipated revenues (Bolwijn et al., 2018; Jansky and Palansky, 2019), that foreign knowledge and technology may fail to "spill over" to domestic firms (Lipsey and Sjöholm, 2004), or that earnings may not fully materialise because of project unprofitability (De Groot and Pérez Ludeña, 2014).

When it comes to domestic investment in agriculture and food systems, governments often focus on the large proportion of citizens whose livelihoods depend on agriculture, the need to reduce poverty and improve food security in rural areas, and the potential for agriculture and small-scale agri-business to provide employment, including for youth or women. Governments thus may hope that opportunities to increase investment in agriculture and agribusiness can offer ways to improve rural livelihoods and well-being.

In addition to those primary goals, governments generally have multiple additional goals for responsible agricultural and food systems investment. Common goals relate to issues such as:

- Supporting better health outcomes, including by improving food security at the household and country levels.

- Achieving food self-sufficiency.

- Improving environmental impacts, from reducing negative environmental impacts of farming to integrating regenerative practices that improve the soil and ecosystem health of existing farmland.

- Increasing local processing and value addition. 


\section{Agricultural and food systems investors}

\section{Who invests in agriculture and food systems?}

Agricultural and food systems investment can come from the public sector, the private sector, international donors, community-based organisations, or non-governmental organisations. It can be domestic or foreign. It can involve investors who are small-scale individual producers or micro/small enterprises, medium-sized producers or enterprises, and large corporations or corporate groups. For example, investments in agricultural land can range from small plots that measure less than 0.5 hectares in size all the way up to tracts of land in the range of hundreds of thousands of hectares.

Research analysing the relative investments made by different types of primary agricultural investors has found that "farmers are by far the largest investors in agriculture" (Lowder et al., 2012). Data taken in 2012 from 76 low- and middle-income countries showed that farmers' on-farm investments were over three times as large as all other sources of investment combined. Specifically, in the countries analysed, domestic private farmers were responsible for 77.5 percent of all agricultural investments, and governments for 19.5 percent (including investment in R\&D), while FDI accounted for 1.5 percent and overseas development assistance was just shy of 1.5 percent. ${ }^{9}$ While it is possible that the relative proportions have shifted since that research was conducted, recent data does indicate a general downward trend in FDI in agriculture over the last five years, along with a likely outsized impact of COVID-19 on FDI numbers (UNCTAD, 2020). Importantly, small-scale producers, both farmers and post-harvest processers, account for a significant share of the global food consumed-up to 80 percent in Asia and sub-Saharan Africa (Nwanze, 2011).

This guide focuses on private investors in agriculture and food systems, which can be broken down into roughly the following groups:

- Domestic small-scale producers and micro and small enterprises (including, for example, farmers, fisherfolk, and small post-harvest processors).

\section{- Domestic mid- or large-scale producers and enterprises.}

- Foreign large-scale enterprises (often taking the form of a corporation).

Given its breadth of scope, this guide does not define who is a small-, mid-, or large-scale investor (in terms of monetary value of the investment or size of a landholding), but simply notes that there are substantial differences between each group that need to be recognised in the policymaking context.

Notably, even within those three overarching groups, investors can be very different. This has significant implications for policy design. For example, important distinctions within the

\footnotetext{
${ }^{9}$ Data analysed and percentages ascribed by guide authors from Lowder et al., (2012).

${ }^{10}$ For example, one of the rare papers focusing on mid-scale agricultural investors found in a study of recent farm size distributions changes in Ghana, Kenya, Tanzania, and Zambia that there were two main types of mid-scale farmer: (1) rural small-scale farmers who have expanded (the minority), and (2) investors who have acquired their land from traditional authorities (the majority). Both groups were found to be predominantly men, with the second group mostly middle aged and urban based with non-farm primary jobs (mostly civil service), and a smaller subsection of that group elite rural men who acquired large landholdings at the outset of their career (Jayne et al., 2016).
} 
oft-overlooked mid-scale investor group exist. ${ }^{10}$ Similarly important distinctions are found with respect to "smallholders", a term frequently used to refer to a diverse range of small-scale producers. For policy purposes, smallholders should be broken into more distinct sub-groups, ranging from, at one end of the spectrum, relatively better-situated producers who can more easily access formal markets, capital, and infrastructure through to, at the other end of the spectrum, small-scale farm households approaching landlessness, who are often the most marginalised and least able to benefit from government programmes (Vorley et al., 2012).

Small- and medium-scale producers' interests and needs are also shaped by other factors, such as gender (Box 2) and age (Box 3).

\section{BOX 2: WOMEN AND INVESTMENT INCENTIVES FOR AGRICULTURE AND FOOD SYSTEMS}

Women play a vitally important role in food production and are critical for achieving food security. Women comprise around 43 percent of the agricultural labour force in low- and middle-income countries (FAO, 2011). They are generally responsible for food crops (for the household and sale of the excess), while men are responsible for cash crops (Villamor et al., 2014). Because of this, women rarely benefit from land moving from food crops to cash crops.

In spite of their centrality to food systems, women often confront exclusion and discrimination within food systems that leaves them with less access to and control over land and productive resources, lower incomes than men, and fewer opportunities to participate in decisionmaking processes that affect them. These factors leave women more vulnerable to the risks of investments, less likely to benefit from investments or investment incentives, and more likely to be harmed by interventions that improve the enabling environment for investment in agriculture and food systems.

Policymakers and technical staff designing incentives for responsible agricultural and food systems investments should:

- Understand that women face specific barriers to investment and that women are also at higher risk of being harmed by other investments.

- Seek to design incentives to avoid unintended negative consequences for women.

- Make women central to incentive design processes and content in order to overcome these barriers and address these risks.

\section{Barriers to own investment and increased risks of others' investment}

Women face specific barriers to investment. Worldwide, the productivity of women farmers is 20-30 percent less than that of men; not because they are less capable, but because they face gender-specific obstacles. These include unequal access to productive resources, markets, and 


\section{BOX 3: YOUTH AND INVESTMENT INCENTIVES FOR AGRICULTURE AND FOOD SYSTEMS12}

\section{The value of youth in agriculture and food systems}

Agricultural production systems need to produce more with less, and supply chains need to become more resilient to systemic shocks, such as the COVID-19 induced market shock. Too many small-scale farmers and processers still operate at subsistence or quasi-subsistence levels, with many more facing lower incomes due to changing market situations. Youth can be agents of change in transforming food systems and enhancing value addition, thus supporting food security. By harnessing their innovative potential, using new technologies and techniques, and taking advantage of new opportunities in emerging value chains, young agri-entrepreneurs could create thriving businesses and enhance value addition of agricultural production.

In some countries, attracting and retaining youth in agriculture may be key to reducing unemployment and distress migration. Youth are three times as likely to be unemployed as adults, with unemployment rates stubbornly stagnating at around 14 percent globally and reaching up to 30 percent in Northern Africa (ILO, 2020). Furthermore, youth are more likely to be in precarious and informal employment and to experience exploitative working conditions (UN, 2013). Burgeoning un- and underemployment in turn fuels rural-urban and international migration, as many rural youth leave their homes in search of a better future. Recent data suggest that 32 percent of international migrants are under the age of 30 (UN, 2015). Since the urban sector has only limited capacities to absorb rural youth migrating to cities in many of today's low- and middle- countries and regions, the promotion of self-employment in agricultural value chains, both production and post-harvest activities, remains the most realistic employment promotion strategy governments have at their disposal, at least in the short term.

\section{Barriers to investment}

Yet, as a joint publication from FAO, CTA, and IFAD concludes, "very few young people see a future for themselves in agriculture" (FAO et al., 2014). As a result, current food systems are put under significant pressure by the agricultural "generation gap"-the aging on-farm labour force and non-rejuvenation of an entire sector. According to a recent study, the average age of an African farmer is about 60 (FAO, 2014b; Rapsomanikis, 2015). Youth face significant barriers that discourage or prevent them from engaging in agriculture and agribusiness. In many cases, market failures (discussed in Part III) are key impediments. In particular, the following are among the most frequently identified "disincentives" for youth investing in agriculture (Fiedler, 2020; FAO, et al. 2014):

\footnotetext{
12 This Box is adapted from: Fiedler, (2020).
} 
- Limited access to knowledge.

- Lack of financial services.

- Insecure land tenure.

- Lack of access to markets.

Other disincentives include low prices/margins and high risk due to price fluctuations, as well as cultural aspects whereby farming is not a prestigious or attractive occupation. These challenges are interdependent, as imperfect capital markets impede the acquisition of factors of production. Conversely, those young people who do stay in agriculture require urgent support to invest in technologies and techniques that will allow them to produce "more with less"-increasing productivity sustainably.

\section{Youth participation in design of incentives}

The best way for government officials to understand the specific barriers faced by young agri-entrepreneurs in investing in agriculture and food systems, and to develop incentives that effectively overcome these barriers, is youth participation in policy planning and design. Details on how and examples of participation are discussed further in Part IV.

The variation across investor groups and sub-groups results in significant differences in agricultural and food systems investors' goals and needs, as well as their approaches to investment decision-making. While all sorts of investors have a role to play in advancing responsible agricultural and food systems investment, their specific contributions, and how they react to incentives and other policy measures, can differ dramatically.

\section{Recommendation: Aim to design policy that is sensitive to the significant differences that exist within investor groups, based on factors such as size, value, role/activities, and location. Gender and age require particular attention and sensitivity in design.}

\section{What do investors want to achieve through investment?}

In spite of the vast differences in the nature of the investor, at their core, most investors want to see the best possible returns on their investment. This is the case with the largescale corporation that owes a profit margin to its shareholders, with the domestic mid-scale agribusiness enterprise that seeks to thrive, with the young agri-entrepreneur who wants to make a viable income off the family's land, and with the landless female labourer who wants decent remuneration for the time she puts into the plot she works. Larger-scale enterprises and foreign investors in particular might also want to achieve access to land to feed home 
markets, the opportunity to sell low-cost products in high value markets (again, maximising profit margins), and good long-term relations with the community and government that can help with branding and public perception (Smaller, 2014; Syed and Miyazako, 2013). Some investors may also have concerns for the state of the environment, or for community and other social relations. For some small-scale producers, including many indigenous peoples, their relationship with the land goes much further, and their modes of production are an integral part of their culture and way of life.

\section{Community members and civil society}

Depending on the nature of the investment, a potentially broad range of people can be affected and so become stakeholders in a given investment decision. The size and location of the land underpinning the investment, as well as other factors, such as environmental impact, often influence how many people fall into that category. For example, if an investment will affect a watercourse, people downstream are likely to be affected and so have an interest in deciding whether and on what terms the investment should go ahead.

Individuals who stand to be affected by the agricultural and food systems investments of others are often small-scale producers themselves. In such cases, these individuals have multiple roles-for example, as an investor and as a community member or local land user affected by another individual or entity's investment.

Broadly speaking, those stakeholders who are most likely to be affected by agricultural and food systems investments can be grouped into the following (often overlapping) categories:

- People who use or rely on land or waters where an investment is to occur (whether formal owners or legitimate tenure rights holders).

- Local community members who own or use the land adjacent to where an investment will occur or whose livelihoods and well-being may otherwise be affected by investment activities.

- Producers whose own activities might feed into, or are impacted by, a larger investment project.

- Employees or waged workers.

- Other stakeholders, in a broader sense, including citizens and consumers in the host state and beyond, as well as advocates and civil society who are working alongside affected stakeholders.

These stakeholders can have many legitimate interests in an investment project, including ensuring that their rights are protected, jobs are created, the environment is not harmed, and access to markets is improved. 
As with the other key stakeholder groups discussed above, this grouping comprises extremely diverse stakeholders with very different-and sometimes divergent-interests and needs. They have an important role to play in encouraging and supporting agricultural investment to be more responsible, from input into relevant policymaking, to participation in consultation and consent processes, through to monitoring investors or government actions. Governments that are able to create spaces for these stakeholders' perspectives can benefit from those insights at multiple points: from the elaboration of relevant legal and policy frameworks, to the determination of priorities regarding agricultural investment, through to the design of investment incentives themselves.

\section{Recommendation: Recognise the important roles of community members, local} landowners, and civil society in ensuring agricultural and food systems investments are responsible, and create opportunities for them to share their perspectives and influence decision-making.

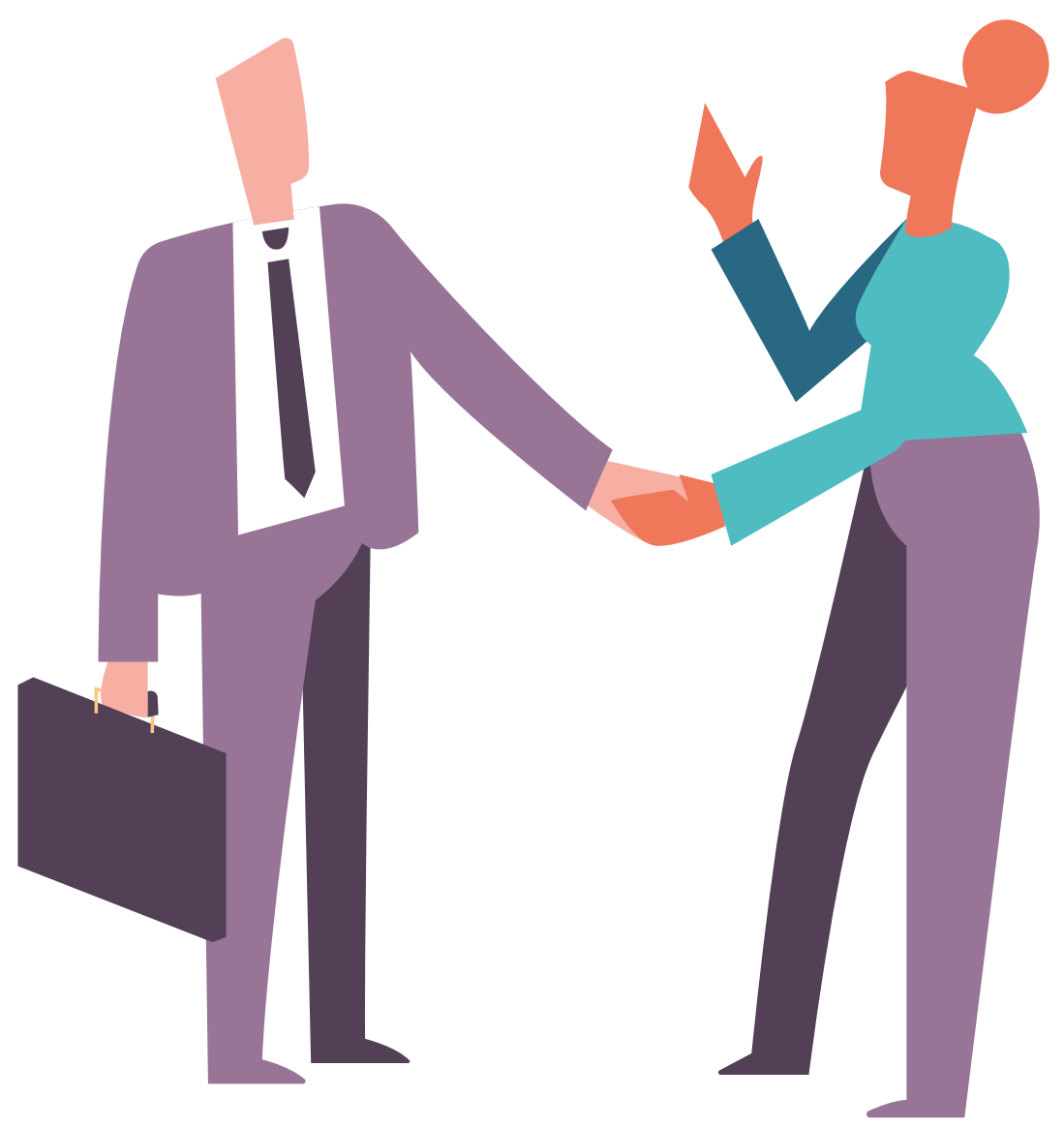




\section{Part II - Understanding investment incentives}

Investment incentives are a tool that governments can use to try to influence the quality and quantity of investment. Incentives are not the only tool that governments have at their disposal to shape investment, and in many cases, they are the wrong tool for the job-actions such as strengthening the content or enforcement of laws, improving physical infrastructure, or imposing penalties might be more appropriate and effective for influencing behaviour. The main questions of this guide are when incentives may be useful and how they can be used, as one tool among many, to enhance responsible investment in agriculture and food systems. To understand the potential and limitations of incentives in this context, it is necessary to first understand investment incentives.

\section{What are investment incentives?}

An "investment incentive" is a targeted measure provided by a government to, or for the benefit of, an investor (including small-scale producers) for a new or expanded investment with the goal of influencing the size, location, impact, behaviour, sector, or other character of such investment. ${ }^{13}$ In other words, incentives are:

- specific benefits (rather than general policies or measures that may influence a jurisdiction's or sector's "investment attractiveness");

- given or offered by a government (national, sub-national, or local)14 to (or for the benefit of) ${ }^{15}$ an investor (e.g. producers, individual investors, corporations; can be domestic or foreign);

- in the hopes of influencing the investor to behave in a certain way that differs from how it would have behaved without the incentive (such as getting the investor to invest at all, more, in a different region, or in a different way).

Investment incentives can be broadly categorised into five groups:

1. Financial incentives - Non-tax-based financial supports (e.g. grants, subsidies, loans).

2. Technical or business support incentives - Can include facilitation services (e.g. assistance obtaining permits and licences), technological packages, research and development, and extension services.

\footnotetext{
13 Adapted from Tavares-Lehmann et al., (2016), at 5; James, (2013), at 63. While there are multiple definitions of investment incentives that have been used, this guide uses a definition that aligns with common understandings of incentives (e.g., a targeted measure, a goal of shaping an investment outcome) and that is also broad enough to cover the range of relevant agricultural and food systems investors and investments that are key to the CFS RAI (e.g., allowing a focus on small-scale producers rather than focusing only on foreign direct investment).

14 Occasionally, investment incentives may be offered or managed by non-governmental entities; for example, if investment promotion agencies are private or joint public-private entities, or if a local economic development entity has been established that is not a part of government. This guide considers all investment incentives to be provided by government, even if on occasion that provision occurs indirectly. 15 While the definition of "investment incentives" in this guide does include incentives that are given "for the benefit of" investors, this guide focuses primarily on incentives that are offered by government directly to investors.
} 
3. Fiscal incentives - Tax-based measures (e.g. tax holidays, reduced income tax rates, accelerated depreciation). For the purposes of this guide, these will be referred to as tax incentives.

4. Regulatory incentives - Derogations from national or sub-national regulations (e.g. social, labour, or environmental) or favourable regulatory terms offered to investors.

5. Other incentives - Measures that are categorised as incentives for the purposes of this guide but that do not fit into the existing established categories listed above (e.g. public procurement, and creation of new and targeted infrastructure).

Although these categories and the definition above can help in identifying and understanding most investment incentives offered by governments, it is not always clear when a government measure should be considered an investment incentive. For example, through public procurement, a government may seek to purchase food (e.g. for school feeding programmes, food aid, public hospitals, etc.) from small-scale producers in order to create a stable market for them, even if this sometimes requires paying an above-market price. Is that public procurement policy an investment incentive? Maybe. The government is using its purchasing power and willingness to (potentially) pay a slightly higher price (targeted measure) to create a stable market (benefit) for small-scale producers (investors), which can encourage increased small-scale producer investment in the good being procured (influencing investor behaviour). Or maybe not. The government is simply purchasing necessary goods that, even if not fully cost competitive, provide the government value while also helping the government fulfil a secondary objective of supporting small-scale producers. Rather than worry too much about how to categorise those measures that could be interpreted either way, such gray areas provide important reminders that: first, governments have many tools at their disposal, of which incentives are only one, and, second, government measures, whether incentives or not, have both costs and benefits that should be weighed and considered in light of policy objectives and development goals.

Indeed, although governments use incentives to try to influence investor behaviour, incentives are often not appropriate, not effective, or not worth their cost. For example, incentives are not an appropriate tool to prevent serious human rights abuses, such as forced labour, which should instead be prohibited by law. And incentives are not effective if they do not change investors' behaviour; this includes redundant incentives, which are provided even when the investment would have been undertaken without the incentive.

\section{Recommendation: Use incentives as a targeted policy instrument to address} specific needs, but only if they are effective, worth their cost, and not redundant.

One way of targeting incentives is by offering sector-specific incentives (see Box 4). In addition, Part III provides more specific considerations for using incentives to enhance responsible investment in agriculture and food systems. 


\section{BOX 4: SECTOR-SPECIFIC INCENTIVES}

Governments can choose to target investment incentives in different ways. For example, they may target by way of any or all of the following:

- Investors of a particular status (e.g. first time / new entities).

- Investment of a particular monetary value.

- Investment in a particular sector.

- Investment in a particular location.

Sector-specific incentives may be more effective at achieving particular development outcomes than generic incentives that apply in the same way to any investor regardless of sector. ${ }^{16}$ To the extent that governments seek to use incentives to encourage both greater quantities of and more responsible agricultural and food systems investments, sector-specific incentivesalong with other careful targeting and use of conditions (see Parts III and IV)—may be more effective than broader incentives.

While sector-specific incentives may be more effective for achieving development goals, they have their limitations. First, sector-specific incentives and policies can be heavily affectedand sometimes neutralised-by economy-wide policies and other macroeconomic issues, including exchange rate policies and industrial protection (Schiff and Valdes, 1996). Second, sector-specific programmes have been reported to be "prone to become subject to political pressures aimed at having their resources applied beyond original mandates," rendering the incentives ineffective (OECD, 2003).

\section{What are the legal and programmatic sources of incentives?}

Investment incentives are offered in many ways, but most commonly through:17

- Government programmes that are not necessarily directly prescribed in law.

- Domestic laws and regulations.

- Contracts signed between the investor and a government entity.

\footnotetext{
16 OECD, (2018b). (Noting that sector-specific incentives are on the rise in ASEAN countries as a means of achieving specific development objectives); Christian Gonzalez, Mike Kerlin, Rachel Schaff, and Sarah Tucker-Ray, "How State and Local Governments Win at Attracting Companies," McKinsey \&amp; Company Insights. September 13, 2019. (Noting, in the US context, that "anchoring incentives to specific sectors enables more thoughtful investments in related areas that can also boost economic growth ....").

${ }^{17}$ Another legal source of investment incentives is arguably international investment agreements. IIAs are outside the scope of this guide; see Box 5 for more information.
} 


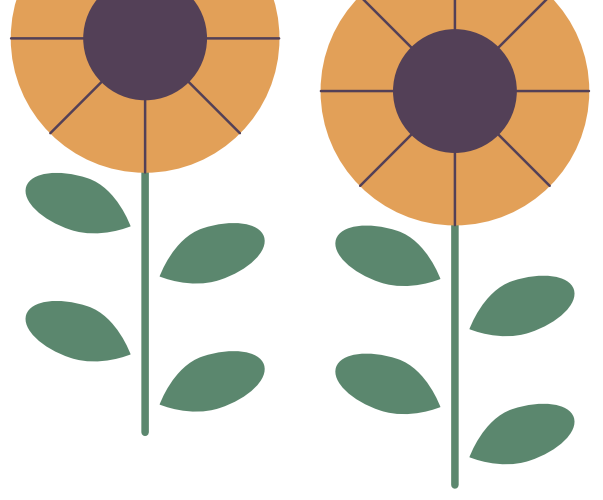

Non-institutionalised programmes and initiatives

Investment incentives-particularly those targeting small-scale producers or subgroups within them-are not always directly prescribed in law, and may instead be programme-based and dependent on donor funding. For example, in Uganda, the FAO-Ministry of Agriculture, Animal Industry and Fisheries Youth Inspiring Youth in Agriculture Initiative has identified youth champions to receive small grants for their businesses. This initiative, as many other similar programmes, depends on donor funding (Fiedler, 2020). While such initiatives do provide useful support to young agri-entrepreneurs, reliance on funding from international organisations or non-governmental organisations can have implications for a programme's longevity.

\section{Domestic and international laws and policies}

Investment incentives relevant to agricultural and food systems investments can be scattered across a number of different laws and policies, such as those specific to investment, to tax, or to agriculture, as well as those establishing free trade zones or other special economic zones.

To the extent feasible, embedding incentives that aim to support small-scale producers into domestic national or sub-national law can help to ensure the longevity of the programme. (See Part IV for more on timeframe and duration.) Embedding incentives in law can also enable more transparency, consistency, and accountability.

Beyond domestic law, incentives may also be found in-or affected by-international investment treaties. Given that evidence demonstrates that the effect of investment treaties on decisions to invest is indeterminate or negligible, and in light of the distinct differences between investment treaty-making and the process of domestic investment incentives design and provision, this guide excludes investment treaties from its coverage of incentives. It is nevertheless important that governments understand the potential risks that investment treaties pose in the context of investment incentives offered at the domestic or project level, as discussed briefly in Box $\mathbf{5}$.

\section{BOX 5: INTERNATIONAL INVESTMENT TREATIES AND INCENTIVES}

International investment treaties, which include bilateral investment treaties and the investment chapters of free trade agreements, provide protections to foreign investors and corresponding obligations for state parties. These investor protections and benefits are usually enforced through the investor-state dispute settlement (ISDS) mechanism, by which foreign investors (individuals and companies) can file an arbitration claim against a host country for measures that are alleged to have negatively affected their real or expected profitability.

While proponents of investment treaties argue that the enforceable investor protections provided by such agreements lead to greater cross-border investment flows-thus serving as a form of investment incentive-a growing body of empirical research shows that investment treaties do not deliver on the promise to increase investment, and that the societal costs 
associated with investment treaties may outweigh any purported benefits of new investments. Furthermore, not all investments positively shape a host country's development, and some directly harm certain development objectives (Johnson et al., 2020; Johnson et al., 2018). For these reasons, this guide excludes investment treaties from its coverage of incentives.

It is nevertheless important that governments understand the potential risks that investment treaties pose in the context of investment incentives offered at the domestic or project level. For example, decisions to modify or withdraw incentives from a covered investor, or offering incentives in a discriminatory manner, may result in costly ISDS claims from investors. ${ }^{18}$ In addition, some investment agreements may limit or prohibit countries' enforcement of performance requirements used by a host state to advance specific development objectives. While such risks should not prevent governments from taking the necessary policy steps to advance specific development objectives, understanding these risks can inform government approaches to incentives design and implementation.

\section{Investor-state contracts}

Contracts between the state (at the national or sub-national level) and a large-scale investor are also used in some contexts to provide project-specific incentives that are agreed upon by the parties. Investment incentive contracts generally give a package of incentives in exchange for certain investment commitments on the part of the investor, and are used by governments in the hopes of inducing the investor to locate in that national or sub-national jurisdiction. In addition to specific incentive contracts, some states also enter into broader investment contracts with investors, such as concession agreements, which also commonly include certain incentives. ${ }^{19}$

Beyond the specific financial and tax incentives that investor-state contracts typically offer, such contracts may also offer regulatory incentives that enable derogations from law. This is sometimes done, for example, through a "stabilisation" provision, which aims to exempt investors from changes in the law that may have the effect of increasing their costs of doing business. Good practice suggests that stabilisation provisions should be avoided.

More generally, the use of investment incentive contracts presents several problems, similar to the challenges that arise with discretionary legislated procedures discussed in Part IV.

\footnotetext{
${ }^{18}$ As an example, numerous ISDS claims have arisen from countries' use of local content requirements and investment incentives to encourage investment in, and consumption of, renewable energy. Spain, Italy, and the Czech Republic were forced to scale back incentives favouring renewable energy after their unexpectedly large success led to dramatic energy market distortions. As a result of these modifications, Spain has faced nearly 40 arbitrations from renewable energy firms, which have contested that measures altering the existing incentives regime were in breach of investment treaties, violating their legitimate expectations and leading to the devaluation of their investments. Italy and the Czech Republic are involved in similar claims. See, for example, Eiser v. Spain; Isolux v. Spain; Novenergia v. Spain; Cosbev, (2017); Reynoso, (2019).

${ }^{19}$ For examples of investor-state contracts that include investment incentives, see the range of contracts available at the Open Land Contracts website: OpenLandContracts.org. At the time of research, a search for investor-state contracts that include income tax exemptions turned up 85 contracts from countries in Asia, Africa, and Latin America.
} 
Leaving incentive provisions to individual negotiators with excessive discretion increases the bargaining power of investors, results in complicated and costly administration and monitoring, and increases the scope for corruption. Using investor-state contracts to offer incentives also inherently favours large-scale investors over small-scale producers and other investors operating at a smaller scale. ${ }^{20}$

\section{Recommendation: Reduce or eliminate the discretion to offer incentives through} contracts and, when possible, embed incentives in domestic national or subnational law.

\section{Common types of investment incentives}

This section provides a brief overview of some of the most common types of investment incentives used in the agricultural and food systems context: financial, technical and business support, fiscal (tax), and regulatory. It also looks at incentives that fall into the category of "Other" under the definition of this guide.

Each sub-category of incentives is presented below in tabular form, with descriptions of what the incentive is and how it works, potential pros, and potential cons. The information is presented in a "traffic light" system, where incentives that are inefficient or carry an excessive risk of negative externalities are coded red, incentives that have the potential to be good or bad policy tools depending on how they are used are coded amber, and incentives that, if designed well, may be more likely to have positive investment outcomes (albeit still with risks of negative externalities) are coded green:

Inefficient or excessive risk of negative externalities

Good or bad depending how used

More likely positive investment outcomes

\section{Thinking about cons and costs}

A number of cons and other considerations specific to each type of incentive have been set out in the "Potential cons" column of the tables below. Beyond those specific potential cons, however, there are a number of cross-cutting cons that may apply across the spectrum of incentives. These cons include:

- The inherent risk that incentives may not achieve their policy objectives.

- The risk that support may not be enjoyed equally by women and men, or that women

\footnotetext{
${ }^{20}$ Although good practice suggests that incentives should not be offered via contract, for governments that plan to continue to conclude investor-state contracts as a vehicle for providing investment incentives, relevant resources on responsible contracts can help guide their negotiations. See e.g. UNIDROIT et al., (2020); Smaller, (2014).
} 
specifically may be negatively affected, if programme design lacks gender sensitivity (see Box 2).

- The possibility that certain incentives could run afoul of international trade laws (see more Box 6).

- The risk that incentives may not be worth their costs.

To understand this last risk, it is necessary to understand the costs associated with incentives. The costs of incentives include the more obvious costs, such as the actual financial outlay for the incentive itself. For example, in the case of a tax holiday (tax incentive), this is revenue foregone. For a grant (financial incentive), it would be the money that is being transferred to the investor. Other direct costs include administrative costs, such as the salaries of government officials whose time goes towards designing, administering, monitoring, and evaluating the incentive. There are additional "hidden costs," which include, for example: opportunity costs (what the money might otherwise be used for), the costs of offering an incentive for an investment that would have been made irrespective of the incentive, capital that is invested inefficiently in order to capture the incentive, and local investment that is displaced by other (typically foreign) investors attracted by the incentive (Thomas, 2007).

\section{BOX 6: INTERNATIONAL TRADE LAW AND AGRICULTURAL INCENTIVES}

While the World Trade Organization (WTO) does not "currently feature a credible set of disciplines on the distortive effects of investment incentives" (Sauve and Soprana, 2016), it is possible that certain agricultural investment incentives may be in breach of existing international trade rules, such as, for example:21

- export-linked incentives;

- market price support; and

- input subsidies.

In addition to the actual incentives, it is possible that certain conditions attached to incentives (discussed in Part III), such as local content requirements, could also breach WTO rules (FAO, 2013a; Sauve and Soprana, 2016; FAO et al., 2010).

Depending on how they are designed, other incentives and conditions, such as decoupled (not linked to production) income support, income insurance and safety-net programmes, natural disaster relief, certain environmental payments, and assistance for agricultural and rural development, may not, however, be in breach of WTO rules (WTO, n.d.).

\footnotetext{
21 For a discussion of the WTO law applying to financial incentives applied to attract agricultural investment see Johnson et al. (forthcoming). See also "Agriculture: Explanation - Domestic support." World Trade Organization. https://www.wto.org/english/tratop e/agric e/ag intro03 domestic e.htm.
} 


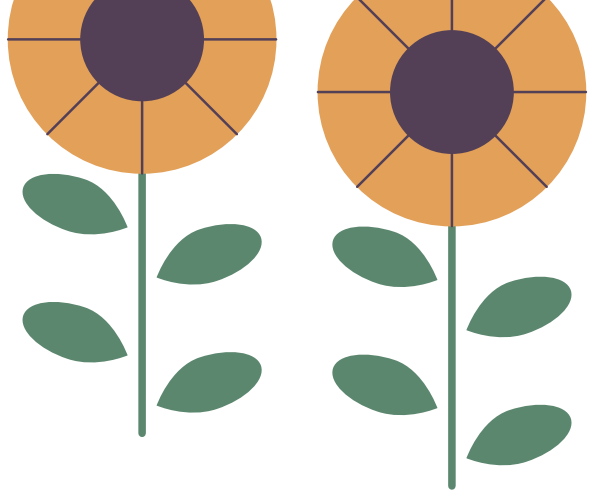

Recommendation: Analyse proposed investment incentives for potential international trade law breaches.

\section{Financial incentives}

Financial incentives are direct financial advantages provided to investors. They may be either non-reimbursable or reimbursable, with or without interest or extra costs. Common types of financial incentives that are offered in the agricultural and food systems context and examined in Table 2 of this guide are:

- Grants / cash / input subsidies

- Loans / credit

- Loan guarantees

- Market price support

- Income support

- Concessional insurance

Financial incentives are used for all sizes of investors. While the eligibility criteria and intended beneficiaries are specific to the incentive (and many may be intended only for investors of a certain size), financial incentives can offer critical support to small-scale producers, enabling them to invest more and invest better. Financial incentives can be especially important for those who face particular challenges in accessing financial services on the market, such as young agri-entrepreneurs and women.

Although well-designed financial incentives can influence investment decision-making, one commonly cited risk factor is that they can create market distortions and have other unintended consequences. To the extent that such incentives are helping to address a market failure, however, the accompanying "distortions" are not necessarily a problem. Due to the nuance and complexity of this topic, market distortion is disregarded in the tables below. 


\section{Table 2: Financial incentives}

This table provides a brief overview of common financial investment incentives that may be offered to investors in agriculture and food systems, employing the traffic light system explained on page 21.

\section{Incentive type}

Grants / Cash / Input subsidies

Loans / Credit

Loans Guarantees

\section{What it is \& how it works}

Direct financial transfers to investors for certain eligible expenses, or subsidised inputs. ${ }^{22}$ These can be provided for a number of different purposes, such as:

- Inputs (e.g. for fertiliser, machinery, mechanisation).

- Job training (these may support trainees, newly recruited employees, or existing staff).

Grants and input subsidies are a potentially powerful tool - for good or bad, depending on what exactly is being subsidised and the conditions of the subsidy.

Concessional loans are provided on more favourable terms than market rates (e.g. lower interest rates, longer grace periods).

Non-concessional loans or credit are provided at market rates on the same conditions as those offered by commercial lenders. They are useful when credit is not widely available; for example, for small- and medium-scale producers who lack a sound capital structure or assets large enough to guarantee loans.

Loan guarantees are a promise by government to assume the debt obligation of the farmer in the event of default. They can be considered a subsidy, and are useful in helping encourage lending from institutions that might not otherwise provide any or accessible loans.
Potential pros

Enable small-scale producers to enter the market.

Enable small-scale producers to increase productivity or otherwise remain economically viable.

Can be effective for achieving environmental benefits (e.g. payments for ecosystems services).

Increased access to finance.

Enable farmers to maximise productivity potential of their land.

Broad reach.

Enhance access to finance to small-scale producers who commonly lack access to commercial banks, such as young agri-entrepreneurs and women.

Mobilise co-financing from external sources.

Possible long-term debt finance for development.

Enable farmers to maximise productivity potential of their land.

Broad reach.

Enhance access to finance to small-scale producers who commonly lack access to commercial banks, such as young agri-entrepreneurs and women.
As they leverage existing (private) financial institutions, they only work when such institutions exist.

Government (or other guarantor) is exposed to risk of principal loss.

\footnotetext{
23 Input subsidies can be provided in various ways. One common approach is through the use of vouchers; another is through the direct provision of the input. For these reasons, this guide has included input subsidies within this category of financial incentive. However, input subsidies may also take the form of a tax incentive or be offered in other ways.
} 


\begin{tabular}{|c|c|}
\hline $\begin{array}{l}\text { Market Price } \\
\text { Support }\end{array}$ & $\begin{array}{l}\text { A form of subsidy that guarantees } \\
\text { minimum prices to producers. }\end{array}$ \\
\hline $\begin{array}{l}\text { Income } \\
\text { Support }\end{array}$ & $\begin{array}{l}\text { Direct payments to farmers, e.g. on the } \\
\text { basis of size of land holdings (European } \\
\text { Commission, n.d.). }\end{array}$ \\
\hline $\begin{array}{l}\text { Concessional } \\
\text { Insurance }\end{array}$ & $\begin{array}{l}\text { Subsidised insurance. Effects may vary } \\
\text { depending on type of insurance and } \\
\text { targeting, e.g.: } \\
\text { - supporting farmers producing specific } \\
\text { crops; } \\
\text { - addressing specific risks (e.g. crop } \\
\text { yield risks, price risks, or climate- } \\
\text { related risks); and/or } \\
\text { - encouraging behavioural changes } \\
\text { (e.g. insurance that mitigates risks of } \\
\text { reduced harvests due to adoption of } \\
\text { more environmentally friendly practices). }\end{array}$ \\
\hline
\end{tabular}

Helps farmers to not produce at a loss.

Encourage more sustainable farming practices by providing cash required to make necessary investments.

Encourage the production of more diverse and nutritious food over more basic, monocropped commodities.

Mitigate price risks.

Reduce impact on farmers of weather- and climate-related production risks.

Encourage small-scale producers to increase production intensity.
Risk breach of international trade rules (see Box 6).

Environmental harm where it encourages unsustainable farming practices or use of resources.

Consumers pay more for product.

Reduce food industry's competitiveness.

\section{Distort markets.}

Encourage excessive risk taking.

Discourage more environmentally sustainable practices if such practices may inadvertently lead to the loss of insurance benefits.

Risk inflating value of farmland and farming practices, to the exclusion of new small-scale producers.

Sources relied upon in the above table: Tavares-Lehmann et al. (2016); Teye (2019); OECD (2020); Laborde et al. (2019); IISD (2019); Streck et al. (2012); OECD (2017); Fleckenstein et al. (2020); Riensche and Vir Jakhar (2019); Cordes et al. (2016); Vorley et al. (2012); Locke et al. (2019). 
The following two case studies illustrate ways in which financial incentives have been used in practice in Tunisia and Senegal.

\section{Case Study: Tunisian Land Loans Scheme ${ }^{23}$}

Like other incentives, financial incentives can be provided broadly or targeted to specific sectors and/or beneficiaries. For countries seeking to address the particular challenges confronting youth, financial incentives catered specifically to youth and young adults is one available tool.

An example of a credit scheme that caters to young agri-entrepreneurs is the Tunisian land loans scheme (prêts fonciers). Designed to support young agri-entrepreneurs to acquire and develop land, the land loans (prêts fonciers) are a specific instrument under the Tunisian investment code and are accessible to all youth under the age of 40 who have graduated from university (in agriculture and related technical fields) or have a certificate of professional competence. The land itself must have a potential which is currently not being fully exploited. The total volume for each loan can reach up to DT 250000 (approx. USD 85 000), with an interest rate of 3 percent, a grace period of 7 years, and 5 percent self-financing requirement for land acquisition, and 10 percent for land development (including electrification).

Young agri-entrepreneurs who have benefitted from the land loans are also eligible for other, non-youth-specific investment subsidies (grants complementing private investments), such as those that cover parts of expenses related to investments in water-saving technologies. While the operational modalities (including eligibility criteria) of the land loans have varied over time, this credit scheme is quite well established, with data on the total amount of loans provided dating back to 1985. The total volume of new prêts fonciers has increased continuously over recent years.

23 This case study is adapted from: Fiedler (2020), Box 2, 22. Citing: APIA (n.d.); FAO, (2013b); FAO and INRAT, (2020). 
access to financial services, but are empowered to improve the productivity and efficiency of their businesses (Fiedler, 2020). Ideally, such support services should be "provided along the entire value chain, delivering field-level interventions as part of more integrated programs." Importantly, because small-scale producers are a heterogeneous group, such services should involve "a diverse portfolio of flexible farm-level interventions" (Gassner et al., 2019).

Technical and business support incentives can be offered pre-investment, during the course of the investment, or after the investment has been implemented. Table 3 highlights the following technical and business support incentives used in the agricultural and food systems context:

- Technological packages

- Research and development, and extension and targeted support services

- Facilitation services: work permits, immigration, residence, licence acquisition

\section{Table 3: Technical and business support incentives}

This table provides a brief overview of common technical and business support incentives that may be offered to investors in agriculture and food systems, employing the traffic light system explained on page 21.

\begin{tabular}{|c|c|}
\hline Incentive type & What it is \& how it works \\
\hline $\begin{array}{l}\text { Technological } \\
\text { Packages }\end{array}$ & $\begin{array}{l}\text { Provision of technological packages } \\
\text { such as disease-resistant or other } \\
\text { quality seeds, composting equipment, } \\
\text { and particular stock breeds. } \\
\text { Combining provision of inputs with } \\
\text { training. }\end{array}$ \\
\hline \multirow[t]{2}{*}{$\begin{array}{l}\text { Research and } \\
\text { Development, } \\
\text { and Extension } \\
\text { and Targeted } \\
\text { Support } \\
\text { Services }\end{array}$} & $\begin{array}{l}\text { Support for investigations into } \\
\text { agricultural good practices. } \\
\text { Agricultural extension services may } \\
\text { come in the form of technical advice, } \\
\text { supply of inputs, information, or new } \\
\text { ideas developed by agricultural } \\
\text { research stations. These services may } \\
\text { focus on a range of topics, including: } \\
\text { improved crop varieties or livestock } \\
\text { breeds; better water management; and } \\
\text { improved control of weeds, pests, or } \\
\text { plant disease (Oakley and Garforth } \\
\text { 1985). Examples of specific extension } \\
\text { services include agricultural colleges, } \\
\text { training, veterinary services, } \\
\text { phytosanitary services and quality } \\
\text { control, plant protection and health, } \\
\text { and engineering services. Importantly, } \\
\text { extension services need to be widely } \\
\text { available for different types of crops. }\end{array}$ \\
\hline & $\begin{array}{l}\text { Targeted support services may include } \\
\text { agri-incubators, coaching, and other } \\
\text { advisory services. }\end{array}$ \\
\hline
\end{tabular}

Potential pros

Training and inputs for small-scale producers.

Encourage environmentally friendly agriculture.

Stimulate responsible investment, especially when accompanied by other carefully targeted incentives and measures.

Improve technical efficiency.

\section{Potential cons}

Limited benefits, or even harms, if inputs are not well-suited to farmer needs (e.g. if seeds cannot be saved or require expensive inputs, if livestock not well-suited for the climate, etc.). 


\begin{tabular}{|c|c|}
\hline $\begin{array}{l}\text { Facilitation } \\
\text { services: Work } \\
\text { permits, } \\
\text { immigration, } \\
\text { residence, } \\
\text { licence } \\
\text { acquisition }\end{array}$ & $\begin{array}{l}\text { Investment facilitation simplifies } \\
\text { administrative procedures by helping } \\
\text { investors understand and meet } \\
\text { regulatory requirements and get set up } \\
\text { in a country, for example, through } \\
\text { "one-stop shops." This can include } \\
\text { support in obtaining permits and } \\
\text { licences from relevant government } \\
\text { departments, addressing immigration } \\
\text { issues for foreign workers, and } \\
\text { permitting residence of foreign } \\
\text { workers. } \\
\text { Investment facilitation that supports } \\
\text { responsible investment should also } \\
\text { include measures to generate } \\
\text { awareness among investors of } \\
\text { applicable laws, regulations, and } \\
\text { processes (such as impact assessment } \\
\text { processes), and compliance with such } \\
\text { rules and processes (see Box } 7 \text { below). }\end{array}$ \\
\hline
\end{tabular}

Make doing business easier.

Valued by mid- and

large-scale investors.

Awareness generation

functions may benefit

small-scale producers as well.
Where investment facilitation measures are solely focused on streamlining and expediting administrative requirements and procedures, this may undermine regulations and processes that are necessary for promoting investments that are responsible (see Box 7).

Risk that permits and licenses are provided without sufficient screening of investment proposals, without sufficient due diligence on investors, or without sufficient engagement in investment assessment processes, and that preliminary permits or licenses may be viewed as a right to operate, even if full set of investment approval processes have not been completed.

Hiring of expatriates, especially high numbers or unlimited, may disincentivise local hiring and career progression opportunities. ${ }^{25}$

Sources relied upon in the above table: Fiedler, (2020); Baliño et al., (2019); Laborde et al., (2018); Lampach et al., (2018); Ayele et al., (2019).

\section{BOX 7: INVESTMENT FACILITATION}

Investment facilitation efforts—often, but not always, oriented around facilitating FDI—can usefully remove undue barriers to investment, such as opaque, confusing, or burdensome regulatory requirements, complicated or delayed administrative procedures, corruption, or a lack of critical infrastructure or services. However, many of today's investment facilitation initiatives are investor-centric_focusing on speeding up approvals, removing regulatory barriers, and stabilising the legal and regulatory environment for the benefit of investors-to the possible detriment of other social and environmental goals. It is critically important that facilitation initiatives not be considered in isolation from a host state's broader development agenda. That is to say, while governments should support an enabling environment for investors and investments, critical factors such as environmental protection, local economic and social development, protection of legitimate tenure rights, industrial upgrading, employment and

25 This can be addressed through hiring caps on expatriates or mandates that such workers provide training to local workforces in instances where there is not existing capacity to carry out required tasks. 
skills training, health, climate, and other development priorities must be advanced alongside investor-oriented policies in order to ensure that investment enhances the benefits of development to society as a whole (Güven, 2020). Evidence also suggests that this kind of broader framing and approach ultimately benefits the investment project itself (Coleman et al., 2018).

Investment facilitation for sustainable development is best understood as a combination of tools, policies, and processes, which will vary by context, that foster a regulatory and administrative framework to facilitate investment that maximises and does not undermine sustainable development objectives. When developing a plan to facilitate investment, a state should holistically consider its sustainable development goals and whether there are regulatory or technical hurdles unduly preventing it from achieving them. It should then determine the appropriate facilitation plan that can address undue burdens for investors while remaining aligned with broader development objectives (Güven, 2020).

The following case study illustrates ways in which technical and business support incentives are being used in practice in Senegal.

\section{Case Study: Modèle d'insertion des jeunes dans l'agriculture (Senegal) ${ }^{26}$}

In Senegal, the Modèle d'insertion des jeunes dans l'agriculture (MIJA, in English: Model for Youth Integration into Agriculture) programme is managed by the government's youth employment agency (ANPEJ) and funded by the government with support from FAO and the Spanish Agency for Development Cooperation. The six MIJA platforms offer comprehensive incubation services, including model farms. The programme has successfully supported young agri-entrepreneurs to organise themselves into the self-help association Réseau africain pour la promotion de l'entrepreneuriat agricole (RAPEA), which in turn provides technical support services to start-up agrientrepreneurs, fosters knowledge sharing, and facilitates collective action.

\section{Tax (Fiscal) Incentives}

Tax incentives involve reductions or exemptions from ordinary taxation obligations and are accounted for as revenue forgone or deferred. Such incentives are often preferred in particular by lower-income countries that have fewer upfront resources for financial incentives and are often used in the context of efforts to attract FDI (Tavares-Lehmann et al., 2016). Yet studies indicate that they are often not worth their cost.

${ }^{26}$ This case study is adapted from: Fiedler, (2020). 


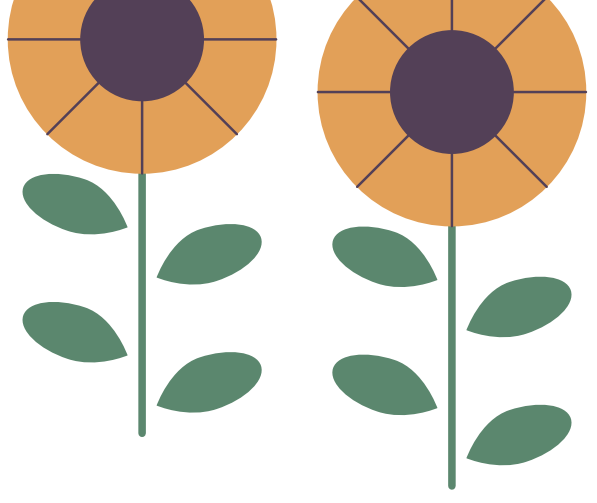

Serious doubt has been cast by various econometric and interview-based studies about the effectiveness of tax incentives as they are generally used. ${ }^{27}$ Essentially, tax incentives cost governments a great deal in terms of lost revenue, but have not been shown to yield commensurate benefits in terms of increased investment. This may especially be the case for some primary production large-scale agricultural investments that could be described as resource-seeking, such as "rubber, tobacco, sugar, bananas, pineapples, palm oil, coffee, and tea" (Tavares-Lehmann et al., 2016).

Recent interview-based studies underscore the limited impact of tax incentives for commercial agriculture in certain countries. Looking at incentives and agribusiness investment in Ethiopia, one study found that "fiscal incentives, in particular, are non-consequential to business Investment" (Ayele et al., 2019), with the agribusinesses interviewed identifying availability of and access to land, infrastructure, concessional loans, and facilitation services as more important for supporting investment. In fact, "despite substantial incentives, investments often fail to start and meet the intended development objectives of the country" (Ayele et al., 2019). Another study looking at agricultural commercialisation in Ghana found that tax incentives can benefit farmers, but "they do not really stimulate investments in the agriculture sector" (Teye, 2019). In particular, decisions about investment location are not particularly influenced by tax incentives, as poor infrastructure-which increases production costs - is a much more relevant factor (Teye, 2019). In addition, a 2020 study of agribusiness investment and incentives in Africa found additional evidence supporting this pattern, ${ }^{28}$ concluding that most tax incentives did not motivate investment (with an exception for import duty exemptions), and asserting that resources should be shifted away from tax incentives towards efforts to improve infrastructure and increase access to finance (Ayele et al., 2020).

Tax incentives are less relevant for investors operating in the informal economy, such as many small-scale producers. And even where smaller local agribusiness investors can technically access tax incentives, they may not benefit from them due to their scale of operations (e.g. they do not import large quantities of capital goods or export their produce) or due to the administrative inaccessibility of such incentives (Ayele, 2019).

An additional challenge of tax incentives is that, even if the incentives are set up to only apply to certain investors or investments, large-scale investors can often find ways to cheat the system to benefit from incentives not intended for them. For example, foreign firms may set up a local affiliate to capture incentives for domestic farmers, local firms may set up foreign entities to capture FDI-oriented incentives, existing firms may set up new corporations to capture benefits available only to new firms, or companies may shift taxable income to a related entity

\footnotetext{
27 For a fuller discussion on the topic, see Annex II.

28 Among other evidence provided for this assertion, the 2020 study included the results of a survey of 14 medium and large- scale agribusiness investors (both foreign and domestic) in Ghana, Ethiopia, and Malawi, which found that only two of the 14 companies reported that fiscal incentives had influenced their investment decisions (Ayele et al., 2020). One exception was with respect to import duty exemptions: seven out of the nine companies who received these reported that theseexemptions "supported greater investment." (Ayele et al., 2020). The study also referenced previous research, including a survey focused on Burundi, Rwanda, Tanzania, and Uganda, which found that only 7.4 percent of investors surveyed said they would not have invested without fiscal incentives (Mwachinga, 2013).
} 
to take advantage of certain incentives. In addition, tax incentives can also create burdensome administration costs (IMF et al., 2015), although some are more complicated to administer than others.

Tax incentives can be profit-based incentives or cost-based incentives. Profit-based tax incentives reduce or eliminate the rates imposed on otherwise taxable income. Cost-based tax incentives, by contrast, focus on expenses related to the investment and provide allowances to reduce the cost of capital (IMF et al., 2015). To the extent that tax incentives are deemed worthwhile in a specific context, cost-based tax incentives have a greater chance of stimulating investment, while profit-based incentives are more likely to be redundant (see Annex II). Table 4 of this guide examines the use of both types of tax incentives in the agricultural and food systems context:29

\section{Profit-Based Tax Incentives}

- Reduced rates on dividends and interest paid abroad

- Tax holidays

- Reduced corporate income tax rates

\section{Cost-Based Tax Incentives}

- Zero-ratings and VAT exemptions

- Investment tax credits

- Zero or reduced tariffs

- Tax deductions

- Loss carry forwards

- Investment allowances

- Export tax exemptions

- Accelerated depreciation

Table 4: Tax incentives

${ }^{29}$ See discussion at Tavares-Lehmann et al., (2016), 24-27. 
This table provides a brief overview of common tax investment incentives that may be offered to investors in agriculture and food systems, employing the traffic light system explained on page 21.

Incentive type

What it is \& how it works

\section{Profit-Based Tax Incentives}

Reduced Rates on Dividends and Interest

Paid Abroad

Tax Holidays

Reduced Corporate Income Tax Rates
Reduces the taxes that investors, particularly those from countries with a worldwide taxation system, pay on dividends and interest abroad.

Complete exemption from paying tax for a certain period. Frequently offered to newly established firms. Common practice in export-processing zones (EPZs) and special economic zones (SEZs).

Lower corporate tax rates for qualifying investors. Extremely common.

\section{desig}

Reduces or prevents double taxation for foreign investors.

Easy to offer, both in terms of design and administration.
Easy to offer, both in terms of esign and administration.

\section{Cost-Based Tax Incentives}

Zero-Ratings and VAT Exemptions
Granted for inputs to reduce costs in the agricultural process.

Granted for produce for sales of agricultural commodities to keep the agricultural sector out of the value added tax (VAT).
VAT zero-rating in agriculture aims to reduce the impact of VAT on the poor (as the consumer ultimately pays more for the product with consumption taxes) by lowering basic agricultural produce prices.

VAT exemptions can be beneficial if administration of the tax is problematic.

Increases financial viability of projects at the margin.

\section{Potential cons}

Revenue forgone.

Can be used by multinationals to avoid taxes by shifting profits.

Creates an unlevel playing field between domestic and foreign investors.

Revenue forgone.

Very blunt instrument:

- Do not encourage capital investment.

- Do not reinject revenues into existing or new businesses.

- Do not encourage domestic partnerships.

- Risk of firms closing operations and reopening as "new" ventures to re-qualify for incentive (tax avoidance).

- Risk of tax avoidance through transfer pricing.

Revenue forgone.

Revenue forgone.

VAT paid on inputs are usually creditable against VAT charged on sales. Therefore, in many cases, an exemption for VAT on inputs may have little effect on the producer, because they would otherwise usually receive a full credit for the VAT. 


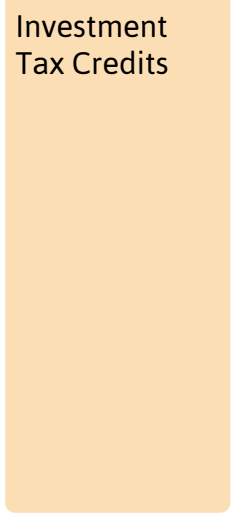

$\begin{array}{ll}\text { Zero or } & \text { Import tariffs or duties on investment } \\ \text { Reduced } & \text { project equipment or spare parts are } \\ \text { Tariffs } & \text { eliminated or reduced. This is a } \\ & \text { common measure in export processing } \\ & \text { zones and are particularly common in } \\ & \text { Southeast Asia. }\end{array}$

Tax

Deductions

oss Carry

Forwards

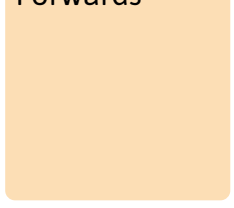

Investment Allowances
Permits a fixed percentage of certain investment expenditures to be deducted from the income tax liability. Often used to encourage investment in R\&D and capital assets. Under a simple investment tax credit mechanism, credits may be earned based on a fixed percentage of qualifying investment expenditures for that year. Other mechanisms may be more complex, such as credits earned for expenditures above a certain threshold, or at different rates depending on the level of expenditures. Southeast Asia.

Allows investor to claim an income tax deduction for certain investment expenditures. The deduction goes beyond what would normally be allowed under general income tax rules.

This is a broader category that includes other more specific types of incentives, such as investment allowances and accelerated depreciation, discussed later in this table.

Taxable losses are permitted to be carried forward or backward (to offset taxable income) within a certain timeframe.

Allows investors to claim an upfront additional deduction for qualifying capital expenditures, over and above the depreciation allowed for the asset. As opposed to investment credits, these provide an income tax deduction, which offset taxable income, rather than a tax credit, which offsets tax payable.

The amount of the deduction is generally set as a percentage of the qualifying expenditures. As the deduction reduces taxable income, their value to investors depends on the corporate tax rate applicable.

Commonly directed at R\&D investment.
Encourage investment in R\&D.

Increase financial viability of projects at the margin.

Increase financial viability of projects at the margin.

Increase financial viability of projects at the margin.

Increase financial viability of projects at the margin.

Appeal to investors who expect losses in the first years (e.g. while penetrating markets or ramping up production).

Increase financial viability of projects at the margin.
Revenue forgone.

Risk of incentivising unnecessary large expenditures.

Revenue forgone.

If tariffs are eliminated on inputs that are available locally, limits the creation of indirect jobs.

Revenue forgone.

Revenue forgone.

Can be manipulated so that an investment project ends up tax-free for a significant portion of its implementation phase.

Revenue forgone. 


\section{Table 5: Regulatory incentives}

This table provides a brief overview of regulatory investment incentives that may be offered to investors in agriculture and food systems, employing the traffic light system explained on page 21.

\begin{tabular}{|c|c|}
\hline Incentive type & What it is \& how it works \\
\hline $\begin{array}{l}\text { Derogations } \\
\text { from Domestic } \\
\text { Laws and } \\
\text { Regulations }\end{array}$ & $\begin{array}{l}\text { Derogations from domestic laws and } \\
\text { regulations that tend to involve a weakening } \\
\text { of environmental, labour, or other social } \\
\text { standards. May be offered on a } \\
\text { project-specific basis, through investment laws } \\
\text { that give foreign investors special substantive } \\
\text { or procedural rights, or in free trading zones or } \\
\text { other special economic zones. }\end{array}$ \\
\hline $\begin{array}{l}\text { Special Land } \\
\text { Tenure } \\
\text { Protections for } \\
\text { Large-Scale } \\
\text { Investors }\end{array}$ & $\begin{array}{l}\text { Land tenure rules govern rights to use land and } \\
\text { are a general factor in the enabling } \\
\text { environment for agricultural and food systems } \\
\text { investment. In countries with weak or } \\
\text { transitioning land governance systems: tenure } \\
\text { rights are often contested, legitimate tenure } \\
\text { rights holders may not have formalised } \\
\text { recognition of their rights, and government } \\
\text { efforts to secure tenure rights for all can be an } \\
\text { ongoing and lengthy process. In this context, } \\
\text { governments may aim to incentivise large-scale } \\
\text { investment by seeking to specifically protect } \\
\text { land rights of investors beyond general efforts } \\
\text { to strengthen tenure--for example, by } \\
\text { prioritising investment-related property for } \\
\text { titling and demarcation. }{ }^{30}\end{array}$ \\
\hline
\end{tabular}

Potential pros

\begin{tabular}{|c|c|}
\hline & $\begin{array}{l}\text { Undermine human rights. } \\
\text { Contradict CFS RAI goals. } \\
\text { Little evidence of increasing } \\
\text { investment. }\end{array}$ \\
\hline $\begin{array}{l}\text { Land tenure rules are } \\
\text { highly relevant to } \\
\text { investors in the context } \\
\text { of agricultural and food } \\
\text { systems investments. } \\
\text { (Only focusing on } \\
\text { strengthening tenure } \\
\text { rights for investors, } \\
\text { however, holds } \\
\text { significant risks - see } \\
\text { Cons column.) }\end{array}$ & $\begin{array}{l}\text { Prioritising tenure protections for } \\
\text { large-scale investors creates risks } \\
\text { that: } \\
\text { - Legitimate tenure rights claims to } \\
\text { the land may be ignored. } \\
\text { - The tenure protections provided } \\
\text { to the investor may be undermined } \\
\text { if the rights are nevertheless } \\
\text { contested (if legitimate rights } \\
\text { were ignored). This in turn, may } \\
\text { lead to costly conflict with local } \\
\text { communities, and/or costly } \\
\text { disputes with the investor } \\
\text { claiming protections under a } \\
\text { relevant contract or treaty. }\end{array}$ \\
\hline
\end{tabular}

Sources relied upon in the above table: Kelly et al., (2015); IISD, (2018); Cordes and Bulman, (2016); FAO, (2013a).

Beyond special tenure protections for investors, governments sometimes take other land-related actions with the aim of supporting investment or investors. These include, for example:

- using the power of compulsory acquisition (eminent domain) to acquire land so that it can be used for an investment or offered to an investor;

- offering land through land banks, where the land is identified or acquired in advance of any specific investor, often despite extreme power differences between the government seeking the land and the legitimate tenure rights holders who have claims to it; 31

- providing large concessions with cheap rent, covering land that the government has qualified as public or state land, even if there are conflicting claims to the land, including by legitimate tenure rights holders whose families and communities have used and relied on the land for generations.

Particularly in the context of weak or transitioning land governance systems, such actions are deeply concerning. They may be in contravention of a government's human rights obligations,

\footnotetext{
30 See e.g., Whitley et al., (2014) (noting that the Government of Zambia "provides incentives in the form of ... land access via titling and demarcation for the expansion of farm blocks as a means of expanding commercial agricultural development.")

31 Under land governance systems with strong land rights protections and less contestation around land rights, land banks may be more 
and can result in conflicts and severe negative outcomes. Whether such actions should be considered "investment incentives" is debatable; for the purposes of this guide, such actions are excluded from its scope.

\section{Other incentives}

The four categories of incentives discussed above (financial, technical and business support, tax, and regulatory) are the most commonly recognised investment incentives. However, under the definition of "incentive" used in this guide and in the context of responsible investment in agriculture and food systems, there are at least two other relevant mechanisms that can be classified as incentives. The following "other" incentives are examined in Table 6:

- Public procurement

- New, targeted infrastructure

\section{Table 6: Other incentives}

This table provides a brief overview of other investment incentives that may be offered to investors in agriculture and food systems, employing the traffic light system explained on page 21.

\section{Incentive type What it is \& how it works}

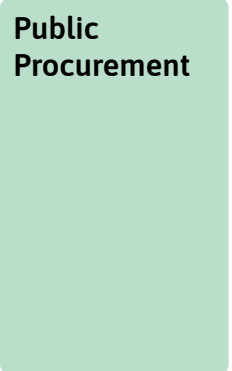

New, Targeted Infrastructure
Purchase food required for social programmes (e.g. for hospitals, food reserve authorities, food aid, and school feeding programmes) from small-scale producers, and/or from suppliers integrating particularly strong sustainability practices. As noted above, whether this is an incentive per se may be debatable.

The creation of new, targeted infrastructure (e.g. quality rural and feeder roads, reliable electricity, harbours, storage facilities, or railways) counts as an investment incentive if it is related to a particular investor or set of investors rather than offered to all investors (even if it may be shared by other actors).

\section{Potential pros}

Create stable markets for small-scale producers.

Create stable markets for investors that integrate sustainability practices that go beyond what is required by law.

Unlock rural agricultural potential as it opens up areas via roads, water control, or markets and incentivises increased production.

Generate on- and off-farm employment.

Irrigation can have an outsized positive effect on women (who typically bear the burden of collecting water).

Stimulate pro-poor growth and improve rural livelihoods.

Improve market access.

Enhance agribusiness investments.

\section{Potential cons}

Might not be cost competitive.

If targeting a specific investor, may divert siting of important infrastructure from places where new or improved infrastructure would benefit a wider set of farmers or would support greater economic growth.

Beneficiaries of infrastructure projects are often landowners.

Infrastructure with a large physical footprint (such as roads) has potential negative impacts on biodiversity, and can be a source of environmental degradation, and, indirectly, greenhouse gas emissions.

May negatively impact tenure rights holders who use or rely on the land needed for the new infrastructure. This may occur if the rights holders do not want their land to be used for infrastructure, or if they are displaced without sufficient due process or adequate compensation.

Sources relied upon in the above table: Kelly et al., (2015); Tavares-Lehman et al. (2016); FAO, (2018b); Teye, (2019); IFPRI, (2020); Jouanjean, (2013); Byiers and Rampa, (2013). 


\section{Part III - Using incentives to enhance responsible investment in agriculture and food systems: General considerations}

This Part discusses general considerations on how incentives can be used-as well as how they should not be used-to enhance responsible agricultural and food systems investment. The Part discusses in detail the following important considerations:

- Responsible agricultural and food systems investment is primarily determined by the enabling environment, not investment incentives. Governments seeking to encourage more investment should first focus on improving the enabling environment.

- Incentives tend to be more effective when they are identified as the best mechanism to overcome a particular barrier to investment that an investor is facing, for example, to overcome specific market failures.

- Incentives should be designed to support the outcomes encouraged by the CFS RAI, particularly to empower small-scale producers, especially young agri-entrepreneurs and women.

- Incentives should not disproportionately benefit large-scale foreign investors to the detriment of other investors or other public goods towards which funds could be directed.

- Regional coordination and governance should be pursued to curb a "race to the bottom" in offering incentives.

- Incentives may work best when offered as part of a package and/or when coupled with other measures, such as regulatory reform or disincentives for undesirable behaviour.

- Attaching a condition or conditions to the granting of an incentive can help guarantee that the government's goal(s) for providing the incentive are met; this includes behavioural goals that would improve the sustainability outcomes of the investment.

Each point is discussed further below. 


\section{Responsible agricultural and food systems investment is primarily determined by the enabling environment}

Responsible investment in agriculture and food systems is heavily influenced, and primarily determined, by factors other than investment incentives. Simply put, "incentives do not work unless certain fundamentals are in place" (Tavares-Lehmann et al. 2016).

In particular, the "enabling environment" within a country influences investment decisionmaking by large-, medium-, and small-scale investors alike. The enabling environment is the set of factors, conditions, and safeguards that encourage investment generally, and responsible investment specifically. Governments seeking to encourage responsible investment should, first and foremost, focus on improving the enabling environment. This is relevant both for promoting more investment, and for ensuring that investment is responsible.

The CFS RAI identify the following as the main elements of an enabling environment:

- Legal, regulatory, and institutional alignment with the CFS RAI and national development strategies.

- Policy coherence and consistency.

- Effective coordination and implementation on the part of government institutions.

- Transparency, inclusiveness, and meaningful participation in the development and implementation of relevant policies, strategies, and incentives, as well as in the context of specific investment decision-making.

While investment incentives could be considered part of the enabling environment (CCSI and FAO, 2019)—and while the distinction between an "incentive" and an "enabling condition" is not always clear-they remain just one small and specific tool against a broader set of conditions and factors that influence whether investment occurs and whether it is responsible.

These factors, inherent in the enabling environment that influence investors' decisions about whether to invest at all, are sometimes referred to as the "investment climate." Many of the factors commonly considered as comprising the investment climate (see Box 8) are more relevant for foreign investors and large-scale domestic investors, but some are equally relevant for small-scale producers making investment decisions. At their core, however, decisions about agricultural and food systems investments are very context-specific, depending on the nature of the investment itself. Investors big and small need the right environmental conditions, decent physical infrastructure, and/or other conditions that will allow them to produce or work profitably. Without those factors, the investment climate will be relatively unattractive for investors who have a choice of where to invest and will be a limiting factor in the success of small-scale producers who do not have such a choice. 


\section{BOX 8: “INVESTMENT CLIMATE” FACTORS RELEVANT TO INVESTOR DECISION- MAKING}

While investment climate factors tend to be a focus of "agribusiness" - whether domestic or foreign—some factors will matter more to foreign firms. Other factors are equally relevant for small-scale producers.

\section{Macro and enabling conditions}

- Political, economic, and social stability.

- Absence of conflict.

- A certain degree of institutional quality and effective coordination between government entities.

- Decent governance.

- Information on the suitability of land available for commercial farming.

- The extent of corruption.

- Protection from unfair international competition.

\section{More tangible investment determinants}

- Access to land or other desired location-bound (natural) resources.

- Access to skilled labour.

- Decent infrastructure, especially in rural areas (e.g. feeder roads, water, electrification, rail and port facilities, storage).

- Access and distance to major markets.

- Proximity of raw materials.

- Size of the domestic market and opportunities to do business in it.

- Access to finance with reasonable interest rates.

- Distance to the target market.

- Availability of agricultural R\&D facilities.

- Reasonable interest rates and access to finance.

- The accessibility of international trade. 


\section{BOX 9: IMPORTANT SOCIAL, LABOUR, AND ENVIRONMENTAL LAWS}

\section{Environmental laws}

- Laws and regulations that prohibit or limit certain negative environmental impacts (water pollution, air pollution, operations in high conservation value areas, etc.).

- Screening for environmental impacts.

- Legal requirements for ex ante and ex post environmental impact assessments for largescale projects, coupled with monitoring and enforcement (Cotula, 2016).

\section{Social and labour laws}

- Protection of tenure rights for legitimate tenure rights holders, even when land is legally considered to be held by the state.

- Legal requirements for local consultation and free, prior, and informed consent.

- Limitations on the use of eminent domain or compulsory acquisition in the context of agricultural and food systems investments, with clear and narrow definitions of what is deemed to be in the "public purpose," as well as equitable compensation requirements for the limited situations in which land may be compulsorily acquired.

- Laws and regulations that prohibit or limit specified negative social impacts.

- Strong labour laws that protect workers' rights, including on issues of remuneration and health and safety, and that prohibit child labour, forced labour, and other violations of fundamental labour rights.

- Legal requirements for ex ante and ex post human rights impact assessments for largescale projects, coupled with monitoring and enforcement.

When does it make sense to use investment incentives or when is a different approach required?

\section{Circumstances where incentives can help}

The most obvious reason to offer an investment incentive is when it is the best mechanism to address a key barrier that is discouraging an investor from making an investment that the government hopes to encourage (for example, an investment that is aligned with the CFS RAI and national development priorities).

In particular, incentives can be used to attempt to overcome market failures. For example: 
- Credit market failures can affect all sizes of investors, and particularly small-scale producers-especially, youth and women-who commonly lack assets for collateral. While an optimal solution would be the much bigger project of fixing the credit market, governments can use financial incentives as a partial fix to overcome credit market failures, influencing who can receive a loan and for what activities (Johnson et al., forthcoming).

- The market volatilities, weather fluctuations, and additional externalities characteristic of investments in agriculture and food systems that often lead to risk aversion that affects the investment decisions of large-, mid- and small-scale investors alike. In this case, incentives such as matching grants, equity participation, and subsidised loans can be used to offset the high risks which an investor is unable to insure against, encouraging investors to take on higher risk projects that nevertheless have promising potential (Johnson et al., forthcoming).

- The failure of the market to value certain public goods and responsible business practices. The incentive can be used to encourage conduct providing positive externalities that are otherwise not presently valued or paid for by the market, such as environmental and social impact.

- Foreign investors may experience information asymmetries/failures due to their lack of familiarity with a host country's economy (Tavares-Lehmann et al., 2016); providing relevant information as a technical support incentive can help overcome related challenges and make investment in the jurisdiction more attractive.

Where the incentive is not designed to overcome a market failure that is highly relevant to an investor, it is likely to feature low down in the list of factors upon which the investor will make its decision, if it is even considered at all.

Beyond correcting specific market failures that might be preventing an investor from investing, certain types of incentives also can be useful in the following circumstances:

- Supporting the development of public goods.

- Providing targeted support during economic downturns.

- Encouraging sustainable behaviours.

- Supporting, in the context of investments in agriculture and food systems, responsible and viable investments by small-scale producers that align with the CFS RAI and the country's national development priorities.

\section{Circumstances where incentives do not make sense}

There are at least two critical circumstances in which incentives do not make sense for responsible investment in agriculture and food systems.

First, an incentive should not be used when it is not the appropriate mechanism for achieving a stated goal. Often, a government measure other than an incentive-such as a law or change in the enabling environment-would be more effective or appropriate. For example, governments 
sometimes seek to address regional disparities by conditioning agricultural and food systems investment incentives on investment occurring in areas that are not otherwise receiving it. However, studies have shown that a tax break for geographical conditions is not sufficient to stimulate investment when other more important factors, such as road infrastructure and access to markets, are not addressed (Teye, 2019).

Recommendation: First understand the barrier that a given investor or group of investors is facing, and then investigate whether an incentive would actually help to overcome that barrier, or whether a different mechanism would be more appropriate.

Second, an incentive should not be used when it is appropriate in theory but is unlikely to be the right tool because it is poorly designed or not worth the cost. Design failure may render an incentive ineffective; this may include, for example, the choice of the wrong type of incentive, the failure to target it strategically, and/or the failure to condition it appropriately. An incentive may also not be an appropriate choice where the total costs outweigh the benefits. As discussed in Parts II and IV, this includes assessing the costs associated with incentives.

\section{Reasons for the unwarranted use of incentives}

In spite of the futility or wastefulness of offering specific investment incentives in particular circumstances, inefficient and redundant incentives continue to be offered. There are a number of reasons why governments may continue to offer inefficient or ineffective incentives:

- Governments may think it is easier to offer tax incentives than to systematically improve a country's legal and institutional systems, improve physical infrastructure, implement economic reforms, develop a skilled workforce, or provide a stable political environmenteven if those enabling environment conditions are much more important for attracting and supporting investment.

- Businesses pressure governments into granting tax incentives, and vested interests in business and even government lobby to keep them (IMF et al., 2015). This is exacerbated by a different type of information asymmetry than that discussed above, whereby the investor holds all the playing cards regarding the relative importance of various factors to their decision-making and the government relies solely on the investor's own claims that an incentive is crucial to their decision as to whether to invest or not-even if that is not actually the case.

- Politicians yield to political factors. For example, politicians may find it expedient to offer tax incentives to send out an image of proactivity in addressing weak economies or supporting particular regions, especially where proven interventions like upgrading physical infrastructure or educational facilities are more likely to take a while to show benefits (Rondinelli and Burpitt, 2000). They may provide certain incentives in spite of advice from international organisations to not offer-or to remove-those incentives (IMF 
recruitment of female extension workers, among others, can all have positive effects (IFPRI, 2019; Mudege et al., 2017; Mamun-Ur-Rashid et al., 2017).

Young agri-entrepreneurs may require incentives that make agriculture more appealing, for example by encouraging innovation and the employment of technologies and techniques that will allow them to produce more with less (see Box 3). In this instance, incentives such as incubation support for start-up businesses and technological packages might be appropriate.

\section{Recommendation: Select different incentives for different sub-groups, depending} on their particular needs.

In designing incentives that support small-scale producers in an attempt to enhance responsible agricultural and food systems investment, policymakers and technical staff must take care to ensure that the incentives do not inadvertently undermine other objectives, such as environmental sustainability or public health. For example, widespread provision of chemical inputs without sufficient training or safety gear may end up negatively affecting farmers' health or the environment. Market price support may ultimately result in environmental harms by encouraging overproduction or intensive monocropping.

Recommendation: Design incentives in recognition of the different dimensions of responsible agricultural and food systems investment, so as to not blindly pursue one dimension (e.g. food security) at the expense of others (e.g. biodiversity).

\section{Reconsidering and managing incentives oriented towards large-scale foreign investors}

\section{Risks of excessive focus on large-scale foreign investors}

Incentives should not disproportionately benefit large-scale foreign investors to the detriment of other investors. As noted above, the majority of agricultural and food systems investment in lowand middle-income countries comes from domestic farmers, with FDI only providing a fraction of total investment in agriculture and food systems. Governments may find it to be a much better use of scarce resources to target incentives to address barriers faced by domestic farmers and SMEs operating upstream and downstream along the value chain (Syed and Miyazako, 2013).

Although responsible foreign investment can bring multiple benefits and contribute to a country's development goals, many negative impacts-including serious human rights abuses and severe environmental damage-have also arisen from large-scale foreign investments in agriculture and food systems. In light of the track record of such investments and their inherent risks, the consistency of large-scale foreign investments in agriculture and food systems with the principles espoused in the CFS RAI is not a given. 
Recommendation: Avoid placing an outsized emphasis on using incentives to attract FDI, and limit barriers that favour certain sized investors over others (e.g. minimum investment size requirements).

\section{Ways to ensure foreign large-scale investments are responsible}

This is not to say that large-scale investments in agriculture and food systems have no place in a country's agricultural development plan. For example, certain types of crops-including cash crops like sugarcane and palm oil, as well as certain cereals-have agronomic characteristics that make large-scale production the more obvious choice (Chan, 2013). Yet even these crops do not necessarily require the allocation of large swathes of land; rather, large-scale investment using inclusive business approaches that permit smallholders to retain their land rights (such as through outgrower schemes) can also be an option.

To the extent that a country continues to include the attraction of large-scale foreign investment into the agricultural and food sector as part of its national development plan, any use of incentives oriented towards such investors should include the following considerations.

First, no investment must be allowed to contravene the CFS RAI to the detriment of human rights (e.g. violating local peoples' legitimate land tenure rights), the environment (e.g. polluting waterways), and the host country's sustainable development (e.g. tax evasion). This is true regardless of whether an incentive is offered.

To prevent such contraventions, governments should ensure that its domestic law protects human rights and the environment from potential investment-related harms. Safeguards can also be embedded at the approval stage, for example, by ensuring adequate due diligence and screening of potential investments, 32 and through the use of robust impact assessments. In addition, although investment contracts are not recommended (see Part II above), to the extent that investment contracts are used, they can explicitly incorporate additional safeguards that go beyond what is currently required by law, and can "mak[e] noncompliance a violation of legally binding contractual terms" (FAO, 2016).

Second, any incentive provided to a large-scale investment should support that investment's contributions to the goals contained in the CFS RAI. Such goals include increased food security and nutrition, sustainable and inclusive economic development and the eradication of poverty, women and youth empowerment, conservation and sustainable management of natural resources, and supporting diversity and innovation.

Policymakers and technical staff can seek to do this through the conditions (discussed later in this Part) that are attached to the incentives. For example, investments will be permitted accelerated depreciation on project-related assets if training is provided through the project to upskill women. Or, for example, an incentive will be provided to investors that integrate

\footnotetext{
32 It is valuable to research the social, labour, and environmental records of potential large-scale investors. One widely used tool to investigate
} companies for problematic behaviours is the Good Jobs First database, Violation Tracker: https://www.goodjobsfirst.org/violation-tracker. 
inclusive business approaches (demonstrated by meeting clear and objective criteria). When attaching conditions, the incentives should be granted only upon proof that conditions were met, and are revocable if the investment breaches the CFS RAI principles. This could take the form of a provision in the relevant law offering the incentive, declaring that incentives may be revoked if any attached conditions are not met, or if the investment breaches the CFS RAI principles and no effort is made to remedy that breach.

\section{Recommendation: Enshrine adequate safeguards in legislation to protect human} rights and the environment in the context of investment. Use additional measures, such as due diligence and screening, to assess whether an investment is likely to contribute to, or undermine, the realisation of human rights and achievement of development priorities.

Recommendation: Consider attaching conditions that support the achievement of CFS RAI goals to incentives offered to foreign large-scale investors, and make those incentives revocable in instances where conditions are not met.

\section{Regional governance and coordination are important}

In the context of locational incentives, countries ideally would coordinate to not offer unnecessary incentives and would simply compete for FDI on the basis of competitive conditions like factor endowments, legal and institutional stability, adequate infrastructure, and political stability. In practice, however, countries' ability to coordinate effectively has been stymied the absence of "an effective supranational monitoring framework and powerful institutions to enforce it" (IMF et al., 2015). Without such coordination, abstaining from unnecessary incentives is not easy, due to the pressure created when other countries offer incentives (particularly tax incentives).

Even if countries do seek to coordinate on either tax incentives or broader tax policy, potential risks may arise. One risk is that agreeing to eliminate tax incentives could shift competition into general tax policies, such as a reduction in overall corporate income tax rates. The second is that if only a subset of the relevant countries agree to coordinate, those countries who do not cooperate might benefit at the cost of those who do (IMF et al., 2015).

Regional efforts to coordinate on harmful tax competition have experienced varying degrees of success to date (IMF et al., 2015). ${ }^{33}$ Nonetheless, options for regional cooperation do exist. As noted by the IMF, World Bank, UNCTAD, and OECD, a non-binding option would be a code of conduct agreeing not to use certain tax incentives, like the Code of Conduct for business

\footnotetext{
33 Example discussed: Southern African Development Community (SADC) Protocol on Finance and Investment and Guidelines for the application and treatment of tax incentives in the SADC region; East African Community (EAC) Code of Conduct; West African Economic and Monetary Union (WEAMU); Committee of Ministers of Finance of Central America, Panama, and the Dominican Republic (COSEFIN) "Declaration of Good Practices" discussions.
} 


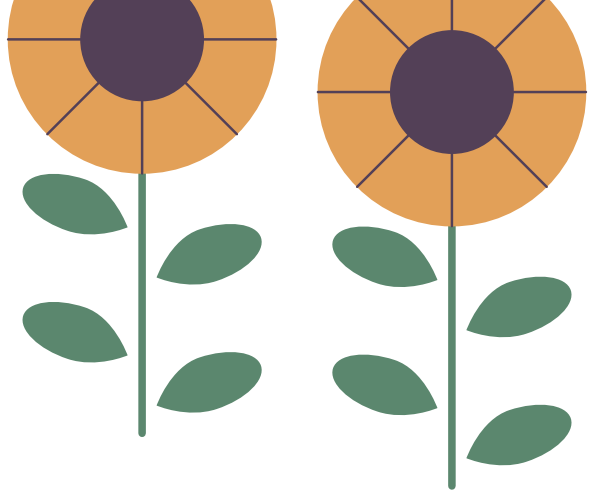

taxation in the European Union. A binding option could be a common legislative framework, like the state-aid rules in the European Union (IMF et al., 2015). A more modest option would be to focus on "a common framework for reporting tax incentives and information exchange to encourage mutual learning" with the goal of enhancing transparency and enabling ex post assessment of tax incentives (Teijeiro, 2015).

In the interim, and to the extent that countries continue to offer investment incentives via contract (not recommended), publishing a list of available incentives on a regional website would provide greater transparency, with the goal of minimising pressure on government negotiators in contractual negotiations. By doing so, this disclosure could make it easier to avoid a regional race to the bottom, as government negotiators gain bargaining power by seeing what other countries offer, thus minimising companies' ability to use opacity to their advantage (Charlton, 2003). There is a risk, however, that such transparency could function as a double-edged sword, if countries feel pressure to match other countries' incentives based on what is published. This suggestion is made in conjunction with the recommendation that the optimal way to offer investment incentives is in national legislation (see discussion in Part II of this guide) and not at the individual contract level.

Despite the challenges, it will be critically important for governments to find ways to cooperate in order to stem the race to the bottom that leads to redundant incentive use. Abstaining from unnecessary incentives in a coordinated way can help governments to ensure that the objectives behind the incentives they offer are linked to their national priorities, as well as to regional development priorities. ${ }^{34}$

Recommendation: Participate in regional efforts to curb redundant incentive use and to combat the "race to the bottom."

\section{Attaching conditions to incentives can be essential for promoting responsible and sustainable practices beyond what is required by law}

Attaching conditions to incentives can be one way to use incentives to promote more responsible investment aligned with the CFS RAI. Using conditions, governments can encourage specific responsible and sustainable practices that go beyond what is required by law, while also ensuring that incentives are not provided when investments do not support responsible practices. For example, payments for ecosystem or environmental services are a popular mechanism for encouraging environmentally sensitive agricultural practices. They are essentially just a grant (or even a loan or loan guarantee) that is given to an investor provided the investor complies with an environmental condition or conditions:

$$
\text { Incentive (type: grant) + Condition (type: environmental) }
$$

\footnotetext{
${ }^{34}$ Regional coordination can and should extend beyond coordination on incentives to other aspects of aligning investment with the CFS RAI. This is explicitly acknowledged in the Association of South East Asian Nations Responsible Investment in Agriculture (ASEAN RAI) Guidelines on Promoting Responsible Investment in Food, Agriculture and Forestry, which highlight the importance of "promoting intra-regional assistance, experience sharing, and capacity building on issues related to responsible investment in food, agriculture, and forestry to strengthen ASEAN Member States governments' capacity on legal, policy and implementation issues." Principle 10.
} 
Such payments can be particularly important for small-scale producers who tend to lack the capital to implement climate- and environmentally-sensitive changes into their practices, such as creating ponds for enhanced water storage (costs cover creation and any loss in agricultural production) (Smith et al., 2013; One Planet and UNEP, 2019).

A condition may not be relevant in all instances of incentive use. Relevance depends on the goal the government is seeking to achieve. For example, if a government wants to encourage reinvestment in an existing large-scale plantation but only if more environmentally-sound farming practices are employed, the incentive that may be offered to the investor could be coupled with a condition that the benefit only be conferred upon proof of cover cropping, planting hedge rows, or some other relevant practice(s). In this context, conditions, when coupled with the right type of incentive, can help filter the types of investments governments wish to encourage and shape agricultural practices to better fit sustainable food system outcomes.

In another scenario, however, a condition may not be necessary. For example, the government's goal may be for smallholders' incomes to increase through greater productivity, and so the government may offer a technological incentive in the form of a more environmentally appropriate plant or livestock variety. In this case, if the farmer takes advantage of that incentive and invests accordingly, the outcome will be achieved (assuming the government has selected the correct variety), and the farmer's productivity should increase by virtue of farming with the improved variety; no condition would be needed.

Importantly, conditions do not work if the incentive does not work, underscoring the need to offer incentives that will actually motivate investors in the manner intended.

Conditions are determined by the government's goals for the targeted investments, which in turn should be grounded in national development priorities more generally. The conditions most likely to be relevant for responsible agricultural and food systems investments are therefore those linked to environmental, social, health, and nutritional issues, as well as locational or other behavioural conditions. As discussed above in Box 9, however, certain aspects of these issues should instead be addressed in law, rather than through incentives.

For some incentives, particularly those targeting large-scale investors, performance-based approaches can be an effective way to ensure that incentives with conditions lead to desired outcomes. Under a performance-based approach, the incentive is contingent on demonstrated impact. This approach can be more likely to result in intended impact than when incentives are provided without a condition, or when they are provided based on an investor's practice or activity (rather than based on the impact) (OECD, 2020). However, a performance-based approach is often not appropriate for small-scale producers, who may not have enough capital to take certain actions that result in impact without upfront support, or who may not be able to afford to wait for that impact to manifest. In such instances, it is more appropriate to provide an incentive once a practice is modified or an activity undertaken (UNDP, n.d.).

Such nuances reinforce the need to ensure that incentive planning and design is participatory and needs driven, especially to identify the practical challenges confronted by the diverse range of small-scale producers who may be intended targets of the incentives. 
Recommendation: Consider attaching environmental, social, health, behavioural, or other conditions to incentives in order to achieve desired investment-related impacts that align with national development priorities.

\section{Incentives may work best as part of a package}

Investment incentives are but one potential mechanism in a raft of measures necessary to achieve responsible investment in agriculture and food systems. Beyond selecting the right incentive, and potentially coupling that incentive with a condition, the effectiveness of an incentive may be enhanced by packaging it with other measures. This is because providing incentives as part of a package can better support the investor in using the incentive(s) more effectively (Fiedler, 2020).

There are multiple ways that agricultural and food systems investment incentives can be packaged to enhance their effectiveness and their ability to support responsible investment. These include:

- Packaging multiple complementary incentives together. For example, under such an approach, a concessional loan to small-scale producers could be combined with training, mentoring, and coaching; in such a package, the financial incentive may be put to more effective use when the recipient also receives the complementary technical support incentives.

- Providing incentives against the backdrop of a sound regulatory regime that may also include disincentives, such as a taxes, fines, and prohibition of use. This, in essence, is strengthening the enabling environment alongside incentive provisions; but can also be viewed as combining the "stick" of disincentives (such as environmental laws that ban certain types of conduct or a land tax that discourages harmful practices) with the "carrot" of incentives.

- Coupled with complementary government investments, such as research into sustainable productions systems (FAO, n.d.).

Packaging may involve any one or more of the above. For example, price interventions and the provision of credit coupled with public investment in research and development and extension services, strong institutions, and investments in primary education and rural infrastructure (especially electrification and irrigation) have been shown to be successful in removing countries' anti-agricultural biases (Laborde et al., 2019). Importantly, different incentives may be relevant at different stages and may seek to effect short- or long-term changes.

When it comes to incentives for women, youth, or other historically marginalised groups, providing a package is generally preferable over stand-alone incentives in order to achieve the expected results. This is true even if it means that a smaller number of beneficiaries will profit from the intervention due to constrained budgets. Of particular importance is the element of skills developments through training and coaching. In order to actively and meaningfully 
participate in policy design, implementation, and monitoring and evaluation processes of new incentives, and then to take advantage of such an intervention, youth and women need the right skills. Their potentially limited advocacy, business, or technical skills can otherwise be significant constraints, preventing them from effectively defending their interests and from taking advantage of incentives available to help them develop and maintain a viable livelihood in agriculture. So, while access to a grant may be a precondition to enable youth and women to invest in agriculture and food systems, packaging that grant with additional services, like access to equipment or harvest facilities, access to business incubators, and ongoing training, coaching, and other advisory services, will empower them to develop, pilot, and implement projects that are economically viable and impactful (Fiedler, 2020). The following Nigerian and Mauritanian case studies provide practical examples of how incentives may be packaged.

\section{Case Study: Nigeria Incentive-Based Risk Sharing System for Agricultural Lending}

Owned by the Central Bank of Nigeria (CBN) and instituted in partnership with the Federal Ministry of Agriculture and Rural Development and Nigerian Bankers' Committee in 2013, the Nigeria Incentive-Based Risk Sharing System for Agricultural Lending (NIRSAL Plc) aims to raise millions of Nigerian farmers above the poverty line by de-risking agricultural lending. Primarily, NIRSAL encourages financiers and investors to lend to the agribusiness sector by providing Credit Risk Guarantees, thereby sharing the risk and catalysing financial and investment flows into agricultural value chains, and increasing smallholder farmers' access to credit.

In addition to Credit Risk Guarantees, NIRSAL (NIRSAL, n.d.):

- offers technical assistance to producers, so that loans received are used more effectively;

- rates banks based on the effectiveness of their lending and social impact;

- offers banks incentives for building their lending capabilities; and

- facilitates the formation of new systems such as producer cooperatives and transportation systems that will cut costs for the transportation of produce.

Before NIRSAL's inception, 2 percent of bank lending in Nigeria was used for agricultural lending, as opposed to 6 percent in comparable developing countries like Kenya (Central Bank of Nigeria, 2012). Despite NIRSAL's efforts over the last decade, however, lending institutions remain reluctant to finance certain areas of the agricultural value chains (Abdulhameed, 2016). To date, NIRSAL has seen USD 500.7 million loans, and 677 projects, guaranteed, and estimates 400,000 jobs created as a result. Their goal is to increase agricultural lending to 7 percent of total lending in Nigeria by 2026 (Abdulhameed, 2019). 


\section{Part IV - Planning for, designing, implementing, monitoring, and evaluating incentives for responsible agricultural and food systems}

This section provides guidance for policymakers and technical staff on all stages of incentives: from planning for a possible intervention that might take the form of an incentive, through to evaluating incentives that have been provided and making decisions based on learnings from the evaluations.

This guide suggests an adaptive approach to incentives. Such an approach can support informed decisions about the use and design of incentives; it also implies consistent efforts to monitor and evaluate incentives, and to adapt incentives based on learnings in order to increase the likelihood that incentives will support desired outcomes (FOS, 2017). This approach is strengthened through increased transparency and inclusive participatory processes. This section provides guidance for developing and managing incentives using the framework below (Webb et al., 2018).

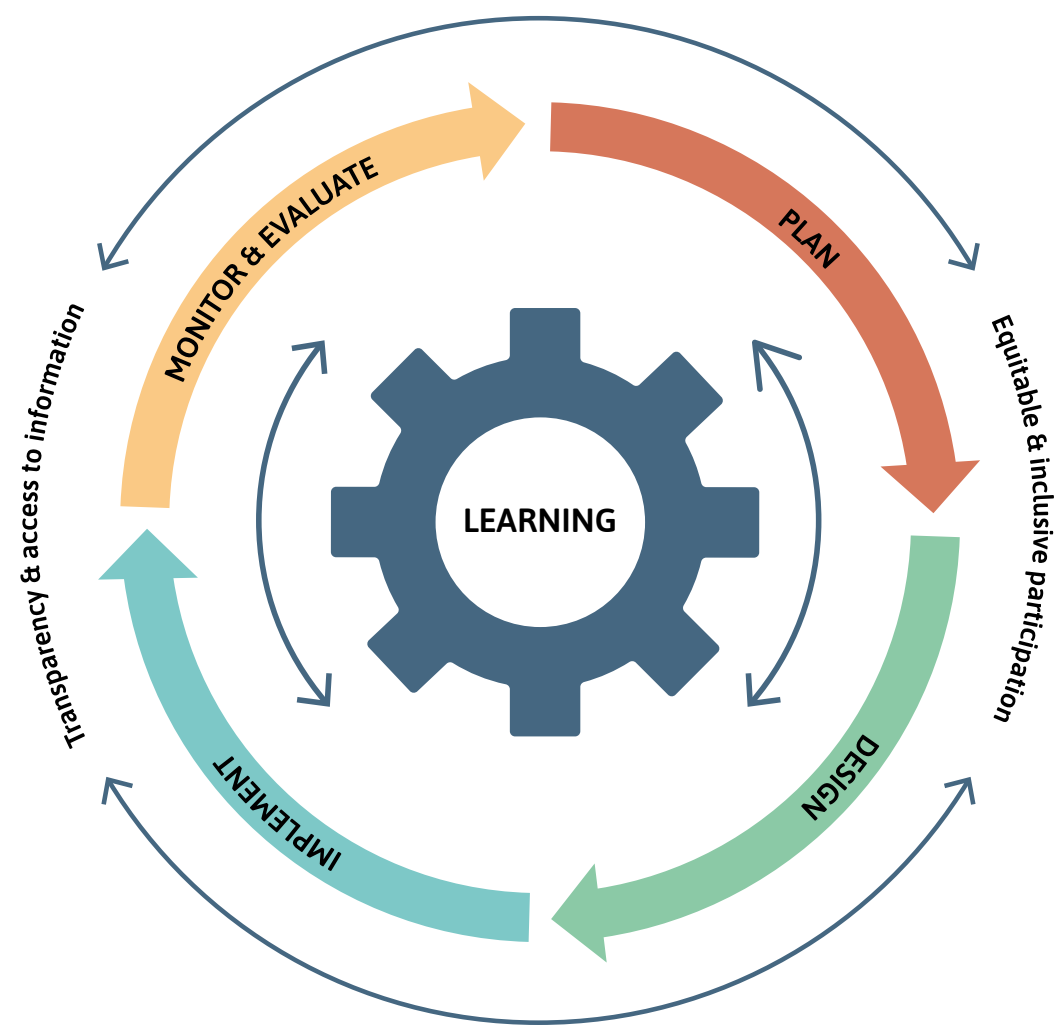




\section{Planning for an appropriate intervention}

Before any specific investment incentives are designed, careful planning can help to clarify whether investment incentives are an appropriate intervention.

A starting point for this planning is to understand the government's national development priorities and how they relate to the government's long-term goals with respect to responsible investment in agriculture and food systems. This guide assumes that policymakers and technical staff considering the use of incentives already have some clarity regarding these priorities and goals, which may include, for example, goals to eradicate rural poverty, increase food security and nutrition among small-scale producers, and foster gender equality and empower youth in rural areas.

With an understanding of those general national development priorities and impacts, the first steps in planning for an intervention-one that might take the form of an incentive-are to identify the needs of investors in agriculture and food systems, the barriers to responsible investment in agriculture and food systems, the problems that the government is trying to address, and what the government is hoping to achieve with the intervention. These crucial steps will enable policymakers and technical staff to ascertain whether incentives are the most appropriate mechanism and, if so, how to design them effectively.

To support this assessment of whether an incentive is the right mechanism, governments can develop a theory of change. A theory of change is an "on-going process of discussion-based analysis and learning that produces powerful insights ... [and is] communicated through diagrams and narratives which are updated at regular intervals" (Vogel, 2012). A theory of change is particularly useful when planning an intervention that seeks to address complex and multi-causal challenges. It can be developed during the planning phase, but can also support the design, implementation, monitoring and evaluation of an incentive or other government measure.

This section describes the steps that policymakers and technical staff can take during the planning stage of an intervention that might take the form of an incentive, and discusses how a theory of change can be developed and used to support the planning process. While these steps are presented sequentially, the process does not necessarily have to be followed in a linear fashion. Rather, these steps can be viewed as a set of good practices that support both the effective planning for policy interventions that may include incentives and the reform of existing incentives (FOS, 2017).

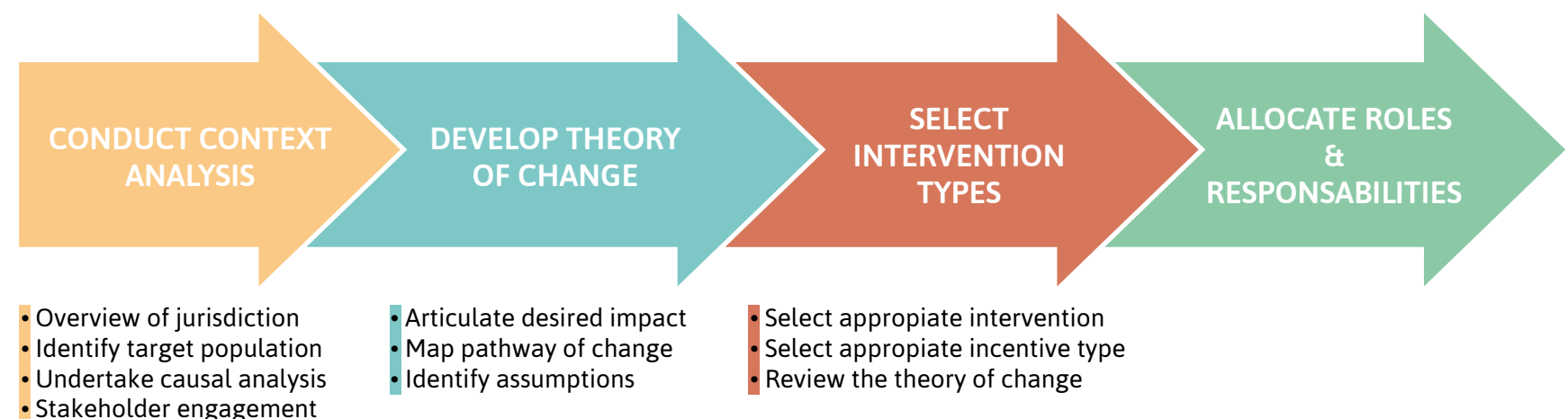




\section{Conduct a Context Analysis}

Policymakers and technical staff considering the use of an incentive can start with a context analysis that seeks to understand and identify the characteristics and conditions of the setting for which the incentive is contemplated. This should include, most critically, the needs of investors in agriculture and food systems, which connote the barriers or unmet problems they face, and the underlying causes of those needs, so that an appropriate intervention can be developed. As such, participatory processes that include intended beneficiaries, such as small-scale producers or other investors, can be critical during this planning stage (see Box 10).

The methods employed to inform the context analysis will depend on the jurisdiction and on the availability of resources and capacity. Broadly speaking, they may include information and evidence gathered from: past policies; previous studies or social science theory (Stein, 2012); surveys, census data, or field visits; and, most critically, from investors themselves.

Ideally, the following elements should feed into the context analysis:

- Overview of jurisdiction or subsector: An overview provides a background on the events, practices, and policies that have shaped the current context in a jurisdiction or subsector. What are the leading economic, environmental, political, and social dynamics that have informed the current context? What issues, if any, have had a disproportionate impact on the context, e.g. natural disasters, economic crises, or political conflicts? What past measures have been implemented? Have interventions attempted to increase responsible investment in agriculture and food systems? What policies failed or succeeded, and why? (FAO, 2019b).

- Identification of target population: In the context of responsible investment in agriculture and food systems, the investors that may benefit from an intervention, such as an incentive, should be identified. These could include, for example, smalland medium-scale producers and micro/small enterprises, young agri-entrepreneurs, women farmers, or other marginalised populations. Given the diversity of investors and the desire to leave no one behind, it is critical to consider the particular challenges of specific groups, such as women, youth, and small-scale producers, who have different needs and will be affected differently by an intervention. 


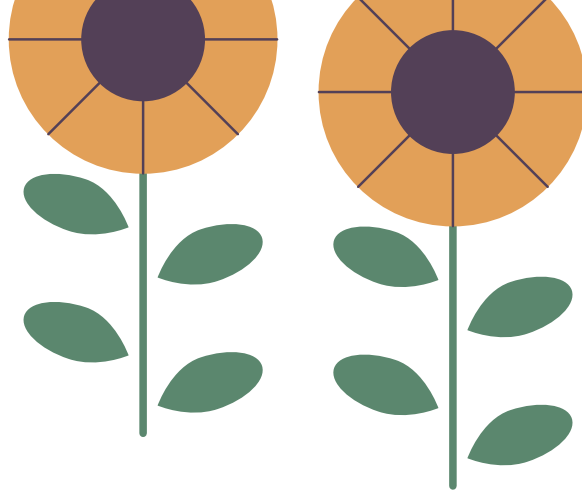

\section{BOX 10: INCLUSIVE AND EQUITABLE PARTICIPATION}

Using a participatory approach through which small-scale producers and other investors can actively participate in planning and decision-making processes fosters cooperation, facilitates consensus of results to be achieved, and provides more representative and meaningful insight to the given context (Maennling and Correa, 2020), which in turn increase the likelihood that outcomes will be defined realistically and achieved (Roberts and Khattri, 2012). In order to support equitable participation of marginalised groups, cultural norms and power dynamics should be taken into account (IIED, 2019). Based on this, specific efforts should be undertaken to enable the participation of women, youth, and indigenous communities, who often confront obstacles in effectively participating in decision-making processes relevant to investment or incentives due to factors such as power imbalances, institutional biases, and lack of access to relevant information.

Participatory approaches may vary, depending on the resources available, the potential scope of intervention, and other factors. Good practice suggests that:

- Governments should start with a well-informed plan (covering, for example, which investors to engage, which government agencies should be involved, the levels and methods of engagement; and time frame and resources required) (FAO, 2005).

- Once engaged, investors and other stakeholders can be supported to assess the current situation and identify possible policy changes and interventions, using a range of tools and techniques (FAO, 2005).

- Levels of engagement may range from consultations through to specific opportunities to collaborate on design. Formal institutionalised opportunities for policy dialogueincluding through multi-stakeholder platforms-may be a particularly useful method to enable participation in ongoing planning and policymaking processes (Fiedler, 2020).

- Causal Analysis: Understanding the causes of any identified problems or needs-as well as the drivers of those causes-is a critical part of developing a theory of change, and helps set the stage as the rationale for the intervention to be developed. ${ }^{36}$ To undertake a casual analysis, start by identifying the core problems faced by a target population (potentially narrowed by factors such as location and subsector). These can be broad problems, e.g. high poverty levels or widespread food insecurity; or more narrow problems, e.g. decline in crop productivity. Are the problems identified by women and by men different?

\footnotetext{
36 Consider the following questions: What are the problems facing investors, and that block them from investing more, in a responsible manner? Who is affected by those problems? Who is particularly vulnerable? What are the consequences of the problem? What are the causes of the problem - individual capacities and/or relationships; financial resources; environmental changes; institutions; infrastructural systems; legal system? What are the barriers to change? What are the opportunities to overcome these barriers? Who else is working to address the problem(s)? What is not happening? (Noble, 2019).
} 
Next, analyse the underlying causes of these problems. Ask "why" the problem exists, and keep asking until the possible reasons are exhausted (FAO, 2019b). Potential causes can range from structural factors, to economic, environmental, social, or political factors. In turn, identify the drivers of those causes. Are there problems that result from the gender-based division of labour or from inequitable access to resources? (FAO, 2005).

This analysis may also surface other factors, such as potential opportunities to help overcome some of the barriers identified, or potential constraints that may make overcoming some of the barriers challenging.

- Stakeholder Engagement: During the context analysis, policymakers and technical staff should use a framework for identifying those entities and individuals ${ }^{37}$ that may affect or be affected by a potential intervention, including the impacts of any investments made because of the intervention. A strategy should be in place to engage these different groups, e.g. through a series of stakeholder workshops, in order to examine how the groups differ in their roles, interests, priorities and concerns, their knowledge and skillset, and how they can contribute to (or obstruct) the outcomes of an intervention. It is also helpful to analyse the power distribution among these groups, and to incorporate strategies to mitigate potential conflict or turn them into opportunities for collaboration (Caldwell, 2002). This stakeholder engagement should support participatory approaches to planning (see Box 10).

\section{Develop the Theory of Change}

Armed with the information collected during the context analysis, the theory of change itself can now be developed. The development of this theory of change should be done in partnership with the target population (and other key stakeholders, where appropriate), who bring specific knowledge and experience to help inform this effort. The resulting theory of change represents the group's best understanding or hypothesis, at that particular point in time, of how changes are anticipated to happen so that activities (such as the provision of an incentive) would lead to desired impacts.

At its core, developing a strong theory of change requires the three steps below. Once developed, a theory of change can be represented in a visual diagram and/or described in a narrative summary (See Annex I for a detailed example).

- Articulate the long-term desired impact: Once the problems and needs have been identified, policymakers and technical staff can shift from focusing on the problems to focusing on the solutions (Hivos, 2015). This can be done by articulating in a statement:

37 These may include national, sub-national and local governments, the private sector, financial institutions, target populations, legitimate tenure rights holders, the community at large, etc. 
- the long-term desired impact that a potential intervention intends to address ("what");

- the target population that will benefit from the intervention ("who"); and

- the purpose for the desired change ("why").

- Map the pathway of change: Mapping a pathway of change is done by working backwards from the long-term desired impact, to the medium- and short-term outcomes, and to the outputs (or activities), asking at each level "what element is necessary and sufficient in order to achieve the change at the next level." This can be organised in a chain of "if-then" statements, and should flow logically, e.g. if output $X$ is achieved, then it is reasonably logical that outcome $Y$ is attainable (Pringle and Thomas 2019). If one element does not logically link to the next, what else can be included? See Figure 1 for elements to consider when developing a theory of change. By clarifying the linkages, the theory of change provides a rationale for the choice of activities (intervention), a justification of resources (input), and a framework to support the development of indicators and targets for the monitoring, evaluation and learning stage (See Annex I for details on selecting proper indicators and targets for each result expected in the pathway of change).

- Identify assumptions: The linkages between each level identified on a pathway of change are only valid if certain conditions are met or in place. What evidence is there that each element leads to the next? If there is weak or no evidence, the link is an assumption. It is important to identify the assumptions made at each causal linkage. These may include assumptions about the target population's reactions to a changed situation, the internal and external conditions that need to be in place at each level, and the causality assumed in the pathway, including the expectations about how or why the activity proposed will bring about the change envisaged (Hivos, 2015). Articulating these assumptions can improve the design of an incentive or other intervention, lead to more coordinated and focused action, enable adaptive planning, form a good basis for risk management, support more focused learning and evaluation, and increase credibility (Hivos, 2015). 
Figure 1 - Elements of a Theory of Change

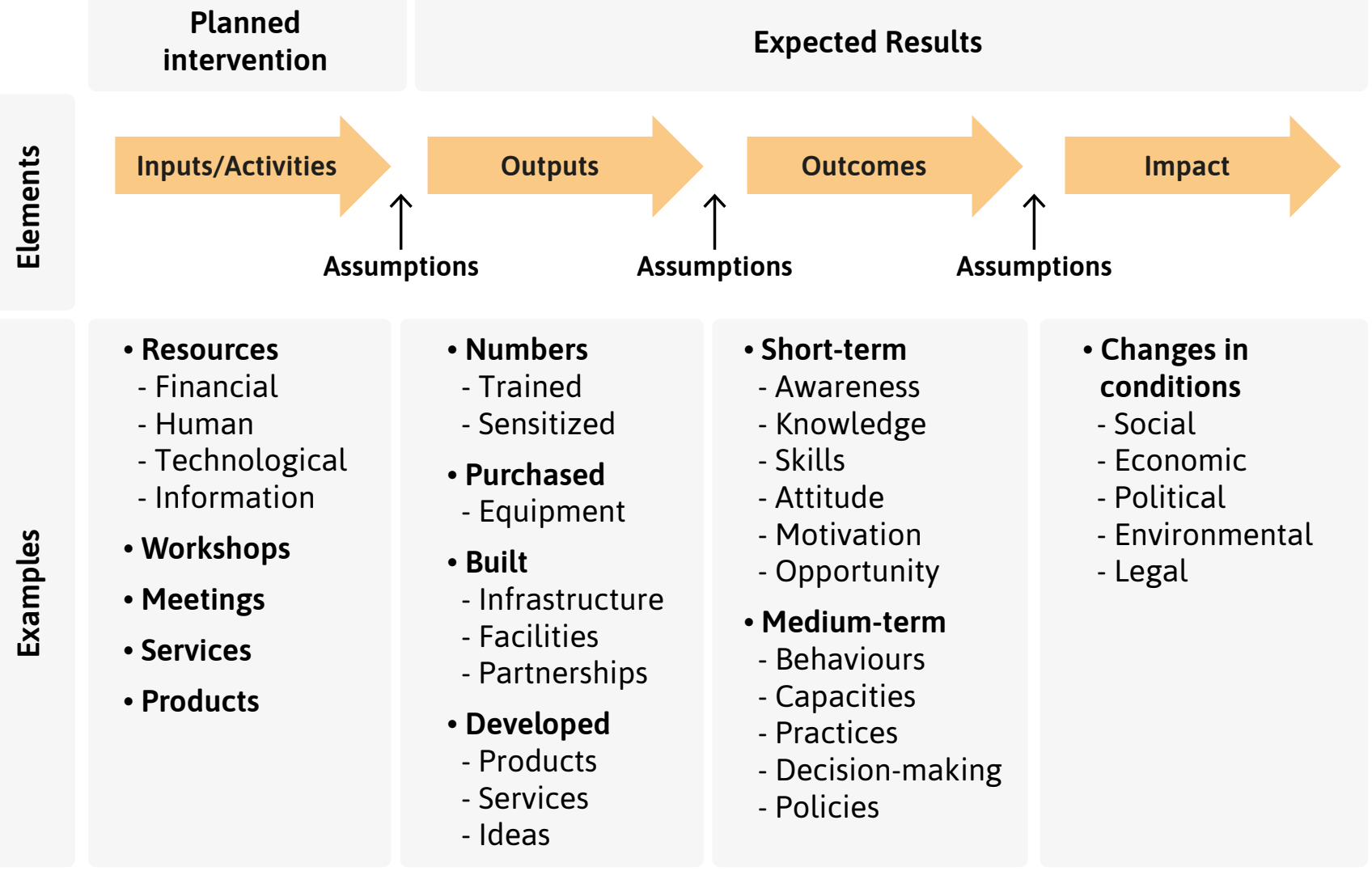

Adapted from source: IIED, (2019), at 96.

\section{Select the intervention (and decide whether to offer an incentive)}

The theory of change can help policymakers and technical staff explore different options-including the use of incentives-to try to find the most appropriate intervention for the problems identified and the impact sought. For example, the theory of change may uncover multiple interventions that could help to achieve a desired impact, as well as their relative strengths, weaknesses, and accompanying assumptions. Based on this information, policymakers and technical staff can:

- Select an appropriate intervention: Develop criteria to help select an intervention that could achieve the desired impact. Some common criteria include: the available budget; the desired impact and timescale to achieve the desired impact; sphere of control and influence (Hivos, 2015); social acceptability; community support; management, implementation and monitoring support and capacity; sustainability; technical feasibility; political sensitivity; level of risk (Caldwell, n.d.); and the potential to collaborate and coordinate with other government agencies, programmes, or institutions. 


\section{Designing investment incentives}

When designing an investment incentive, government officials should ensure that each incentive:

1. has a clear policy objective that aligns with national development priorities;

2. is appropriately targeted and has clear eligibility criteria;

3. can be easily and fairly administered;

4. will be granted at the right stage of the investment;

5. has a defined time frame; and

6. is specifically budgeted for.

Each of these elements is discussed in turn. Annex II provides additional notes on designing tax incentives for the limited contexts in which they are deemed appropriate.

\section{Ensure the incentive has a clear objective that aligns with national development priorities}

Each incentive should have a clear and strategic objective that aligns with national development priorities and sustainable development goals. The strategic objective may include a series of sub-objectives that will vary by jurisdiction depending on economic and political factors (Parilla and Liu, 2018). These objectives should take into account the needs identified during the planning phase, and should be supported by the theory of change developed at that time. This helps to ensure that the incentive is designed in a way that is logical.

Participatory processes during the design phase can also enable government to account for investor and other stakeholder needs when designing new incentives.

\section{Decide on the appropriate level of targeting and use clear eligibility criteria}

- Incentives can be tailored narrowly or more broadly, depending on the objective of the incentive. For example, eligibility criteria might include:

- type of activity (e.g. R\&D, production, market facilitation);

- size of investor or investment (e.g. small-, medium-, large-scale);

- identity of target beneficiary (e.g. marginalised groups; domestic or foreign investors; etc.);

- specific location in need of investment; and/or

- compliance with specified conditions, with objective and quantifiable performance criteria (e.g. linked to local employment; inclusive business approaches; climatesmart production practices; ecosystem services; etc.). 
Targeting criteria should be selected carefully, keeping in mind the objectives, desired impact, and intended beneficiaries of the incentives. Targeting involves a deliberate balancing process. On the one hand, offering incentives too broadly may increase the likelihood of providing redundant incentives. On the other, narrowing criteria excessively may risk excluding investors whose investments could support the government's goals. This underscores the importance of carefully assessing the potential impacts and costs of particular incentives.

The eligibility criteria should be simple and clear. Carefully crafted criteria can help to ensure that targeted investors or investments are actually the ones who receive incentives. Clear criteria can also manage investor expectations. This, in turn, can help to avoid disputes with investors who expect to be eligible for a specific incentive based on broad or ambiguous language.

\section{Minimise discretion in the granting of incentives}

Incentives can be awarded automatically or through a discretionary process that requires an application and approval.

Under an automatic process (sometimes referred to as rules-based process), an incentive provided for in the applicable law is automatically available to any potential beneficiary who meets the prescribed objective eligibility criteria. An automatic process should be used for any tax incentives offered. Automatic processes are also preferable when the incentive is targeted more broadly. The advantages of this method are its simplicity of administration, including the approval, implementation, and monitoring processes; savings on transaction costs; and the minimal discretion and increased transparency that reduce the potential for corruption (Tavares-Lehmann et al., 2016).

A discretionary process requires that a potential beneficiary go through an approval process or allows an investor to negotiate on a case-by-case basis with the relevant agency or authority to obtain the incentive or incentive package. Discretionary processes may be more appropriate, for example, when an assessment of the potential beneficiary's ability to use the incentive effectively is required. And for governments with strong administrative capacity, discretionary processes may be less likely to result in redundant incentives, thereby reducing overall spending on incentives. However, the discretionary method is more likely to enable corruption, especially with respect to how objectively and thoroughly merit is assessed by the relevant administrating agency. Given this greater potential for abuse, a discretionary process should still incorporate many non-discretionary elements, such as objective eligibility criteria, as well as criteria to determine set amounts/value of an incentive that an eligible investor can receive. Discretionary processes can also include several stages of approval, and should be subject to ongoing monitoring (TavaresLehmann et al., 2016; Brennan and Ruane, 2016). 


\section{Select the right timing: ex ante vs. ex post}

Incentives may be granted before the investment is made (ex ante or front-loaded) or after the investment has met qualifying conditions or achieved expected results (ex post or back-loaded). Ex ante provisions are based on the expectation of future, unconfirmed performance by the beneficiary. While they are the preferred method by investors and producers, they can be undermined by investors who do not deliver the expected results or who invest only until the incentive ends. For domestic small-scale producers and especially for under-represented groups, such as women, youth, and so on, however, ex ante provision of incentives may be essential for investments to be made by them.

Ex post provisions are based on the compliance of conditions by the beneficiary of the incentive. For large-scale investors, incentives should be tied to meeting qualifying conditions and offered on an ex post basis. Conditions may be defined in terms of export targets, employment targets, the establishment of certain activities like R\&D, use of environmentally-friendly technology, or other conditions aimed at achieving the jurisdiction's sustainable development goals. This performance-based approach helps governments to ensure that they only offer incentives to qualifying investors that meet any corresponding conditions and obligations; such an approach can be administratively easier for governments than attempting to use "claw-back" provisions when investors fail to meet their obligations tied to any incentives that were provided ex ante (TavaresLehmann et al., 2016).

\section{Establish a clear timeframe: continuity and duration}

An incentive can be offered as a one-time event, as in a matching grant or a training course, or continuously over a set number of years, as in a mentorship programme for youth in agriculture. For small-scale producers, continuous incentives can be attractive, although also risky: if they become overly reliant on non-institutionalised incentives, for example, they risk making decisions based on incentives that might be terminated prematurely.

The time frame during which an incentive is offered, and its results measured, should be specified. This may help investors, small or large, make more informed decisions. Specified time frames can also reduce the risk that the incentives programme is kept alive due to administrative or political inertia or despite its ineffectiveness. ${ }^{38}$ For legislated tax incentives, for example, the inclusion of "sunset" clauses (where the legislation automatically expires after a specified number of years unless proactively extended) is considered good practice (see Annex II).

While some stability and continuity of incentives can support informed investor decisionmaking, governments should always retain appropriate flexibility to end incentives

\footnotetext{
${ }^{38}$ Tax incentives, such as tax holidays, tend to remain in the statute books well after the original period for which they were granted and well after any benefit for such a policy has been exhausted. This creates a financial burden on the State without any benefit (Johnson et al. forthcoming).
} 


\section{Implementing investment incentives}

After incentives have been designed, they are ready to be implemented. This includes:

- offering the incentive (e.g. in legislation, via non-institutionalised programmes, or otherwise);

- administering the incentive (including any required applications and approval processes, reviewing whether potential beneficiaries meet the eligibility criteria, and ensuring the incentive is provided to those deemed eligible);

- operating any programmatic components (e.g. operating youth mentorship programmes or training programmes for women producers);

- addressing grievances or disputes related to incentive implementation; and

- assessing whether an incentive should be adjusted or withdrawn (either from a specific recipient because of non-compliance with conditions, or generally in light of evaluation and learning).

The implementation phase of incentives is extremely context-specific. Given the vast range of incentives and investors considered under this guide, it is not possible to provide a detailed discussion on implementation in practice. Rather, this section focuses on three key elements of successful implementation of incentives for responsible investment in agriculture and food systems:

- Focusing on inter-institutional coordination and collaboration

- Providing transparency and access to information

- Addressing grievances

Each element is discussed briefly.

\section{Ensure strong inter-institutional coordination and collaboration}

A clear allocation of responsibilities for implementing investment incentives, coupled with strong institutional coordination and collaboration as needed, can improve efficiency and effectiveness among the entities charged with the various stages of implementing incentives. Processes that facilitate coordination between government entities can help to foster information exchange, can support an appropriate allocation of capacity and resources, and can help to address disagreements that may arise between entities.

\section{Provide transparency and support access to information}

Public disclosure of information in accessible formats is fundamental to ensuring investors and other stakeholders are reliably informed in a timely manner regarding available 
incentives, as well as regarding incentives that governments have already provided. 40 Access to this information allows investors to make more informed decisions and supports public oversight of the use of public resources. Together with meaningful participation, information disclosure contributes to credibility, legitimacy, and trust (FAO, 2014c).

\section{i. Information on available incentives}

Timely and accurate information on available incentives and their objectives should be publicly accessible to all relevant stakeholders in an equitable and suitable manner, using appropriate communication channels. To make information available to smallscale producers, for example, communication channels may include using rural radio and posters; when targeting youth, television and social media may increase access (Fiedler, 2020). ${ }^{41}$

Clearly communicating information about available incentives has multiple benefits:

- Intended beneficiaries are more likely to be aware of and access the incentives.

- If done well, information disclosure and strong communications can help to reduce information asymmetries that would otherwise disadvantage certain intended beneficiaries (such as more disadvantaged youth in impoverished rural areas).

- The overall investment climate is strengthened, as investors-from small-scale producers to large enterprises-generally prefer clarity and certainty, which enables more informed decision-making.

\section{ii. Access to information about incentives already granted}

All incentives have associated costs. Disclosing these costs, and providing information about incentives that have been granted, can enable public scrutiny of whether incentives are aligned with jurisdictional goals and objectives.

At a minimum, governments should disclose:

- the costs of incentives programmes, and

- the details of any specific incentives negotiated with large corporate investors.

The costs of incentives include spending on specific programmes, as well as tax expenditures from tax incentives that reduce government revenue. Annex II discusses this further. Disclosing these costs helps policymakers, technical staff, and the general public better assess the effectiveness, impact, and value of the incentives.

\footnotetext{
40 Public disclosure of information is one element of transparency, which also includes access, comprehension, and use of information. For a discussion of key elements of transparency, see Szoke-Burke, (2021).

${ }^{41}$ CFS RAI, (2014) principle 9 stresses the need to share "information relevant to the investment, in accordance with applicable law, in an inclusive, equitable, accessible, and transparent manner at all stages of the investment cycle."
} 
Many investment contracts between large-scale investors and governments have included negotiated investment incentives. This is not recommended: as discussed above in Part II, if a government plans to offer any incentives to large-scale investors, such incentives should be provided for in law. However, for those investment contracts that do incorporate incentives, public disclosure is imperative. Governments should disclose these contracts-along with other important information, such as associated impact assessments, due diligence reports, and performance reports-to the general public. This can be done by disclosing such documents online, either on a governmenthosted website or via the Open Land Contracts repository. ${ }^{42}$ Governments should also take steps to ensure access by local communities (and their civil society partners) that stand to be affected by the underlying investment.

\section{Be prepared to address disputes or grievances}

Governments should be prepared to deal with disputes or grievances raised by investors regarding investment incentives. Such disputes might arise, for example, if the eligibility criteria are unclear and the government and investor disagree on whether the investor is entitled to a certain incentive, or if the government withdraws an incentive for noncompliance with conditions but the investor believes it was in compliance. While some grievances may be inevitable, careful design can help to minimise them, as discussed above. ${ }^{43}$

During the implementation phase, there should be a clear process and allocation of roles and responsibilities for resolving disputes and addressing grievances. This includes processes for addressing eligibility disputes, as well as for responding to feedback from beneficiaries.

For incentives that have a strong programmatic component (such as programmes that combine loans with training and mentoring services), governments should ensure there are adequate grievance mechanisms that allow beneficiaries to raise concerns. Good practice suggests that there should be:

- adequate information about the grievance mechanism;

- multiple ways to receive grievances (e.g. complaints box, call centre, grievance committees, etc.);

- opportunities to raise grievances both via the programme as well as through independent channels (such as an ombudsman); and

- sufficient and trained staff to address grievances that may be raised (Barca, 2016).

\footnotetext{
42 For instance, the governments of Liberia and Ethiopia have disclosed agricultural contracts and associated documents online. At the time of writing, OpenLandContracts.org hosts publicly available contracts from 25 countries.

43 If governments are providing incentives to investors whose projects run a high risk of creating grievances on the part of third parties-such as a large-scale investment that might affect nearby communities-the government should require the investor to set up a project-level grievance mechanism. Such a mechanism should follow good practice: for example, it should be rights-compliant; ensure accessibility, safety, and privacy; address power imbalances; and complement but not preclude access to other judicial or non-judicial mechanisms. This guide takes the position, however, that investments with high risks of creating grievances are not good candidates for incentives.
} 


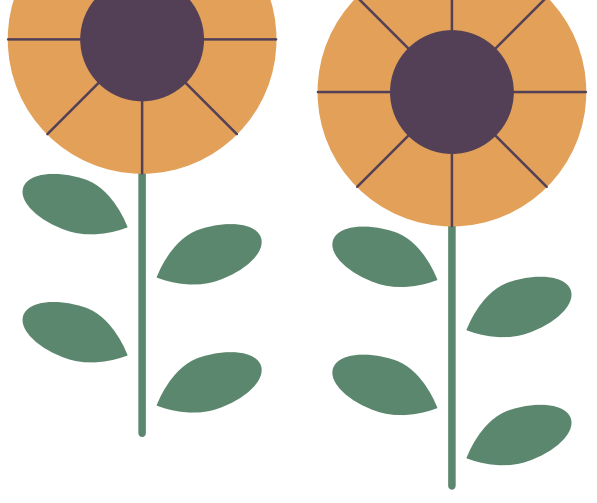

\section{Monitoring, evaluation, and learning for investment incentives}

Monitoring and evaluating incentives are critical for tracking and assessing their progress and impact. Learnings based on those efforts can help governments determine whether to continue offering certain incentives, whether to adjust any incentives proffered, and/or how to improve future incentives. It is good practice to develop a Monitoring, Evaluation, and Learning (MEL) plan at the design phase of an investment incentive.

More specifically, MEL should enable processes to assess whether incentives should be withdrawn or adjusted at two levels:

- whether an incentive should be withdrawn from an investor that is not complying with requisite conditions; and

- whether an incentive is moving toward achieving its intended objective given assessments of its effectiveness and costs, and if not, whether it should be adjusted or discontinued.

While monitoring compliance with conditions should be fairly straightforward, assessing whether incentives are able to fulfil their intended objective(s) and remain worth their costs may be more complicated. To support such an assessment, governments can draw on the specific indicators, selected at the planning stage of the incentive, that point to the targets expected of each output and outcome identified. In cases where indicators to monitor progress towards specific goals were not initially defined, or a theory of change not clearly developed, these can be retrospectively generated for MEL purposes, based on the expectations at the design phase, in order to track progress (IIED, 2019).

This section provides a very brief overview of MEL for incentives. Annex III provides more details on implementing a MEL plan; policymakers and technical staff tasked with designing, implementing, or monitoring and evaluating incentives can refer to Annex III for more specific guidance.

\section{Monitoring and Evaluation}

Monitoring is the continuous collection and tracking of data regarding ongoing incentives, which can be used to make informed decisions for policy management. Evaluation is an objective assessment of an ongoing or completed incentive programme to determine whether it is meeting or has met its goals.

When governments offer incentives with conditions, there should be a process for monitoring and evaluating whether the investors who have received those incentives are complying with the conditions. What this looks like in practice will depend on the type of incentive offered, the condition(s) imposed, how the investor demonstrates compliance with the condition(s), and what monitoring is feasible on the part of government.

In some cases, for example, the simplest approach may be to require that the investor certify that it has met the (objective and quantifiable) conditions, and to monitor using "spot checks" 
and/or audits. To the extent that the government decides an investor is not in compliance, there should be a clear process for withdrawing the incentive (and, if needed, an effective mechanism to "claw back" the incentive already provided).

Beyond monitoring and evaluating specific investor compliance with incentive conditions, governments should also monitor and evaluate incentives at the programme level. This can support understanding of what works and what does not, and to probe into the reasons for these results (IIED, 2019). For example, were the assumptions made in the theory of change invalid, was the incentive offered inappropriate for the target population, or was the eligibility criteria too broad (or too narrow)? This understanding, in turn, can help governments ultimately make more informed decisions about what incentives they offer.

To do this, governments can develop a monitoring and evaluation plan linked to an incentives programme. The goal of monitoring is the collection of data that can be used for regular reporting, analysis, and assessment of the incentives at the evaluation phase. Broadly speaking, monitoring can seek to focus on whether incentives have been implemented as intended and/ or whether the incentives are leading to expected results.

In developing the monitoring component of the plan, the following considerations (details of which are included in Annex III) should be kept in mind:

- what data to collect;

- entity (or entities) responsible for monitoring data;

- data source(s) to be used;

- data collection method(s) to be used;

- disaggregated data collection;

- frequency of data collection; and

- data reporting.

Evaluation is the assessment made based on the data collected during the monitoring phase. An effective evaluation can provide useful evidence that supports improvements or adjustments to incentives or that provides guidance for future incentives.

Various approaches may be used in conducting an evaluation. An appropriate evaluation approach will depend on a number of elements, including the purpose and scope of the evaluation, the criteria to be addressed, and the type of evaluation to be conducted (IIED, 2019). Annex III provides key issues to consider when determining the evaluation approach.

Some governments may find it easiest to seek an external evaluation of certain incentives or incentives programmes. External evaluations and recommendations can help provide insight into the benefits and drawbacks of the government's current approach, and can help to guide strategic decision-making about whether to continue, adjust, or withdraw incentives. 


\section{Applying Learnings}

Together, monitoring and evaluation drive learning, which is an ongoing process throughout the duration of each offered incentive. Learning can be used to make decisions about ongoing incentives; in particular, whether they need to be adjusted or discontinued. It allows for and encourages adjustments to be made to the design and implementation of an incentive in response to the information and knowledge generated through the monitoring and evaluation processes, as well as modifications in the design of an incentive in response to implementation challenges incurred. For example, adjustments can be made to the eligibility criteria of tax incentives or the conditions imposed if its redundancy ratio is greater than zero indicating a sizable loss of potential revenue, or if its social cost becomes much higher than its benefits.

Learning can help assess whether these challenges were preventable, and how to avoid such challenges in a similar future situation (IIED, 2019). In this way, learning can also be used in the design of new incentives.

However, if evaluations and the learnings from them suggest that an incentive is far from fulfilling its intended objective, is not worth its costs, and/or has become irrelevant, this might support a decision to discontinue the incentive. To the extent that governments decide to discontinue an incentive before the anticipated end date, they should seek to apply good practice, such as clearly communicating the planned phase-out and, potentially, providing parameters under which investors may continue to benefit from an incentive already granted to them.

Learnings are, of course, only useful if relevant officials are willing to consider them, and to adapt their approaches to incentives accordingly. Political and other factors can influence how governments think about incentives, whether and what they will offer, and how they will condition them. Too often, governments persist in using incentives despite evidence that they may not be effective or worth their costs. Pressure from investors, from other states, from citizens and other stakeholders can colour a government's calculations about what makes sense, while individual interests of decision-makers may also influence the shape that incentives take. It is not uncommon for evaluations of incentives to be omitted, or for government officials to overlook the recommendations made on the basis of evaluations and learnings.

Yet, if governments are serious about using incentives to increase and enhance responsible investment in agriculture and food systems that supports their development priorities, it is critical that monitoring and evaluations are undertaken, and that learnings are applied seriously. Effective MEL can make the difference between incentives that work and those that do not. 


\section{Conclusion}

This guide demonstrates that incentives can play a role in stimulating more responsible investment in agriculture and food systems, although they are not always the right tool for the job. Incentives are expensive, and should be used carefully. Incentives are not a substitute for improving the enabling environment, which is generally much more important for small- and large-scale investors alike.

When offering incentives, governments should prioritise incentives that support small-scale producer households and micro- and small-scale enterprises upstream and downstream, particularly youth and women. Supporting these investors can make a meaningful contribution to achieving national development priorities and the goals of the CFS RAI.

Incentives should be carefully planned for, with strong participatory processes and a view to gender and youth sensitivity in design. Through careful planning, governments can assess whether and, if so, how incentives should be used. Where incentives are deemed an appropriate policy response, design can be guided by clear objectives, with careful targeting, minimal discretion, appropriate timing and timeframe, and an adequate budget. Finally, the progress and impact of incentives should be tracked by monitoring and evaluating processes, while learnings based on those efforts can help to assess whether incentives should be withdrawn or adjusted.

Incentives require deliberate consideration and design if they are to be an effective mechanism for encouraging more and better quality investment in agriculture and food systems. It is hoped that this guide will serve as a useful tool in achieving that aim.
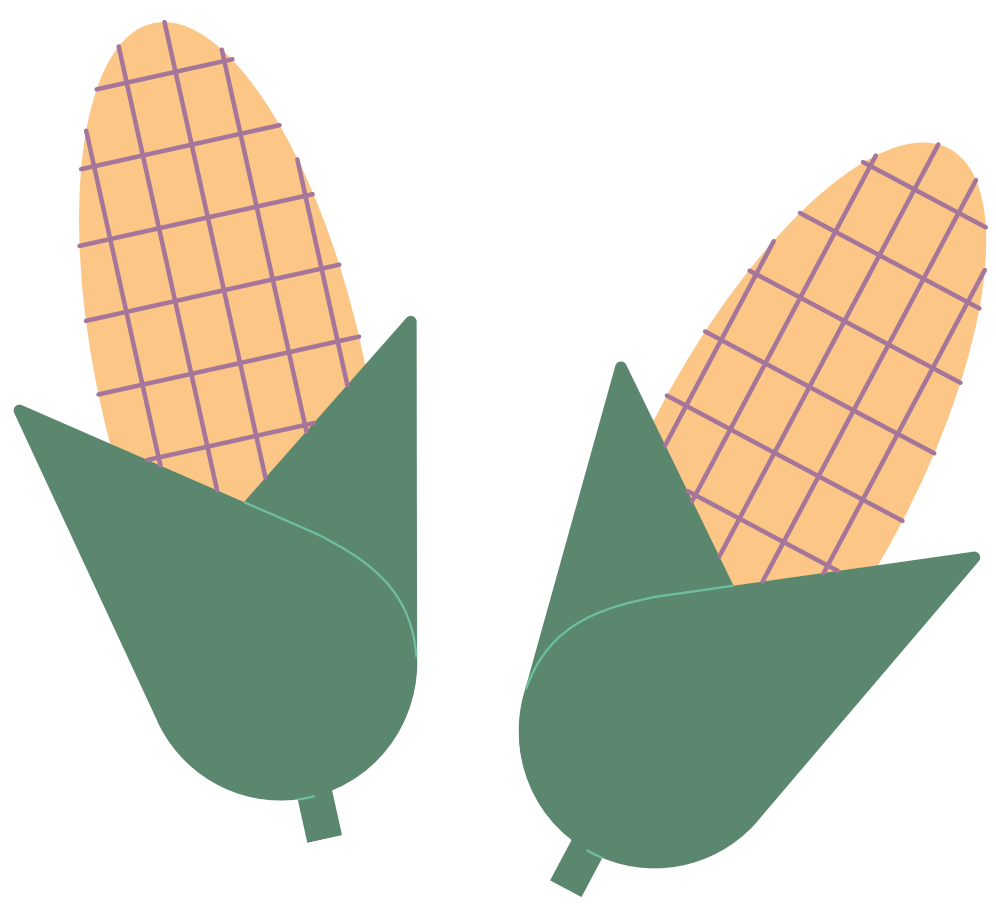


\section{Glossary}

Agriculture and food systems: the range of activities required to produce, process, market, retail, consume, and dispose of agricultural goods. This includes not only food and nonfood products, forestry, livestock and fisheries, but also the goods needed and produced along each step of these processes. Food systems involve a wide range of stakeholders and institutions. ${ }^{1}$

CFS RAl: (Committee on World Food Security Principles for Responsible Investment in Agriculture and Food Systems). A voluntary international instrument developed through an inclusive multi-stakeholder process that consists of 10 principles for achieving investments that are responsible, contribute to food security, and promote sustainable development.

Community members: local stakeholders who own or use the land underlying or near an investment project, or whose livelihoods and well-being may otherwise be affected by investment activities.

Downstream activities: the processing, marketing, retail, consumption, and disposal stages of production activities.

Enabling environment: the set of factors, conditions, and safeguards that encourage investment generally, and responsible investment specifically.

Foreign direct investment (FDI): an investment made by an individual or private sector enterprise from one ("home") country into another ("host") country.

Investment: the commitment of capital (whether financial, physical, intellectual, or other) to something with the expectation of accumulating additional income or benefits in the future.

Investment climate: the conditions (financial, socio-political, and economic) that affect the favourability of a given jurisdiction to investors considering it as an investment location, or that affect the decision-making around investments more generally. Similar to the "enabling environment."

Investment incentive: a targeted measure provided by a government to or for the benefit of an investor (including small-scale producers) for a new or expanded investment with the goal of influencing the size, location, impact, behaviour, sector, or other character of such investment. They can broadly be categorized into five groups:

- Financial incentives: non-tax-based financial supports.

- Technical and business support incentives: can include facilitation services, technological packages, research and development, and extension services.

- Tax (fiscal) incentives: tax-based measures.

${ }^{1}$ Adapted from the CFS RAI. 
- Regulatory incentives: derogations from national or sub-national regulations or favourable regulatory terms offered to investors.

- Other incentives: measures that are categorised as incentives for the purpose of this guide but do not fit into the existing established categories listed above.

In addition to these categories of incentives types, investment incentives are sometimes described based on their underlying goal, in particular:

- Behavioural investment incentives: targeted measures provided by the government to or for the benefit of an investor to influence investor behaviour.

- Locational investment incentives: targeted measures provided by the government to or for the benefit of an investor to attract investment into a particular location.

Investor: for the purposes of this guide, refers to the wide range of individuals and private sector enterprises that invest in agriculture (including livestock and pastoralism), fisheries and aquaculture, and forestry, including investments in primary agriculture as well as those in upstream or downstream activities. Investors include both domestic and foreign investors, ranging from small-scale producers and micro-enterprises to large-scale corporate investors.

Investment Promotion Agencies (IPAs): public agencies that focus primarily on attracting inward foreign direct investment (FDI) into a country or sub-national region. Some IPAs may also focus on promoting or attracting domestic investments, and/or on other related mandates such as innovation promotion or export promotion.

Micro-, small-, and medium-sized enterprises (MSME): while difficult to define across countries, within a country, these may be defined by number of staff employed and asset base.

Responsible investment in agriculture and food systems: a responsible investment in agriculture and food systems contributes to sustainable development, enhances food security and nutrition, and respects human rights.

Small-scale producer: includes family farmers, pastoralists and fishers, women and youth producing food, indigenous peoples, and post-harvest processors. While what is considered "small-scale" is context-specific and varies across countries, scale is generally identified by physical size (e.g. size of land being farmed) and/or economic size.

Sustainable Development Goals (SDGs): seventeen goals adopted unanimously in 2015 by UN Member States as part of the Agenda 2030 for sustainable development that lay out an integrated blue print to achieve socially inclusive, environmentally sustainable economic growth, and to end poverty, address climate change, strengthen global institutions, and promote peace. 


\section{Considerations regarding how incentives can be used}

Responsible agricultural and food systems investment is primarily determined by the enabling environment, not investment incentives. Governments seeking to encourage more responsible investment should, first and foremost, focus on improving the enabling environment. In addition, incentives are not appropriate tools for ensuring that investment does not result in human rights abuses or environmental harm; for that, governments must ensure that domestic law prevents such outcomes.

In some circumstances, investment incentives may be appropriate, and may be the most effective mechanism for overcoming a particular barrier to investment that supports the government's national development priorities. In such cases, incentives can be used as a targeted policy instrument to address specific needs, but should be effective, worth their cost, and ideally not offered to investors who would have undertaken the investment even without the incentive.

When investment incentives are appropriate, the following recommendations can guide the approach of policymakers and technical staff:

\section{Process recommendations}

- Seek strong coordination across relevant institutions on issues that influence investments in agriculture and food systems, and ensure that all relevant institutions are included as needed in incentives planning, design, and implementation.

- Create opportunities for community members, civil society, and other stakeholders to share their perspectives and influence decision-making around investments and the planning and design of incentives.

- Participate in regional efforts to curb redundant incentive use and to combat the "race to the bottom."

\section{Substantive recommendations}

- To use incentives to enhance responsible investment aligned with national development priorities and the CFS RAI, prioritise the development of investment incentives that target small-scale producers, especially youth and women, as well as micro- and small-scale enterprises upstream and downstream. Avoid placing an outsized emphasis on using incentives to attract FDI.

- Consider attaching environmental, social, health, behavioural, or other conditions to incentives in order to achieve desired investment-related impacts that align with national development priorities. 
- Design incentives in recognition of the different dimensions of responsible agricultural and food systems investment, so as to not blindly pursue one dimension (e.g. food security) at the expense of others (e.g. biodiversity).

- Consider how incentives may be packaged (including through the provision of multiple complementary incentives together, or alongside disincentives) in order to better support target investors' effective use of incentives and the achievement of government's goals.

\section{Technical recommendations}

- Reduce or eliminate the discretion to offer incentives through contracts and, when possible, embed incentives in domestic national or sub-national law.

- Analyse proposed investment incentives for potential international trade law breaches.

\section{Planning for, designing, monitoring, and evaluating investment incentives for responsible investment in agriculture and food systems}

Taking the above considerations and recommendations into account, this guide provides specific information on how to plan for, design, implement, monitor, and evaluate incentives for responsible agricultural and food systems investment.

\section{Planning}

Before any specific investment incentives are designed, careful planning can help to clarify whether investment incentives are an appropriate intervention.

A starting point for this planning is to understand the government's national development priorities and how they relate to the government's long-term goals with respect to responsible investment in agriculture and food systems. With this understanding, the first steps in planning for an intervention-one that might take the form of an incentive-are to identify the needs of investors in agriculture and food systems, the barriers to responsible investment in agriculture and food systems, the problems that the government is trying to address, and what the government is hoping to achieve with the intervention. These steps will enable policymakers and technical staff to ascertain whether incentives are the most appropriate mechanism and, if so, how to design them effectively.

To support this assessment, policymakers and technical staff can conduct a context analysis, articulate a long-term desired impact, and then use a theory of change to assess possible interventions, in order to ultimately determine whether to use an incentive. 


\section{Annex l: Theory of change}

\section{Developing a theory of change}

Box 11, below, provides the basic elements to include in the development of a theory of change, followed by an example of a theory of change narrative and its associated diagram.

\section{BOX 11: ELEMENTS TO INCLUDE IN A THEORY OF CHANGE}

A theory of change includes a number of elements, their causal relationships, and assumptions and risks that may influence the success or failure of achieving the expected goal at each level:

Impact is the long-term desired change to be achieved for a target population reasonably and causally attributed to the intervention. Positive impacts should be aligned with national development priorities.

Proximate outcomes may be added, where relevant, if the desired impact cannot be measured directly.

Outcomes are the short- and medium-term goals expected to be achieved as a result of the completion of the outputs. They describe changes in institutional and behavioural capacities or performance of beneficiaries due to the outputs.

Outputs describe the changes in skills or abilities and capacities of beneficiaries, or the availability of new products and/or services that are achieved from the completion of activities within a specified time period.

Activities define how the intervention will be carried out - the actions, processes, or strategies that will be implemented to produce the desired outputs.

Inputs are the financial, human, technological, and information resources used to deliver activities.

Assumptions are the necessary (internal or external) conditions that must be in place or events that must occur for goals to be achieved at each level of the theory of change.

Risks are potential circumstances fully or partially beyond the control of the theory developed, such as social, political, or economic factors that may affect the ability to achieve expected goal(s) at any level of the model. 


\section{Example of a theory of change narrative}

The problem, goals, and proposed incentives

In a farming community, located in a climate change hotspot, the majority of the population is experiencing severe food insecurity. There is a significant gap between potential agricultural productivity and actual agricultural productivity, i.e. yield gap, which climate variability is likely to exacerbate. After a comprehensive context analysis, aided by local farmers and representatives from the community, a theory of change is developed. In order to close the yield gap (strategic objective) and contribute to improving food security (desired impact), and at the same time, avoid dangerous cropland expansion and negative environmental impacts, it is decided that a series of training courses (incentive) be offered and implemented, targeting local small-scale producers (target population). The training courses would focus on the adoption of climate-smart agricultural (CSA) practices, including the use of improved crop varieties, residue management, crop diversification, laser land leveling, and zero tillage with residue retention. The theory of change that was developed predicts that if the majority of local small-scale producers attend these training courses and acquire new skills and knowledge, they will apply these skills systematically and sustainably, which in turn will improve productivity and close the yield gap, and therefore contribute to an increase in food security.

\section{Identifying missing steps}

During the participatory process, consideration is given to missing steps in the theory of change, from the potential intervention to the desired impact. One significant missing step is that the beneficiaries of the incentive, equipped with the relevant CSA knowledge and skills, must be able to purchase the related and necessary CSA technology in order to put those skills into practice. This may include the equipment needed to achieve laser land leveling, which enhances water use efficiency compared to unlevelled fields, and zero tillage with residue retention, which conserves soil moisture, reducing evaporative loss of moisture, thus requiring less water than conventionally tilled fields (Khatri-Chetri et al., 2016). Without the ability to pay for these initial capital requirements, the farmers' application of CSA practices may not lead to the increased agricultural productivity that the incentive is intended to achieve. This realization may lead to a reconceptualization of the theory of change by, for instance, adding a crucial step at the start of the model whereby a financial incentive (through subsidies and/ or loans) is offered by public financial institutions to these farmers to help them purchase the necessary CSA technology.

\section{Applying a gender lens to the incentives}

Consideration should also be given to any unintended consequences of the theory developed. One such consequence that may arise from the implementation of the incentives is the danger of leaving behind women producers, who play a critical role in the production of food crops. To ensure that women producers benefit equally from the CSA training courses and have equal access to financial resources required to put their newly acquired skills into practice, gendersensitive measures need to be adopted that take into account the needs of, and constraints 
faced by, women in the community. For example, the training courses may be taught by a set proportion of female trainers who are sensitive to gender differences in agricultural practices, crops traditionally grown by women, and illiterate farmers. In addition, the training courses may be taught during school hours or include the provision of childcare services to ensure the attendance of women producers. In terms of the financial support provided to farmers to purchase the CSA technology, the existence of discriminatory practices of financial institutions often means that women have poorer access to credit since loan agreements require collateral, like land or asset ownership, which are usually registered in men's names (Vorley et al., 2012). To support women's equal access to credit, the government may adopt policies that urge financial institutions to implement gender-sensitive loan mechanisms and procedures or to allocate a proportion of credit sources to women producers.

\section{Risk analysis}

In addition to the missing steps and unintended consequences, the assumptions made and any associated risks that they may carry are examined. In a case where an assumption is seen to represent a more substantial risk, policymakers and technical staff may adjust the intervention, re-design the incentives, develop a contingency plan, or establish a risk management plan to monitor and address conditions as needed (Roberts and Khattri , 2012). If, for instance, the jurisdiction is located in an area prone to frequent floods or drought, the training courses could include strengthening capacities of key stakeholders to mitigate and respond to disasters, environmental challenges, and climate crises (FAO, 2019a). See Figure 3.

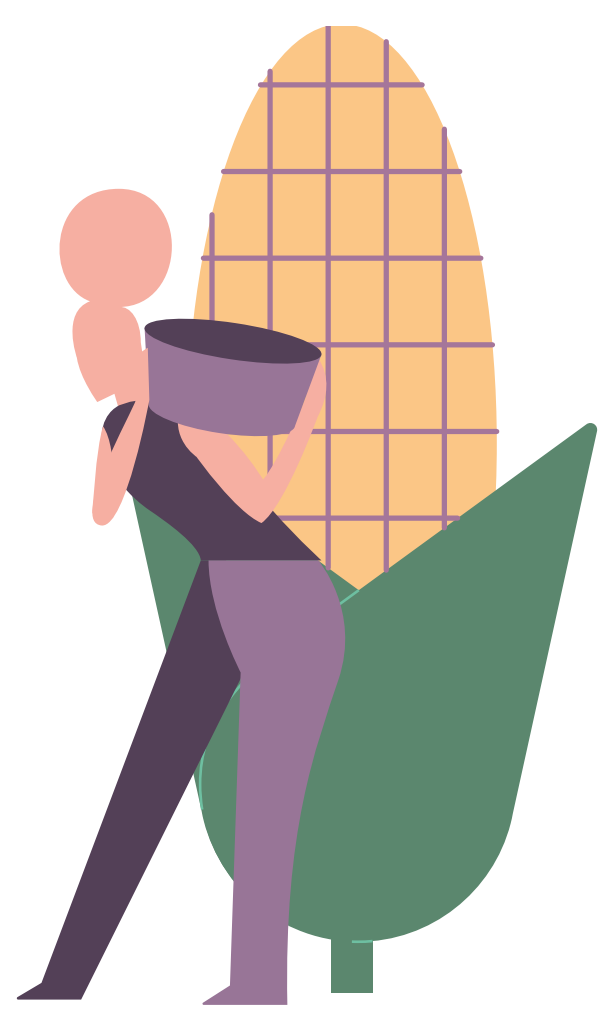


Figure 3 - Theory of change visual

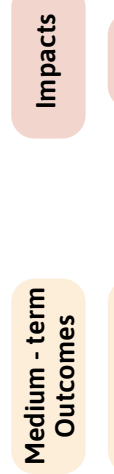

Improved food security (and income) among small-scale farmers, including women producers

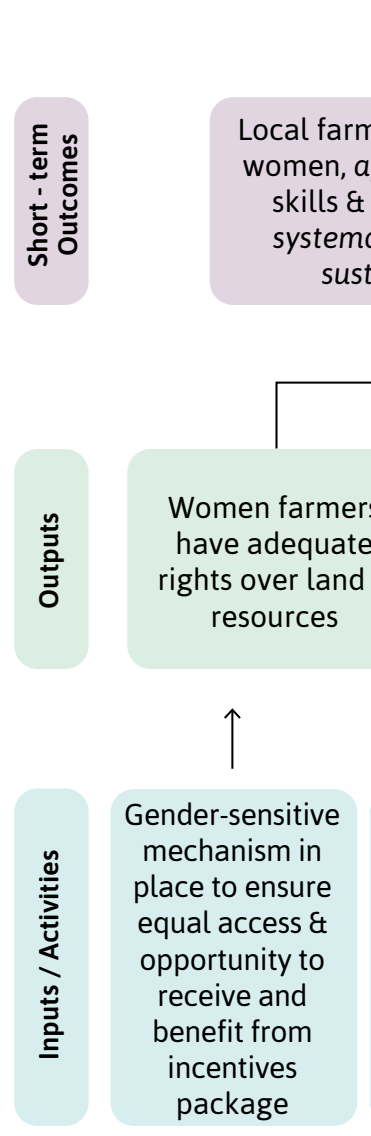

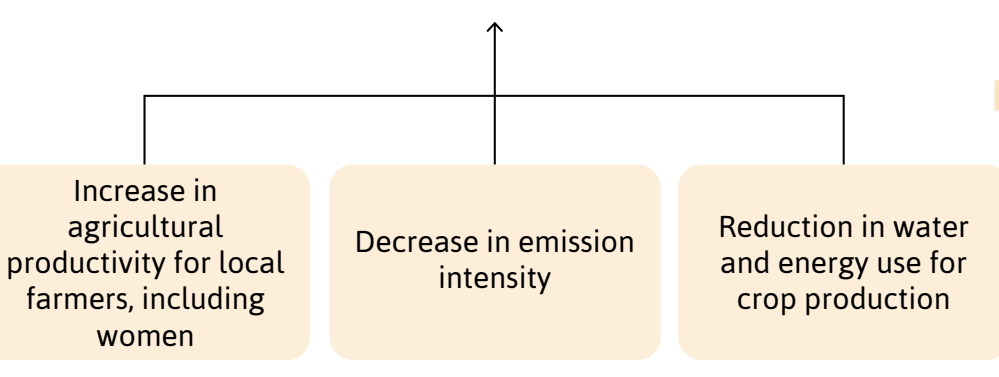

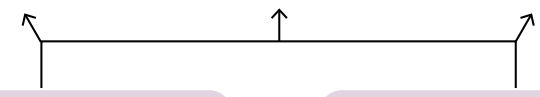
echnology sustainably sustainably

crease in crop land under CSA technology \& practice

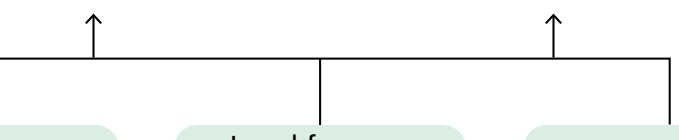

Local farmers, including women, attend training courses and acquire new skills \& knowledge
Local farmers purchase appropiate $\rightarrow$ technology to implement new skills

\begin{tabular}{|c|c|c|}
\hline $\begin{array}{c}\text { Public } \\
\text { awareness of } \\
\text { incentives } \\
\text { package being } \\
\text { granted by local } \\
\text { government }\end{array}$ & $\begin{array}{l}\text { Training courses } \\
\text { offered to } \\
\text { small-scale } \\
\text { farmers on CSA } \\
\text { practices \& } \\
\text { technology to } \\
\text { improve } \\
\text { agricultural } \\
\text { productivity }\end{array}$ & $\begin{array}{c}\text { Financial } \\
\text { resources } \\
\text { granted to } \\
\text { small-scale } \\
\text { farmers to help } \\
\text { them purchase } \\
\text { necessary CSA } \\
\text { technology }\end{array}$ \\
\hline
\end{tabular}

Increase in agricultural productivity translates to increase in food security

Farmers have access to markets with reduced food loses \& waste

Market prices and demand of crops produced remains stable

Climate conditions remain stable over time

CSA practice \& technology actually reduce emission intensity

CSA practice \& technology actually increase agricultural productivity

Climate - sensitive crops are available \& accesible for use

Farmers endorse the CSA skills \& knowledge acquired

Farmers have financial means to purchase technology

Farmers have financial \& physical means to attend training sessions

Local government develops theory of change via an inclusive and equitable participatory approach 


\section{Using the theory of change developed to inform MEL}

The theory of change developed at the planning stage established the logic hierarchy (from inputs to impact) that an incentive is hypothesised to follow. Policymakers and technical staff designing an incentive should establish complementary detail to the logic developed to help track progress towards achieving the desired impact. The details, discussed below, will form the basis of the Monitoring, Evaluation, and Learning (MEL) stage of an incentive.

A first step is to work out the indicators and targets associated with each of the expected results anticipated in the theory of change. Indicators are quantitative or qualitative measures that enable one to assess the degree to which activities, outputs, outcomes and impacts have been achieved. Indicators define in measurable terms the performance required at each level of the theory of change in order to reach the next desired level. For instance, using the theory of change example above, several outcome indicators may be selected to measure the change in agricultural productivity over time, including measures of soil health, crop diversity, and/ or seed quality used. On the other hand, a single indicator may be sufficient to measure an expected result, like the number of small-scale producers that attend the training sessions (an output indicator).

Targets are the desired level of performance, or magnitude of change, expected at a specific point in time for each indicator (IIED, 2019). In other words, targeting is the act of putting numbers and dates on indicators. ${ }^{44}$ An outcome target using the example above could be: by 2025 , emission intensity, in particular from agricultural activities, will be reduced by 50 percent. Targets can be quantitative or qualitative, depending on the indicator, and should satisfy the SMART criterion (specific, measurable, achievable, relevant, timely) to have the greatest potential for achieving the expected results at each level of the theory of change.

In order to understand the rate of change over time of an indicator and the likelihood that a target will be met, benchmarks can be established. Benchmarks are the expected levels of achievement of an indicator at specified points in an incentive cycle. When such benchmarks are not met, policymakers and technical staff may wish to adjust the design or implementation of an incentive, the indicators and/or targets selected, or decide to withdraw or discontinue an incentive altogether.

Finally, baseline data should be set for each indicator. Baseline data is the status of the indicator at the start of a project or incentive and serves as the reference point for comparison, i.e. to measure progress or achievements against the situation that prevailed before the implementation of an incentive. This data may be collected during the planning stage of the incentive as part of the context analysis.

\footnotetext{
44 CFS RAI Principle 10 recognises the need to "defin[e] baseline data and indicators for monitoring and to measure impacts." In addition, "[s] tates are encouraged, in consultation with all relevant stakeholders, especially the most vulnerable, and as appropriate with national human rights institutions, to establish monitoring, assessment, and reporting systems ..." See: FAO, (2016), 23.
} 
It is important to address and integrate issues and differences relating to gender and age into these elements in order for disaggregated data to be collected and reported for all expected results. This is especially critical when differentiated gender impacts might occur and be relevant. Other demographic data, where relevant, should also be disaggregated to understand the different way targeted groups benefit (or not) from the incentives offered.

If resources-such as time, money, knowledge, and/ or skills-are limited, focus on a small core set of critical results, and then develop indicators for which data collection is realistic: available in a timely way and neither too burdensome nor too costly. It is also wise to establish:

- how the data for the indicators and targets will be tracked and analysed;

- how often the measurements will occur;

- the source of data;

- who will be responsible for the data collection;

- how the data will be collected;

- whether the data will be checked for quality; and

- the financial resources to be used (IIED, 2019).

Clarifying these elements at the planning stage and in conjunction with the theory of change can greatly facilitate the MEL stage. Policymakers and technical staff can gradually strengthen these tools as the incentives are implemented and monitored.

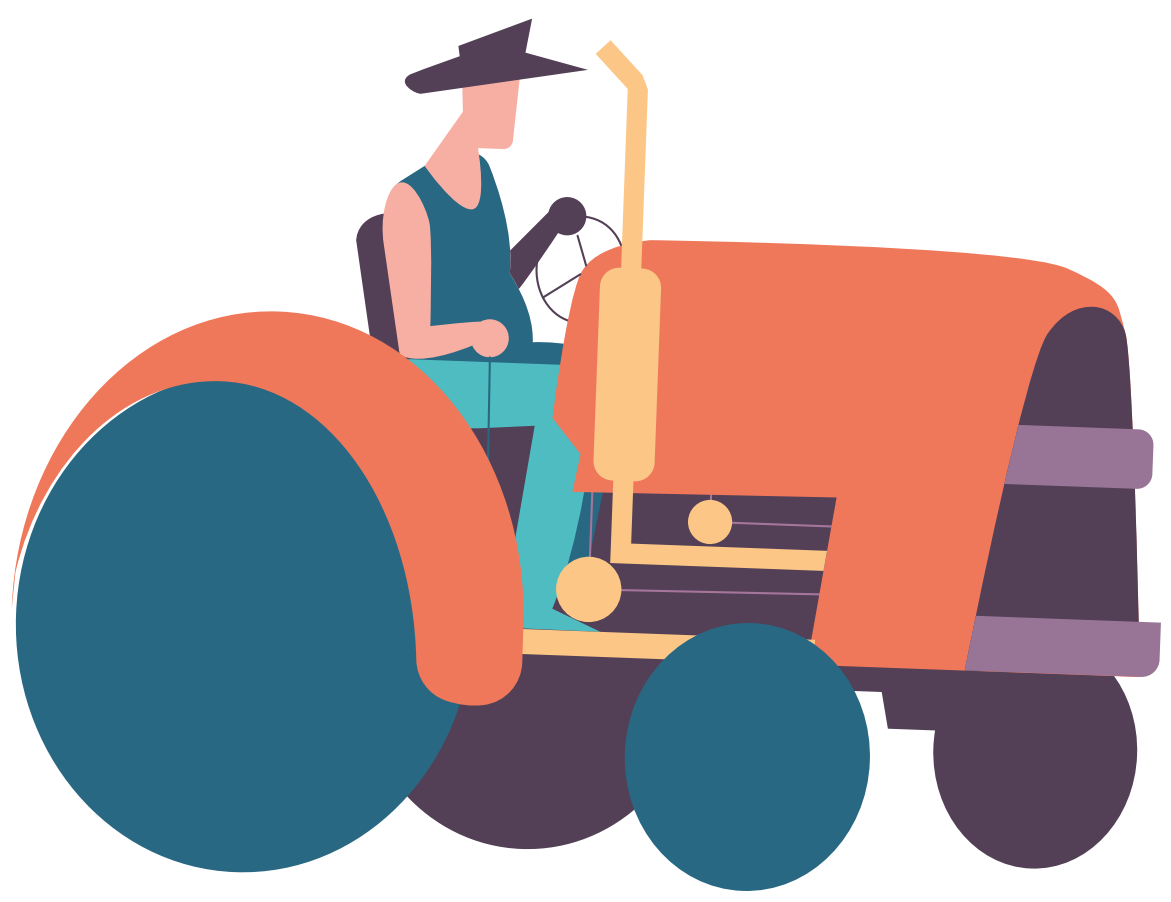




\section{Annex II - Designing tax} incentives

As noted in Part II of the guide, evidence suggests that tax incentives, as they are generally used, may not be worth their costs or even effective. Some of this research is highlighted below in Box 12.

In light of this evidence, policymakers and technical staff should carefully consider whether it is necessary to offer tax incentives in the agricultural and food systems context. In many cases, it may not be. In the event that they are still offered, effective and efficient use of tax incentives requires that they be carefully designed, with a view to improving their transparency and governance, and systematically monitored and evaluated to facilitate informed decision-making (IMF et al., 2015). This Annex provides guiding principles relevant to the design of tax incentives.

\section{BOX 12: DOUBTS ABOUT THE EFFECTIVENESS AND VALUE OF TAX INCENTIVES}

Investment incentives and their impacts are difficult to quantify, yet researchers have sought to measure the impact of various tax incentives through both econometric and qualitative studies. When assessing incentive impacts, one primary question is effectiveness- i.e., do they induce the desired investment or behavioural change. Even if some level of effectiveness is proven, another question is whether incentives "are worth the costs and trade-offs they imply," as they may reduce governments' ability to spend on important public goods and services (Tavares-Lehmann et al., 2016).

\section{Econometric Studies}

Econometric studies have drawn varied conclusions regarding tax incentives. For example, an analysis by a World Bank economist (James, 2013) found that econometric studies of investment incentives (not specifically focused on agriculture and food systems) showed the following results:

- "Investments are not strongly influenced by lower tax rates in countries with weak investment climate." James, (2013).

- "Investments in developed countries respond strongly to incentives." de Mooij and Enderveen, (2003), Desai, Foley, and Hines, (2004).

- "Investments have responded to incentives in some developing countries, but the elasticity was smaller than [in] developed countries." Klemm and Van Parys, (2009).

- "Export-oriented investments-especially mobile ones-are more sensitive to tax incentives." 45 Grubert and Mutti, (2004), Rolfe and White, (1992), Wells, (1986).

- "Investment incentives create significant distortions by encouraging inefficient investments." Hassett and Hubbard, (2002).

\footnotetext{
45 One downside of this effectiveness vis-a-vis mobile firms is that such firms may be more likely move to other jurisdictions when offered more attractive incentives there. This can limit the benefits to the original jurisdiction, and also exacerbate a "race to the bottom" in offering incentives.
} 
- "Low inflation is the best investment incentive." Hassett and Hubbard, (2002).

- "Temporary incentives have bigger short-run impact than permanent ones." Hassett and Hubbard, (2002).

To add to those conclusions:

- Increased FDI flows do not necessarily increase total investment as they can displace local investment. Klemm and Van Parys, (2012).

- Even in the context of export-oriented investments, the ultimate impact on a country's economic output can be limited in spite of all FDI incentives offered. FAO, (2013a).

\section{Interview-Based Studies}

Qualitative studies based on firm-level information have helped to shed light on investment decision-making and the effect of tax incentives. The same World Bank study that reviewed econometric studies also reviewed qualitative studies available at the time, finding that studies show that redundancy levels (whereby incentives are provided even though investors would have invested without the incentives) "are quite high for investors in almost all the countries," with the main exception being exporters, for whom "tax incentives are far more important." The review also found that investment incentives "did not affect the level of investment for most investors" (James, 2013). In particular, the review of qualitative studies showed that tax incentives are "particularly redundant for investments oriented toward domestic markets and those based on natural resources ... unique to a country" (James, 2013), which arguably can include certain large-scale agricultural plantations such as rubber and bananas (Tavares-Lehmann et al., 2016).

These conclusions align with the research results of other international institutions. According to the IMF, investment surveys reveal that "tax incentives usually do not top the list of investment factors in developing countries." In addition, the United Nations Industrial Development Organization 2010 business survey of 7,000 companies in 19 sub-Saharan African countries ranked incentives packages 11 th out of 12 location factors, with this importance falling over time. By contrast, transparency of the legal framework ranked much higher and grew in importance, leading to the conclusion that investors "seem to care much more about deficient legislation and onerous regulations than about the availability of tax incentives" (IMF et al., 2015).

Two agriculture-specific, interview-based studies that reach similar conclusions-finding that tax incentives have not stimulated agricultural/agribusiness investments in Ethiopia and Ghana-are discussed above in Part II.

\section{Profit- versus cost-based tax incentives}

To the extent that tax incentives are worth using, research has shown that cost-based tax incentives may have a greater chance of stimulating investment. By lowering the cost of capital, cost-based incentives "make a greater number of investment projects more profitable at the margin - that is, may generate investments that would not otherwise have been made." By contrast, the effect of profit-based tax incentives may be to "forego government revenue in 
order to make even more profitable investment projects that would be profitable, and hence undertaken, even without the incentive" (IMF et al., 2015). This is especially the case where there exist location-specific factors, including "natural resources, agglomerations, or local markets" (IMF et al., 2015; Mansour, 2019). However, as with any incentive, each particular type of tax incentive requires close examination in the context in which it would be offered to understand potential efficacy and to assess whether it is worth the costs.

To the extent that tax incentives will be offered, governments are encouraged to adhere to the guiding principles enumerated below, in conjunction with the more general principles in this guide. Many of the below principles are adopted directly from the OECD's Principles to Enhance Transparency and Governance of Tax Incentives for Investment in Developing Countries (OECD, 2013).

1. Tax incentives should aim to contribute to a country's development goals, which should be aligned with the CFS RAI principles

If governments decide to offer tax incentives for investment in agriculture and food systems, such incentives should be used narrowly to address specific market failures or obstacles to responsible investment. More generally, they should contribute to a country's national development priorities, which should be aligned with the CFS RAI. As such, the benefits they generate should support sustainable development goals, and should also exceed their associated costs.

To try to understand whether the tax incentives' quantifiable benefits would outweigh the associated costs, governments can use a financial model, i.e. a cost benefit analysis (CBA). A well-designed CBA can help mitigate several potential problems associated with tax (and other) incentives:

- by quantifying expected costs, a jurisdiction can avoid overcommitting its resources to investors;

- the process of comparing costs with benefits over time gives the jurisdiction the opportunity to understand more specifically whether and how an investment is likely to improve or enhance sustainable development in that jurisdiction;

- the CBA can be used to build support for high-quality, responsible investments and to steer the jurisdiction's interest away from lower-quality opportunities; and

- the expectations set as a result of the CBA can be used after the fact to monitor and evaluate the actual outcomes of the investments made under the incentive to determine whether net benefits were achieved (Harpel, 2016).

Despite these benefits, there are limits to what governments can accomplish with CBAs. Some governments do not have the technical tools to develop and run sophisticated models. Others do not have sufficient and adequate data. Even if the tools and the data are available, the analysis may be subpar: incorrect assumptions, incorrect use of the tools 
helps promote transparency and accountability, and encourages investor certainty, so long as the eligibility criteria is clearly defined and objective (Johnson et al. forthcoming). Granting incentives in this way can then be largely automatic once the taxpayer satisfies the stipulated conditions of the criterion.

The eligibility criteria should include minimum conditions to be met in order to be eligible for the tax incentive. These include basic steps an investor must take (such as the requirement to file a tax return, or to provide a statement detailing the duty or exemptions availed in the prescribed period) (OECD, 2013), as well as criteria used to target investors and investments that meet certain conditions inherent to the investment that the government is seeking to attract (such as the size of the project or investment made, type of activity conducted, home state of the investor, or location of the investment) (TavaresLehmann et al., 2016). Given the potential of SMEs and small-scale producers to contribute to sustainable development and inclusive economic growth, and considering the risk of crowding out their investments, it may be preferable in many cases to avoid imposing conditions based on the size of the project.

In addition, eligibility criteria can hinge on requirements that investors behave in ways that the host country considers particularly conducive to responsible investment. These types of conditions may target, for example, investors that: comply with environmental or labour standards that are above and beyond those required by the law; exclusively use climate-smart technology and practice; generate a certain number of permanent, wellcompensated jobs; or integrate an inclusive business model that sources produce from small-scale producers or involves them as shareholders in a joint venture. Providing tax incentives upon proof that such conditions have been met allows jurisdictions to target investors that invest responsibly, with the aim of achieving sustainable development goals.

\section{Cost-based vs. profit-based tax incentives}

When tax incentives are offered, cost-based tax incentives are more likely to serve government goals than profit-based ones. A profit-based incentive lowers the tax rate for any amount of profit earned by an investor. Thus, the value of the incentive is a direct function of the company's profits, which results in the incentive favouring firms with high profits and therefore least in need of an incentive to invest (Andersen et al., 2017). A profitbased incentive is also more likely to be redundant. A cost-based incentive is independent of the profit level of a company and instead focuses on lowering the cost of capital, which increases the chances that project is profitable; cost-based incentives thus are more likely to stimulate investment that would not have occurred without such incentives. Cost-based incentives are also encouraged because tax revenue loss is more predictable, and they are less likely to be abused (Andersen et al., 2017).

\section{Ensure that certain safeguards are included to minimise the potential for abuse}

There are multiple ways that investors have sought to abuse tax incentives, in particular by engaging in various practices that make them appear eligible to receive incentives even though they should be excluded from eligibility. These practices include, for example, 
transforming into new entities (when the incentive is not available for existing firms), "roundtripping" or restructuring as foreign entities (when the incentive is not available to domestic firms), and engaging in transfer pricing or similar practices that seek to inaccurately allocate profit to a tax exempt/privileged entity or activity (UN and CIAT, 2018).

Understanding the likely ways in which specific tax incentives can be abused can help governments both in selecting the appropriate incentives that are least likely to be abused, as well as in including safeguards, when possible, to minimise such abuse (UN and CIAT, 2018).

\section{Ensure tax incentives are time-bound}

The legislation that provides tax incentives should have a built-in sunset provision, which means that the legislation will expire at a certain time, unless proactively renewed by the legislature. By doing so, the government can seek to ensure that investment incentives neither outlive their usefulness nor become a line-item that is difficult to repeal because of entrenched interests.

\section{Monitor and evaluate performance, relevance and compliance}

Tax incentives are not always effective at meeting the government's goals: they may have been designed poorly at the outset, or they may simply outlast their usefulness as economies evolve and a country's needs and goals change. While sunset provisions provide one mechanism for ending inefficient or redundant incentives, there is also a need to build in mechanisms for monitoring and evaluating the effectiveness of ongoing incentives.

The monitoring and evaluation of tax incentives should consider, for example, whether they are incentivising new investment, whether it is helping to meet the stated development goal(s), whether it continues to be relevant, and whether investors have complied with the conditions tied to the incentive. The results of such periodic reviews should inform decision-making on the continuation or withdrawal of the tax incentive. The review criteria and results should also be reported publicly.

Separately, tax authorities should also periodically carry out audits of investments where tax incentives have been granted to ensure that they are not misused, e.g. tax avoidance or evasion, and impose penalties if misuse occurred.

\section{Collect data systematically to support the statement of tax expenditures and to monitor individual tax incentives}

While the periodic analysis of tax incentives is data- and resource- intensive, such analysis is necessary for providing transparent public statements, budgeting, calculating amount of revenue forgone, and tracking of behavioural responses by businesses. The analysis should include a record of the beneficiaries of tax incentives, their duration, individual taxpayer data, behavioural responses both good (e.g. employing local youth) and bad (e.g. aggressive tax planning), and the costs in forgone revenue. This kind of analysis may require the introduction of new mechanisms and tools in some countries, and sufficient funds should be allocated to ensure that adequate analyses can be done. 


\section{Annex III - Monitoring, evaluation and learning}

\section{Monitoring}

Monitoring is the routine and continuous collection and tracking of data to provide the relevant government agency, the management team, and key stakeholders of an ongoing incentive with indications of the extent of progress (or lack of) and achievement of expected results, and progress in the use of allocated funds. The goal of monitoring should be the collection of data, stored in an information system, that can be used for regular reporting, analysis, and assessment of the incentive at the evaluation phase.

Broadly speaking, monitoring can focus on an assessment of the expected results at the outcome and impact levels, or whether incentives have been implemented as intended and are leading to expected outputs. The following considerations should be kept in mind when developing a monitoring plan.

\section{What data to collect}

A fundamental first step is deciding what data needs to be collected. Data collection is the process of systematically gathering quantitative and/or qualitative data for the purposes of monitoring, evaluating, and learning. The indicators from the theory of change developed at the planning stage can be used for this purpose, or it may be necessary to develop sub-indicators that feed into the existing ones (IIED, 2019). The data collected for each indicator are monitored against baselines, on the one hand, and targets, on the other, at each stage of the theory of change developed. Baseline data, which is the situation before the incentive is implemented, must also be collected before the implementation of the incentive to measure change toward targets. Without the baseline data, it is difficult to measure the progress made as a result of an incentive.

Consideration should be given to the time, effort, and resources required for data collection (University of Arkansas Division of Agriculture n.d.). Government ministries and agencies should be encouraged to share data among relevant sectors and key stakeholders for the promotion of widespread learning and transfer of knowledge (IIED, 2019).

\section{Entity responsible for monitoring data}

Identify the entity or entities responsible for collecting, analysing, reporting, and communicating the data (IIED, 2019). Including key stakeholders beyond government authorities (e.g. beneficiaries of the incentives, and/or farming cooperatives and organisations) can strengthen monitoring efforts, as well as subsequent evaluation and learning efforts. 


\section{Identify the source of data}

The source of data that will be used for each indicator must also be identified. Data can be collected through an existing source (secondary data) or a new one (primary data). There are advantages and disadvantages to both. Secondary data sources include any relevant data already collected, government agencies and authorities, and/or academia. These sources can provide relevant information for MEL purposes, such as official statistics, national account data, national household surveys, or on external factors that may affect the implementation and progress of the incentives (USAID, 2019). Primary data sources are collected specifically for the purposes of the incentive (and therefore are more costly), such as recording the number of beneficiaries attending a training course (output data); or recording the proportion of small-scale farmers' use of sustainable practices during site visits (outcome data).

\section{Identify the data collection method to be used}

The monitoring plan should also include the data collection method for each indicator, i.e. the procedure for how data are collected. This method can be quantitative or qualitative. When selecting a method for data collection, a number of factors need to be kept in mind, including the cost of the method chosen, the appropriateness of the method given local context and traditions, and the level of rigour necessary (USAID 2019). In addition, it may be necessary to adapt the data collection method for a particular indicator in the face of unforeseen challenges (IIED, 2019).

Some commonly used quantitative methods include:

- recording data through administrative actions, e.g. recording the number of farmers who purchased specified technology using the subsidies provided;

- electronic data collection, e.g. beneficiaries record actions into a mobile app;

- surveys, e.g. questions asked of beneficiaries regarding their knowledge after completion of the training courses; and

- observations, e.g. trained observer recording total farmland coverage using new practices in a given jurisdiction (USAID, 2019).

Some commonly used qualitative methods include:

- interviews, e.g. an interviewer asks a beneficiary about her knowledge, experience and perception of certain practices;

- focus group discussions, e.g. moderator leads a discussion among a group on their perception about the sustainability of certain practices; and

- observations, e.g. trained observer attends training course to make observations informed by her interactions with beneficiaries during the activity (USAID, 2019). 


\section{Use of disaggregated data}

Data should be disaggregated for each indicator, where necessary, by demographics that will inform the decision-making process regarding the breadth of reach at each stage of the incentive. For example, if incentives are targeting youth farmers, it is important to monitor how the incentives are affecting farmers of different age categories; if the incentives are geared toward empowering small-scale farmers, it is critical to monitor how the incentives may be impacting women and men differently. Disaggregated data can improve understanding of the progress made toward the expected results by providing details of the experiences of a subset of the beneficiaries monitored by that indicator. Without such data, it is not possible to assess whether the incentives have been effective at benefiting the target beneficiaries, or to identify any potential unintended consequences on other groups (FAO, 2018a).

\section{Frequency of data collection}

The frequency of data collection for each indicator will need to be considered. This will depend on the specific indicator being measured. Monitoring an output indicator, like attendance at a training course, will be a one-time recording of the number of attendees. However, monitoring an impact indicator, like a change in farmers' income after the introduction of improved seed to increase productivity, might need to be collected annually, at the end of the farming season, and only after allowing time for its distribution, adoption, and improved yield. The frequency of data collection will also depend on the method being used. For instance, in-person observations or in-depth interviews by trained personnel are more resource- and time- intensive and therefore may occur once at the end of an incentive cycle, whereas electronic collection of data by beneficiaries could occur on a weekly basis (USAID, 2019).

\section{Data reporting}

The regular reporting of data can help track the success (or failure) of incentives as it will feed into the analysis of the data at the evaluation phase. It will also help generate and share lessons learned across government levels and agencies. Without this final step, the resources devoted to data collection will largely be wasted.

\section{Evaluation}

Evaluation is the systematic and critical assessment of an ongoing or completed project, programme or policy, its design, implementation and/or results. It uses data collected through monitoring, as a starting point, to provide information about what works, what does not, and probes into the reasons for these results (IIED, 2019).

There are many reasons why an evaluation may be conducted: to determine the efficiency of an incentive; to examine whether an incentive has fulfilled its intended objective(s); or to assess the sustainability of an incentive. An effective evaluation should also provide useful evidence to contribute to learning processes that can be used to improve an incentive or to provide 
provided; was it the change in the land tenure system that allowed women to receive bigger grants to invest in agriculture; etc. This information can impact future allocation of resources to achieve more transformational or cost-effective outcomes (IIED, 2019).

\section{Identify the appropriate evaluation criteria}

Once the evaluation questions have been formulated, consideration should be given to the evaluation criteria to use as the basis of the assessment (IIED, 2019). The OECD Development Assistance Committee's (DAC) evaluation criteria, revised and published in December 2019, provides one of the most commonly used sets of evaluation criteria, known as the DAC criteria (see Box 13). The application of these criteria-or any additional ones-depends on the evaluation questions and the objectives of the evaluation.

\section{BOX 13: DAC EVALUATION CRITERIA}

Relevance: The extent to which an incentive's objectives and design respond to the intended beneficiaries' or jurisdiction's needs, the region's, country's or global priorities, and/or the priorities and policies of development partners and donors, and continue to do so if circumstances change. A relevant incentive will clearly demonstrate the theory of change logic developed and any causal relationships identified (IIED, 2019).

Coherence: The extent of the compatibility of the incentive with other interventions in a country, sector or institution. A lack of coherence can lead to duplication or cancellation of efforts, which can undermine overall progress.

Effectiveness: The extent to which the incentive achieved, or is expected to achieve, its objectives and results. It can also be used as an aggregate measure of (or judgment about) the merit or worth of an activity, i.e. the extent to which an incentive has attained, or is expected to attain, its strategic objective(s) efficiently, in a sustainable fashion, and with positive institutional development impact.

Efficiency: The extent to which the incentive delivers, or is likely to deliver, results in an economic and timely way. "Economic" is the conversion of inputs into outputs, outcomes and impacts, in the most cost-effective way possible. The goal is to achieve the desired results at each level in the least costly way possible. "Timely" delivery means delivery of results within the intended timeframe, or a timeframe reasonably adjusted to the demands of the evolving context.

Impact: The extent to which the incentive has generated, or is expected to generate, significant positive or negative, intended or unintended, higher-level effects. Impact addresses the ultimate significance and potentially transformative effects of the incentive. It seeks to identify the social, environmental and economic effects of the incentive that are longerterm or broader in scope than those already captured under the effectiveness criterion.

Sustainability: The extent to which the net benefits of the incentive continue, or are likely to continue, after the incentive cycle. This includes an examination of the financial, economic, 
social, environmental, and institutional capacities of the systems needed to sustain net benefits over time. It involves analyses of resilience, risks and potential trade-offs.

Adapted from source: OECD DAC (2019) and OECD DAC (2010).

\section{Evaluation types}

There are several types of evaluations that can be conducted, depending largely on the evaluation purpose, objective, and questions. Table 7 includes several common evaluation types.

Table 7 - Common Evaluation Types

\section{Evaluation Types}

Formative Evaluation

Evaluability

Assessment

Needs Assessment

Context Analysis

Process Evaluation
Monitoring of
Incentive

Outcome Evaluation

Objectives-Based Evaluation

Economic Evaluation:

Cost-Effectiveness Evaluation,

Cost-Benefit Analysis,

Cost-Utility Analysis

Impact Evaluation
When to use

During the development of a new incentive.

When an existing incentive is being modified or is being used in a new setting or with a new population.

\begin{abstract}
As soon as incentive implementation begins.

During operation of an existing incentive.
\end{abstract}

After the incentive has made contact with at least one person or group in the target population.

At the beginning of an incentive.

During the operation of an existing incentive.

During the operation of an existing incentive at appropriate intervals.

At the end of an incentive.
What it shows

Whether the proposed incentive is likely to be needed, understood and accepted by the population you want to reach.

The extent to which an evaluation is possible, based on the goals and objectives.

How well the incentive is working.

The extent to which the incentive is being implemented as designed.

Whether the incentive is accessible and acceptable to its target population.

The degree to which the incentive is having

an effect on the target population's behaviours.

What resources are being used for an incentive and their costs (direct and indirect) compared to outcomes.

The degree to which the incentive meets its ultimate goal (desired impact).

\section{Why it is useful}

It allows for modifications to be made to the plan before full implementation begins.

Maximises the likelihood that the incentive will succeed.

Provides an early warning for any problems that may occur.

Allows implementing team to monitor how well the incentive plans and activities are working.

Tells whether the incentive is being effective in meeting objectives.

Provides relevant government agency and managers a way to assess cost relative to effects. "How much bang for your buck."

Provides evidence for use in policy and funding decisions.

Adapted from source: National Center for HIV/AIDS, Viral Hepatitis, STD, and TB Prevention (n.d.). 


\section{Learning}

To maximise the utility of lessons learned, the information and knowledge generated through the monitoring and evaluation processes should be analysed to identify any challenges faced, how those challenges were overcome, and whether in hindsight those challenges were preventable. The lessons learned about the way(s) to avoid such challenges in a similar future situation is important in the learning process (IIED, 2019). Sharing lessons learned is also important, and mechanisms should be developed for disseminating the information to relevant stakeholders and beyond.

When learning is effectively incorporated into a MEL plan, such learning can help policymakers and technical staff inform, adjust, and improve current and future incentive design and implementation, and/or withdraw or discontinue an incentive. This cycle of monitoring, evaluating, and learning by adjusting and improving incentives is centred on an iterative process of making decisions based on that learning (Williams and Brown, 2014). It allows for and encourages adjustments to be made in response to changing circumstances, including politics, law, environment, socioeconomics, and so on; new information surfaced; or when targets and indicators are not performing as expected or if they become irrelevant (IIED, 2019). 


\section{Bibliography}

Abdulhameed, A. A. 2016. AfDB Workshop on Establishing an African Agriculture Sharing and Financing Mechanism: The Nigeria Incentive-Based Risk Sharing System for Agricultural Lending (NIRSAL) Model. Nairobi, Kenya. NIRSAL Plc.

Abdulhameed, A. A. 2019. New Mechanism for Managing Financial Risks of Investments. Presentation delivered at the Agritechnica trade fair, 10-16 November 2019, Hanover, Germany. (also available at: https://www.snrd-africa.net/wp-content/uploads/2020/03/4 NIRSAL A.Abdulhameed.pdf).

Agricultural Investment Promotion Agency (APIA). 2021. APIA [online]. Tunis, Tunisia. [Cited 20 October 2021]. http://www.apia.com.tn/

Agricultural Promotion and Investment Corporation of Odisha Limited. Welcome [online]. Bhubaneswar, India. [Cited 20 October 2021]. http://www.apicol.nic.in/.

Aisbett, E. 2007. Bilateral Investment Treaties and Foreign Direct Investment: Correlation versus Causation. CUDARE Working Papers 1032. Berkeley, US, University of California.

Alexandratos, N. \& Bruinsma, J. 2012. World Agriculture Towards 2030/2050: The 2012 Revision. FAO Agricultural Development Economics Division Working Paper No. 12-03. Rome, FAO. 140 pp.

Andersen, M.R., Benjamin R.K. \& Uexkull, E. 2019. Corporate Tax Incentives and FDI in Developing Countries. In Global Investment Competitiveness Report 2017/2018: Foreign Investor Perspectives and Policy Implications. Washington DC, US, World Bank. 73-100 pp. (also available at: http://hdl.handle.net/10986/28493).

APIA. 2021. Prêts Fonciers [online]. Tunis, Tunisia. [Cited 20 October 2020]. http://www.apia. com.tn/prets-fonciers.html.

APIA. 2021. Quels Sont Les Services Que Peut Offrir Une Pépinière [online]. Tunis, Tunisia. [Cited 20 October 2020]. http://www.apia.com.tn/qu-elles-sont-les-services-que-peut-offrir-une-pep.html

Ayele, S., Ayele, G., Niguissie, T. \& Thorpe, J. 2019. Policy Incentives and Agribusiness Investment in Ethiopia: Benefit or Deadweight?. Agricultural Policy Research in Africa Brief No. 20. Future Agricultures Consortium. 6 pp. (also available at: https://www.future-agricultures. org/publications/apra-briefs/apra-brief-20policy-incentives-and-agribusiness-investment-inethiopia-benefit-or-deadweight/).

Ayele, S., Thorpe, G., Ayele, H. Chingaipe, Teye, J.K. \& O’Flynn, P. 2020. Agribusiness Investment in Agricultural Commercialisation: Rethinking Policy Incentives in Africa. Agricultural Policy Research in Africa Working Paper No. 33. Future Agricultures Consortium. 51 pp. (also available at: https://bit.ly/3cFjdn4).

Bartik, T.J. 2018. "But for" Percentages for Economic Development Incentives: What Percentage Estimates Are Plausible Based on the Research Literature?. Kalamazoo, US, Upjohn Institute Working Paper 18-289. Upjohn Institute for Employment Research. 36 pp. (also available at: https://doi.org/10.17848/wp18-289). 
Better Evaluation. 2013. Define What Is to Be Evaluated. Melbourne, Australia. Better Evaluation. 2 pp. (also available at: https://bit.ly/3wvjoJM).

Bizikova, Liva. 2016. Private Investments in Agriculture: The Importance of Integrating Sustainability into Planning and Implementation Geneva, Switzerland. IISD Briefing Note. 10 pp. (also available at: https://bit.ly/3fxRk2u).

Boettiger, S., Denis, N. \& Sanghvi, S. 2017. Successful Agricultural Transformations: Six Core Elements of Planning and Delivery [online]. New York, US. McKinsey \& Company. [Cited 20 October 2020] https://mck.co/2PGVSIN.

Bolnick, B. 2009. Investing in Mozambique - The Role of Fiscal Incentives. Washington DC, Nathan Associates for United States Agency for International Development. 169 pp.

Bolwijn, R., Casella, B. \& Rigo, D. 2018. An FDI-Driven Approach to Measuring the Scale and Economic Impact of BEPS. Geneva, Switzerland. United Nations Conference on Trade and Development, Transnational Corporations Volume 25, 2018, No. 2. 38 pp.

Bonnitcha, J. 2017. Assessing the Impacts of Investment Treaties: Overview of the Evidence. Geneva, Switzerland. International Institute for Sustainable Development.

Borga, M., Flores, P.I. \& Sztajerowska, M. 2020. Drivers of Divestment Decisions of Multinational Enterprises - A Cross-Country Firm-Level Perspective. Organisation for Economic Co-operation and Development Working Papers on International Investment, No. 2019/03.

Bou Mansour, M. 2019. Ineffective tax incentives on profits heavily used by African nations compared to European nations, study finds. Buckinghamshire, UK. Tax Justice Network, 3 January 2019. (also available at https://www.taxjustice.net/press/ineffective-tax-incentiveson-profits-heavily-used-by-african-nations-compared-to-european-nations-study-finds/).

Brada, J. C., Drabek, Z. \& Iwasaki, I. 2020. Does investor protection increase foreign direct investment? A meta-analysis. Journal of Economic Surveys, 30 September 2020. (also available at https://onlinelibrary.wiley.com/doi/full/10.1111/joes.12392).

Brennan, L. \& Ruane, F. 2016. A Holistic Approach to Investment Incentives. In Rethinking Investment Incentives: Trends and Policy Options. New York, US. Columbia University Press. 368 pp. (also available at: http://cup.columbia.edu/book/rethinking-investmentincentives/9780231172981).

Byiers, B. \& Rampa, F. 2013. Corridors of Power or Plenty? Lessons from Tanzania and Mozambique and Implications for CAADP. Maastricht, Netherlands. European Centre for Development Policy Management (ECDPM) Discussion Paper No. 138. ECDPM. 48 pp. (also available at: https://ecdpm.org/publications/corridors-power-plenty-lessons-tanzaniamozambique-implications-caadp/).

Caldwell, R. 2002. Project Design Handbook. Tucson, US. CARE. 176 pp. (also available at: https://www.fsnnetwork.org/sites/default/files/dme_- cares_project_design_handbook.pdf). 


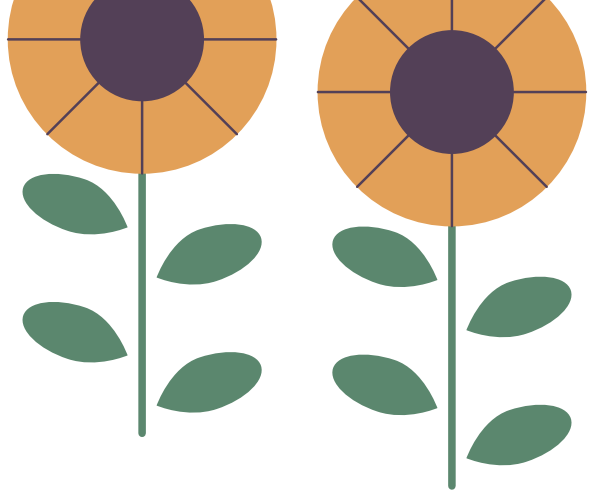

CCSI \& FAO. 2019. Creating an Enabling Environment for Responsible Investment in Agriculture and Food Systems - Fundamentals. FAO E-learning Academy. Rome, Italy. (also available at: https://elearning.fao.org/course/view.php?id=455).

Central Bank of Nigeria. 2012. The Nigerian Incentive-Based Risk Sharing System for Agricultural Lending (NIRSAL). Abuja, Nigeria. (also available at: https://www.cbn.gov.ng/OUT/2011/ PUBLICATIONS/REPORTS/DFD/BRIEF\%200N\%20NIRSAL.PDF).

Chan, M.K. 2013. Inclusive Agricultural Investment: Sharing Lessons from Experience, London, UK. International Institute for Environment and Development. 4 pp. (also available at: https:// pubs.iied.org/17160iied).

Charlton, A. 2003. Incentive Bidding for Mobile Investment: Economic Consequences and Potential Responses. OECD Development Centre Working Papers 203, OECD Publishing.

Coleman, J., Brooke Güven, L.J. \& Sachs, L. 2018. What Do We Mean by Investment Facilitation? Columbia Center on Sustainable Investment. (also available at http://ccsi.columbia. edu/2018/02/22/what-do-we-mean-by-investment-facilitation/).

Columbia Center for Sustainable Development. 2015. Open Land Contracts [online]. https:// www.openlandcontracts.org/.

Columbia Center on Sustainable Investment. 2019. Human Rights Law and the Investment Treaty Regime. CCSI. (also available at: https://bit.ly/3m8NObb).

Committee on World Food Security. 2014. Principles for Responsible Investment in Agriculture and Food Systems. Rome, Italy. CFS. (also available at: http://www.fao.org/3/au866e/au866e.pdf).

Cordes, K., Johnson, L. \& Sam Szoke-Burke. 2016. Land Deal Dilemmas: Grievances, Human Rights, and Investor Protections. Columbia Center on Sustainable Investment.

Cordes, Kaitlin Y. \& Anna Bulman. 2016. Corporate Agricultural Investment and the Right to Food: Addressing Disparate Protections and Promoting Rights-Consistent Outcomes. UCLA Journal of International Law \& Foreign Affairs No. 75.

Cordes, Kaitlin Y., Östensson, O. \& Toledano, P. 2016. Employment from Mining and Agricultural Investments: How Much Myth, How Much Reality? Columbia Center on Sustainable Investment. 105 pp. (also available at: http://ccsi.columbia.edu/2016/07/21/employment-from-miningand-agricultural-investments-how-much-myth-how-much-reality/).

Cosbey, A. 2017. Can Investor-State Dispute Settlement Be Good for the Environment? International Institute for Sustainable Development, April 12, 2017.

Cotula, L. \& Mouan, L. 2018. Special Economic Zones: Engines of Development or Sites of Exploitation? London, UK. IIED Briefing, International Institute for Environment and Development. 4 pp. (also available at: https://pubs.iied.org/17481iied). 
Cotula, L. 2010. Investment Contracts and Sustainable Development: How to Make Contracts for Fairer and More Sustainable Natural Resource Investments. London, UK. Natural Resource Issues No. 20. IIED. 115 pp. (also available at: https://pubs.iied.org/sites/default/files/pdfs/ migrate/17507IIED.pdf?).

Cotula, L. 2016. Foreign Investment, Law and Sustainable Development: A Handbook on Agriculture and Extractive Industries. London, UK. IIED Natural Resource Issues, International Institute for Environment and Development. 184 pp. (also available at: https://pubs.iied. org/12587iied).

De Groot, O. \& Pérez Ludeña, M. 2014. Foreign direct investment in the caribbean: trends, determinants and policies. Port of Spain, Trinidad and Tobago. United Nations Economic Commission for Latin America and the Caribbean (ECLAC). 49 pp. (also available at: https://repositorio.cepal.org/bitstream/handle/11362/36620/S2014046 en.pdf? sequence=1\&isAllowed=y).

de Mooij, R.A. \& Ederveen, S. 2003. Taxation and Foreign Direct Investment: A Synthesis of Empirical Research. International Tax and Public Finance 10: 673-93.

Desai, M.A., Fritz Foley, C. \& Hines, J. 2004. Foreign Direct Investment in a World of Multiple Taxes. Journal of Public Economics 88: 2727-44.

Dorward, A., Kydd, J. \& Poulton, C. 2005. Beyond Liberalisation: 'Development Coordination' Policies for African Smallholder Agriculture. Brighton, UK. Institute of Development Studies 36, No. 2. Institute of Development Studies. (also available at: https://bit.ly/31E4yTa).

European Commission. 2018. Income support explained: Overview of direct payments for farmers [online]. Brussels, Belgium. European Commission. [Cited 20 October 2020]. https://bit. ly/2PgZWjh.

European Commission Enterprise Directorate-General. 2020. Final report - Benchmarking of business incubators. Brussels, Belgium. (also available at: https://op.europa.eu/s/oTdc).

FAO. 2002. Participatory Policy Reform from a Sustainable Livelihoods Perspective - Review of concepts and practical experiences. Rome, Italy. FAO.

FAO. 2005. SARD Project Toolkit: A Resource Guide for Promoting SARD in Projects and Programmes, Rome, Italy. FAO. 108 pp. (also available at: http://www.fao.org/3/ag249e/ ag249e.pdf).

FAO, IFAD, UNCTAD \& World Bank Group. 2010. Principles for responsible agricultural investment that respects rights, livelihoods and resources: a discussion note. Geneva, Switzerland. UNCTAD. 8 pp. (also available at: https://digitallibrary.un.org/record/699484?!n=en).

FAO. 2011. The State of Food and Agriculture 2010-2011: Women in Agriculture - Closing the Gender Gap for Development. Rome. FAO. 160 pp. (also available at: http://www.fao.org/ publications/sofa/2010-11/en/). 
FAO. 2012a. Smallholders and Family Farmers. Rome, FAO. 4 pp. (also available at: http://www. fao.org/3/ar588e/ar588e.pdf).

FAO. 2012b. Voluntary Guidelines on the Responsible Governance of Tenure of Land, Fisheries and Forests in the Context of National Food Security. Rome, Italy. FAO. 47 pp. (also available at: http://www.fao.org/3/i2801e/i2801e.pdf).

FA0.2013a.Trends and impacts offoreign investment in developing countryagriculture:evidence from case studies. Rome, Italy. FAO. 382 pp. (also available at: http://www.fao.org/fileadmin/ templates/est/INTERNATIONAL-TRADE/FDIs/Trends_publication_12_November_2012.pdf).

FAO. 2013b. Tunisie: Financement du secteur agricole. Rome, Italy. FAO. 325 pp. (also available at: http://www.fao.org/3/i3210f/i3210f.pdf).

FAO et al. 2014. Youth and agriculture: Key challenges and concrete solutions. FAO with the Technical Centre for Agricultural and Rural Cooperation, and the International Fund for Agricultural Development. 128 pp. (also available at: http://www.fao.org/3/i3947e/i3947e.pdf).

FAO. 2014a. Building a common vision for sustainable food and agriculture - principles and approaches. Rome, Italy. FAO. 56 pp. (also available at: http://www.fao.org/3/a-i3940e.pdf).

FAO. 2014b. Contribution to the 2014 United Nations Economic and Social Council (ECOSOC) Integration Segment. Rome, Italy. (also available at: https://www.un.org/en/ecosoc/integration/ pdf/foodandagricultureorganization.pdf).

FAO. 2014c. Policy Engagement \& Theory of Change - Monitoring and analysing food and agricultural policies II (MAFAP II). Rome, Italy. FAO. (also available at: http://www.fao.org/3/ i4244e/i4244e.pdf).

FAO. 2015. Inclusive business models - Guidelines for improving linkages between producer groups and buyers of agricultural produce, by Kelly, S., Vergara, N. \& Bammann, H. Rome, Italy. 128 pp. (also available at: https://bit.ly/3mbaXyu).

FAO. 2015a. Key recommendations for improving nutrition through agriculture and food systems. Rome, FAO. 2 pp. (also available at: http://www.fao.org/3/i4922e/i4922e.pdf).

FAO. 2015b. Safeguarding land tenure rights in the context of agricultural investment. Rome, Italy. FAO. 112 pp. (also available at: http://www.fao.org/3/i4998e/i4998e.pdf).

FAO. 2015c. Voluntary Guidelines for Securing Sustainable Small-Scale Fisheries in the Context of Food Security and Poverty Reduction. Rome, Italy. FAO. 35 pp. (also available at: http://www. fao.org/documents/card/en/c/l4356EN).

FAO. 2017. Overview of the FAO Umbrella Programme Supporting Responsible Investments in Agriculture and Food Systems. Rome, Italy, FAO. 12 pp. (also available at: https://bit.ly/3drh7GG).

FAO. 2018a. Integrating gender into implementation and monitoring and evaluation of cash transfer and public works programmes - FAO Technical Guide 3. Rome, Italy, FAO. 52 pp. (also available at: http://www.fao.org/documents/card/en/c/CA2035EN). 
FAO. 2018b. Transforming food and agriculture to achieve the SDGs. Rome, Italy. FAO. 76 pp. (also available at: http://www.fao.org/3/19900EN/i9900en.pdf).

FAO. 2019a. Country Programming Framework (CPF) Namibia, 2019-2023. FAO. Windhoek, Namibia. 31 pp. (also available at: http://www.fao.org/3/ca4070en/CA4070EN.pdf).

FAO. 2019b. Guide to context analysis: Informing FAO decision-making - Approaches to working in fragile and conflict-affected contexts. Rome, Italy. 32 pp. (also available at: https:// bit.ly/3rIK8CV).

FAO. 2021. Incentives for Ecosystem Services [online]. Rome, Italy. [Cited 22 October 2020]. http://www.fao.org/in-action/incentives-for-ecosystem-services/en/.

FAO \& INRAT. 2020. Dynamique de l'investissement dans le système agricole tunisien et perspectives de développement des investissements par et pour les jeunes. Rome, Italy. 88 pp. (also available at: https://doi.org/10.4060/cb0563fr).

FAO, IFAD \& UNIDROIT. 2020. Legal Guide on Agricultural Land Investment Contracts. Rome, Italy. FAO, IFAD \& UNIDROIT. 244 pp. (also available at: https://bit.ly/3dmwPmx).

Fiedler, Y. 2020. Empowering young agri-entrepreneurs to invest in agriculture and food systems - Policy recommendations based on lessons learned from eleven African countries. Rome, Italy. FAO. 66 pp. https://doi.org/10.4060/cb1124en

Fongip. 2020. Garantie Individuelle [online]. Fonds de Garantie des investissements Prioritaires. https://bit.ly/3uhLHtj.

Foundations of Success. 2017. Conceptualizing and Planning Conservation Projects and Programs: A Training Manual. Foundations of Success, Bethesda, US. (also available at: https:// fosonline.org/library/conceptualizing-and-planning-manual/).

Gassner, A, Harris, D., Mausch, K., Terheggen, A., Lopes, C., Finlayson, R.F. \& Dobie. P. 2019. Poverty Eradication and Food Security through Agriculture in Africa: Rethinking Objectives and Entry Points. Outlook on Agriculture 2019;48(4):309-315.

Global Agriculture and Food Security Program. 2020. Agricultural Productivity and Market Enhancement Project [online]. GAFSP. [Cited 20 October 2020]. https://www.gafspfund.org/ projects/agricultural-productivity-and-market-enhancement-project-apmep.

Gonzales, C., Kerlin, M., Schaff, R. \& Tucker-Ray, S. 2019. How state and local governments win at attracting companies [online]. McKinsey \& Company Insights. [Cited 20 October 2020]. https:// mck.co/31IG8HP.

Government of Liberia. National Investment Commission [online]. http://investliberia.gov.lr/ index.php\#.

Government of Senegal. 2017. Introduction Au Débat d'Orientation Budgétaire 2017. Document de Programmation Budgétaire et Économique Pluriannuelle (DPBEP) 2018-2020, Dakar, Senegal, Ministère de l’Economie, des Finances et du Plan. 


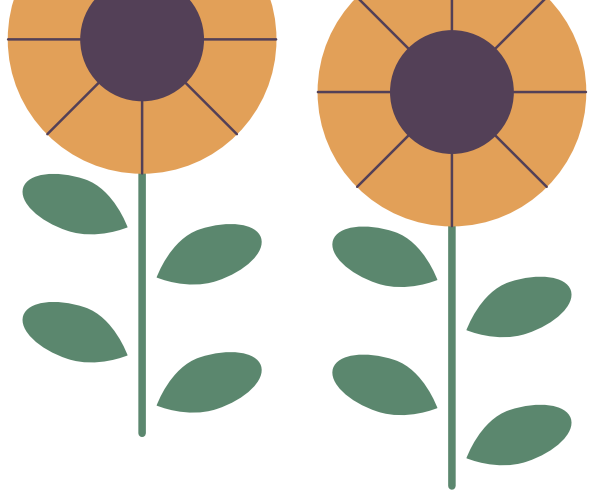

Grubert, H. \& Mutti, J. 2004. Empirical asymmetries in foreign direct investment and taxation. Journal of International Economics 62: 337-58 (2004).

Güven, B.S. 2020. Briefing Note: Investment Promotion and Facilitation for Sustainable Development. Geneva, Columbia Center on Sustainable Investment. (also available at: https:// bit.ly/3cEUcZm).

Harding, T.\& Javorcik, B.S. 2013. Developing Economies and International Investors: Do Investment Promotion Agencies Bring Them Together? World Bank Policy Research Working Papers.

Harpel, E. 2016. Cost-Benefit Analysis of Investment Incentives. In Rethinking Investment Incentives: Trends and Policy Options.

Hassett, K. \& Hubbard, R.G. 2002. Tax policy and business investment. In Handbook of Public Economics, vol. 3: 1293-1343. North Holland Publishing Co.

Hymer, S.H. 1976. The International Operations of National Firms: A Study of Foreign Direct Investment. Cambridge, MA: MIT Press.

IMF, OECD \& World Bank. 2015. Options for low income countries' effective and efficient use of tax incentives for investment. 44 pp. (also available at: https://bit.ly/20XXezB).

International Institute for Environment and Development. 2016. Counting critically: SDG 'follow-up and review' needs interlinked indicators, monitoring and evaluation. London, UK. International Institute for Environment and Development Briefing, IIED. 4 pp. (also available at: https://pubs.iled.org/17363iied).

International Institute for Environment and Development. 2019. MEL Handbook for SDG 14 - Conserve and sustainably use the oceans, seas and marine resources for sustainable development. London, UK. IIED. 120 pp. (also available at: https://bit.ly/3sL3QiS).

International Labour Organization. 2020. Global Employment Trends for Youth 2020: Technology and the future of jobs. ILO. (also available at: https://bit.ly/31J4C3H).

James, S. 2013. Tax and Non-Tax Incentives and Investments: Evidence and Policy Implications. Investment Climate Advisory Services of the World Bank Group. (also available at: https://bit. ly/3wqdv0z).

Jansky, P. \& Palansky, M. 2019. Estimating the scale of profit shifting and tax revenue losses related to foreign direct investment. International Tax and Public Finance 26 No. 5. (also available at: https://bit.ly/3mejxfN).

Janus, H. \& Holzapfel, S. 2016. Results-Based Approaches in Agriculture: What Is the Potential? Bonn, German Development Institute, Discussion Paper, 25/2016. (also available at: https://bit. (y/2PNkJKU).

Jayne, T.S., Chamberlin, J., Traub, L., Sitko, N., Muyanga, M., Yeboah, F.K., Ward A. et al. 2016. Africa's Changing Farm Size Distribution Patterns: The Rise of Medium scale Farms. Agricultural Economics 47 No. S1. 
Johnson, L., Sachs, L. \& Lobel, N. 2020. Aligning International Investment Agreements with the Sustainable Development Goals. Columbia Journal of Transnational Law No. 58. (also available at: https://bit.ly/2OS(Lpz).

Johnson, L., Sachs, L., Güven, B. \& Coleman, J. 2018. Costs and Benefits of Investment Treaties: Practical Considerations for States. Columbia Center on Sustainable Investment.

Johnson, L., Toledano, P. \& Jensen, N. 2020. Investment Incentives (Draft). Geneva, Switzerland, Columbia Center on Sustainable Investment.

Jouanjean, M.A. 2013. Targeting infrastructure development to foster agricultural trade and market integration in developing countries: an analytical review, Overseas Development Institute. 2013. (also available at: https://bit.ly/3fteerD).

Khatri-Chhetri, A., Jeetendra, P.A., Sapkota, T.B. \& Khurana, R. 2016. Economic Benefits of Climate-Smart Agricultural Practices to Smallholder Farmers in the Indo-Gangetic Plains of India. Current science 110(7):1251-1256.

Klemm, A. \& Parys, S. 2009. Empirical Evidence on the Effect of Tax Incentives. International Monetary Fund Working Paper 09/136.

Klemm, A. \& Parys, S. 2012. Empirical Evidence on the Effects of Tax Incentives. International Tax and Public Finance 19, 393-423.

Kumar, A. \& Saroj, S. 2019. Direct Benefit Transfers Can Help Double Indian Farmers' Income by 2022-2023. IFPRI Blog, [Cited 20 October 2020]. https://bit.ly/3fymdng

Laborde, D., Lallemant, T., McDougal, K., Smaller, C. \& Traore, F. 2019. Transforming Agriculture in Africa \& Asia: What Are the Policy Priorities?, International Institute for Sustainable Development and International Food Policy Research Institute. (also available at: https://bit. ly/3maWtOX).

Lampach, N., Van Phu, N. \& To The, N. 2021. The Effect of Agricultural Extension Programs on Technical Efficiency of Crop Farms in Low and Middle-Income Countries. (also available at: https://bit.ly/3dsPKvs).

Le Billon, P., Lujala, P. \& Aas Rustad, S. 2011. A Theory of Change for the Extractive Industries Transparency Initiative: Designing Resource Governance Pathways to Improve Developmental Outcomes. U4 Anti-Corruption Resource Centre, Chr. Michelsen Institute, no. 2011:11.

Lecoutere, E., Spielman, D.J. \& Van Campenhout, B. 2019. Women's Empowerment, Agricultural Extension, and Digitalization: Disentangling Information and Role-Model Effects in Rural Uganda. IFPRI Discussion Paper 1889. Washington DC: International Food Policy Research Institute (IFPRI). (also available at: https://bit.ly/3mbbgth).

LiberiaEITI. 2020. Agriculture [online]. Extractive Industries Transparency Initiative. Monrovia, Liberia. [Cited 20 October 2020] https://www.scribd.com/lists/4297678/Agriculture. 
Lipsey, R.E. \& Sjöholm, F. 2004. The Impact of Inward FDI on Host Countries: Why Such Different Answers? European Journal of Information Systems Working Paper Series No. 192. 22 pp. (also available at: https://bit.ly/20VE51c).

Locke, A., Munden, L. Feyertag, J. \& Bowie, B. 2019. Assessing the Costs of Tenure Risks to Agribusiness, London, UK, Overseas Development Institute. (also available at: https://bit. ly/3rHATCO).

Lowder, S.K., Carisma, B. \& Skoet, J. 2012. Who Invests in Agriculture and How Much? An Empirical Review of the Relative Size of Various Investments in Agriculture in Low- and Middle-Income Countries. FAO Agricultural Development Economics Division Working Papers 288992, Rome, Italy. FAO. 22 pp. (also available at: https://bit.ly/2PouY8M).

Lowder, S.K., Skoet, J. \& Raney, T. 2016. The Number, Size, and Distribution of Farms, Smallholder Farms, and Family Farms Worldwide. World Development Volume 87. Rome, Italy. FAO.

Maennling, N. \& Correa, J. 2020. Best Practices in Data Driven Development Planning in Mining Regions, New York, US. Columbia Center on Sustainable Investment. (also available at: https:// bit.ly/31F1dD4).

Mamun-Ur-Rashid, M., Kamruzzaman, M. \& Emad, M. 2017. Women Participation in Agricultural Extension Services in Bangladesh: Current Status, Prospects and Challenges, Bangladesh Journal of Extension Education 29, no. 1 \& 2.

Mayne, J. \& Johnson, N. Using Theories of Change in the CGIAR Research Program on Agriculture for Nutrition and Health. The Tavistock Institute Evaluation 21 (4): 407-28. (also available at: https://bit.ly/31C7WxD).

McCrimmon, R. 2020. 'Here's Your Check': Trump's Massive Payouts to Farmers Will Be Hard to Pull Back [online]. Politico, [Cited 14 July 2020]. https://politi.co/200jj3m.

McKinsey Global Institute. 2003. New Horizons: Multinational Company Investment in Developing Economies. New York, US. McKinsey\&Company. 530 pp. (also available at: https:// mck.co/2Pi5MAY).

Morisset, J. \& Andrews-Johnson, K. 2004. The Effectiveness of Promotion Agencies at Attracting Foreign Direct Investment. Washington DC, FIAS Occasional Paper No. 16. World Bank. 124 pp. (also available at: http://hdl.handle.net/10986/15073).

Mudege, N.N., Mdege, N., Abidin, P.E. \& Bhatasara, S. 2017. The Role of Gender Norms in Access to Agricultural Training in Chikwawa and Phalombe, Malawi. Gender, Place \& Culture: A Journal of Feminist Geography 24:12, 1689-1710. 24 pp. (also available at: https://bit.ly/3rDVGXV).

NEPAD-OECD. 2011. Draft Policy Framework for Investment in Agriculture: Reaping the Benefits of Investment in Africa's Agriculture through an Integrated Policy Framework. Dakar, Senegal. NEPAD.OECD. 34 pp. (also available at: https://bit.ly/31C80gT). 
Nigeria Incentive-Based Risk Sharing System for Agricultural Lending. 2021. About NIRSAL [online]. Abuja, Nigeria. [Cited 16 October 2020]. https://nirsal.com/who-we-are/.

Nikièma, S.H. 2014. Performance Requirements in Investment Treaties. Best Practices Series, Manitoba, Canada, International Institute for Sustainable Development. (also available at: https://bit.ly/3mevhyT).

NIRSAL. 2020. Credit risk guarantee [online]. In: Nigeria Incentive-Based Risk Sharing System for Agricultural Lending. Abuja. [Cited 16 October 2020]. https://nirsal.com/credit-riskguarantee/\#!/crg.

Noble, J. 2019. Theory of Change in Ten Steps, London, UK, NPC. (also available at: https://bit. (y/3cDM9fq).

Novik, A. \& de Crombrugghe, A. 2018. Towards an International Framework for Investment Facilitation. Paris, France, Investment Insights, Organisation for Economic Co-operation and Development. (Also available at: https://bit.ly/3cBWJ6x).

Nwanze, K.F. 2011. Viewpoint: Smallholders Can Feed the World. Rome, Italy, International Fund for Agricultural Development. (also available at: https://bit.ly/3ubJOGb).

Oakley, P. \& Garforth, C. 1985. Guide to Extension Training (2. Understanding Extension). Rome, Italy, FAO. (also available at: http://www.fao.org/3/t0060e/T0060E03.htm).

OECD DAC Network on Development Evaluation. 2010. Evaluating Development Co-Operation: Summary of Key Norms and Standards. Paris, France. (also available at: https://bit.ly/3rFvH2x).

OECD DAC Network on Development Evaluation. 2019. Better Criteria for Better Evaluation Revised Evaluation Criteria Definitions and Principles for Use. Paris, France. (also available at: http://www.oecd.org/dac/evaluation/revised-evaluation-criteria-dec-2019.pdf).

One Planet and United Nations Environment Programme. 2019. Collaborative Framework for Food Systems Transformation: A Multi-Stakeholder Pathway for Sustainable Food Systems. (also available at: https://bit.ly/3sAewR8).

OrganisationforEconomicCo-operationandDevelopment.2001.PolicyFrameworkforInvestment User's Toolkit: Chapter 2. Investment Promotion and Facilitation. OECD. (also available at: http:// www.oecd.org/investment/toolkit/policyareas/investmentpromotionfacilitation/41246119.pdf).

Organisation for Economic Co-operation and Development. 2013. Tax and Development: Principles to Enhance the Transparency and Governance of Tax Incentives for Investment in Developing Countries. OECD. (also available at: https://bit.ly/3uc2fmf).

Organisation for Economic Co-operation and Development. 2017. Agricultural Policies Should Shift from Price Support to Greater Emphasis on Encouraging a Resilient and Sustainable Food Sector [online]. Geneva, Switzerland. [Cited 16 October 2020]. https://bit.ly/3dmo0ZX. 


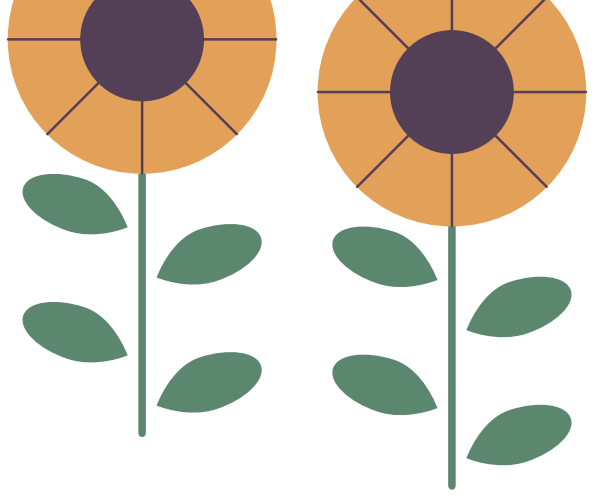

Organisation for Economic Co-operation and Development. 2018a. Mapping of Investment Promotion Agencies in OECD Countries. Paris, France, OECD. (also available at: https://bit. ly/3dkJTc2).

Organisation for Economic Co-operation and Development. 2018b. OECD Investment Policy Reviews: Southeast Asia. OECD. (also available at: https://bit.ly/3sHHGxQ).

Organisation for Economic Co-operation and Development. 2020. Towards Sustainable Land Use: Aligning Biodiversity, Climate and Food Policies. Paris, France. OECD. (also available at: https://www.oecd.org/environment/towards-sustainable-land-use-3809b6al-en.htm).

Organisation for Economic Cooperation and Development. 2003. Checklist for Foreign Direct Investment Incentive Policies. Paris, France.

Oxelheim, L. \& Ghauri, P.N. 2004. European Union and the Race for Foreign Direct Investment. Oxford, UK. Elsevier.

Oxford Review of Economic Policy. 2008. Corporate Tax Elasticities: A Reader's Guide to Empirical Findings. Oxford Review of Economic Policy 24, no. 4 (2008): 680-97.

Parilla, J. \& Liu, S. 2018. Examining the Local Value of Economic Development Incentives: Evidence from Four US Cities. Washington DC, Brookings Metropolitan Policy Program. (also available at: https://brook.gs/3ftoNuN).

Perera, 0. 2012. Rethinking Investment Incentives, Geneva, Switzerland, International Institute for Sustainable Development. (also available at: https://bit.ly/2PputeD).

Pohl, J. Societal Benefits and Costs of International Investment Agreements: A Critical Review of Aspects and Available Empirical Evidence. OECD Working Papers on International Investment No. 2019/03. 2018.

Pringle, P. \& Thomas, A. 2019. Climate Adaptation and Theory of Change: Making It Work for You-A Practical Guide for Small Island Developing States (SIDS). Climate Analytics. September 2019.

Rappeport, A. 2020. Trump Funnels Record Subsidies to Farmers Ahead of Election Day. The New York Times, October 12, 2020. https://www.nytimes.com/2020/10/12/us/politics/trumpfarmers-subsidies.html.

Rapsomanikis, G. 2015. The Economic Lives of Smallholder Farmers: An Analysis Based on Household Data from Nine Countries. Rome. FAO.

Raudonen, S. 2008. The Impact of Corporate Taxation on Foreign Direct Investment: A Survey. Working Papers 182, Tallinn School of Economics and Business Administration, Tallinn University of Technology, 2008.

Reuber, G.L. 1974. Private Foreign Investment in Development. London, UK. The Economic Journal 84:335. 
Reynoso, I. 2019. Spain's Renewable Energy Saga: Lessons for International Investment Law and Sustainable Development. Investment Treaty News, International Institute for Sustainable Development. [Cited 16 October 2020]. https://bit.ly/3cEc2vu.

Riensche, B. \& Jakhar, A.V. 2019. Here's How We Can Use Agriculture to Fight Climate Change [online]. World Economic Forum. [Cited 16 October 2020]. https://bit.ly/3wdaDUF.

Roberts, D. \& Khattri, N. 2012. Designing a Results Framework for Achieving Results: A How-to Guide. Independent Evaluation Group (IEG) and The World Bank.

Rolfe, R.J. \& White, R.A. 1992. Investors' Assessment of the Importance of Tax Incentives in Locating Foreign Export-Oriented Investment: An Exploratory Study. The Journal of the American Taxation Association, 14(1), 39.

Rondinelli, D.A. \& Burpitt, W.J. 2000. Do Government Incentives Attract and Retain International Investment? A Study of Foreign-Owned Firms in North Carolina. Policy Sciences 33, no. 2. pp. 181-205.

Sachs, J., Cordes, K.Y., Rising, J., Toledano, P. \& Maennling, N. 2019. Ensuring Economic Viability \& Sustainability of Coffee Production. Columbia Center on Sustainable Investment. (also available at: https://bit.ly/3rE66ag).

Sachs, L., Johnson, L. \& Merrill, E. 2020. Environmental Injustice: How Treaties Undermine Human Rights Related to the Environment. Paris, France. La Revue de Juristes de Sciences PO 18, No. 18.

Sauvant, K. \& Sachs, L. 2009. The Effect of Treaties on Foreign Direct Investment. Oxford University Press.

Sauvé, P. \& Soprana, M. 2016. Disciplining Investment Incentives: A Lost Cause?, E15Initiative, International Centre for Trade and Sustainable Development; World Economic Forum.

Schiff, M. \& Valdes, A. 1996. Agricultural Incentives and Growth in Developing Countries: A Cross-Country Perspective. In The Economics of Agriculture, 2:386-99. University of Chicago Press.

Sexsmith, K. 2017. Promoting Gender Equality in Foreign Agricultural Investments: Lessons from Voluntary Sustainability Standards. International Institute for Sustainable Development. (also available at: https://bit.ly/2PJP7pC).

Sierra Leone Investment \& Export Promotion Agency. 2020. Agriculture [online]. Freetown, Sierra Leone. [Cited 16 October 2020]. https://sliepa.org/investment/agriculture/.

Smaller, C. 2014. The IISD Guide to Negotiating Investment Contracts for Farmland and Water. International Institute for Sustainable Development. (also available at: https://bit.ly/3cDIH4f).

Smith, S., Rowcroft, P., Everard, M., Couldrick, L., Reed, M., Quick, T., Eves, C. \& White, C. 2013. Payments for Ecosystem Services: A Best Practice Guide. London, UK. Department for Environment \& Rural Affairs, UK Government. 
SNV. 2020. Opportunities for Youth Employment (OYE) in Mozambique, Rwanda and Tanzania [online]. SNV. https://bit.ly/3sFPjoo.

Spar, D. 1998. Attracting High Technology Investment: Intel's Costa Rican Plant. Washington DC. FIAS Occasional Paper No. 11. Foreign Investment Advisory Service.

Stein, D. \& Valters, C. 2012. Understanding Theory of Change in International Development. London, UK. Justice and Security Research Programme, London School of Economics and Political Science.

Streck, C., Burns, D. \& Guimaraes, L. 2012. Towards Policies for Climate Change Mitigation: Incentives and Benefits for Smallholder Farmers. No. 7, CCAFS.

Syed, S. \& Miyazako, M. 2013. Promoting Investment in Agriculture for Increased Production and Productivity. Rome, Italy, FAO. (also available at: http://www.fao.org/3/az725e/az725e.pdf).

Szoke-Burke, S. 2021. Transparency of Land-Based Investments: Cameroon Country Snapshot, Columbia Center on Sustainable Investment.

Tavares-Lehmann, A.T., Coelho, A. \& Lehman, F. 2012. Taxes and Foreign Direct Investment: A Literature Review. In New Policy Challenges for European Multinationals. Bingley, United Kingdom. 89- 117. Emerald Group Publishing.

Tavares-Lehmann, A.T., Toledano, P., Johnson, L. \& Sachs, L. 2016. Rethinking Investment Incentives: Trends and Policy Options. New York, US. Columbia University Press. (also available at: https://bit.ly/39tXpcc).

Teijeiro, G.0. 2015. BEPS Ancillary Matters Concerning Low Income Countries: Tax Treaties and Tax Incentives [online]. Kluwer International Tax Blog, [Cited 16 October 2020]. https://bit. ly/3do36cL.

Teye, J. 2019. Agribusiness Investment in Agricultural Commercialisation in Ghana: Rethinking Policy Incentives. Agricultural Policy Research in Africa Brief No. 19, APRA. 5 pp. (also available at: https://bit.ly/3mbY1bF).

Thi Canh, N. et al. 2004. An Empirical Study of Corporate Income Tax Investment Incentives for Domestic Companies in Vietnam. Washington DC, USAID. 93 pp. (also available at: https:// www.yumpu.com/en/document/read/21084862/an-empirical-study-of-corporate-income-taxinvestment-frp2org).

Thomas, K.P. 2007. Investment Incentives: Growing Use, Uncertain Benefits, Uneven Controls - An Exploration of Government Measures to Attract Investment. Geneva, Switzerland. Global Subsidies Initiative of the International Institute for Sustainable Development. 84 pp. (also available at: https://www.iisd.org/system/files/publications/gsi_investment_incentives.pdf).

Thompson, R.L. 2002. Agricultural Price Supports [online]. The Concise Encyclopedia of Economics. [Cited 20 October 2020] https://bit.ly/20XLe11. 
Tienhaara, K. \& Cotula, L. 2020. Raising the Cost of Climate Action? Investor-State Dispute Settlement and Compensation for Stranded Fossil Fuel Assets. London, UK. International Institute

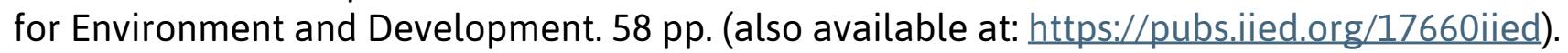

UNCTAD. 2001. The World of Investment Promotion at a Glance: A Survey of Investment Promotion Practices. Geneva, Switzerland. UNCTAD ASIT Advisory Studies No. 17. UNCTAD. (also available at: https://unctad.org/en/Docs/poiteipcd3.en.pdf).

UNCTAD. 2020. World Investment Report 2020: International Production beyond the Pandemic. Geneva, Switzerland. UNCTAD. (also available at: https://unctad.org/webflyer/worldinvestment-report-2020).

UNDP. 2015. Guidance Note - A Development Approach to Migration and Displacement. New York, US. United Nations Development Programme. (also available at: https://bit.ly/20aje9e).

UNDP. 2020. Payments for Ecosystem Services [online]. New York, US. UNDP Global: Financing Solutions for Sustainable Development. [Cited 20 October 2020] https://www.sdfinance.undp. org/content/sdfinance/en/home/solutions/payments-for-ecosystem-services.html.

United Nations and Inter-American Center of Tax Administrations. 2018. Design and Assessment of Tax Incentives in Developing Countries: Selected Issues and a Country Experience. New York. (also available at: https://www.un.org/esa/ffd/wp-content/uploads/2018/02/tax-incentives_eng. pdf).

United Nations Commission on International Trade Law. 2021. Working Group III: InvestorState Dispute Settlement Reform [online]. Vienna, Austria. UNCITRAL. [Cited 20 October 2020] https://uncitral.un.org/en/working_groups/3/investor-state.

United Nations Conference on Trade and Development. 2015. Investment Policy Framework for Sustainable Development. Geneva, Switzerland. UNCTAD. (also available at: https://bit. $\underline{\text { ly/3drGIz9). }}$

United Nations Human Rights Office of the High Commissioner. 2011. Guiding Principles on Business and Human Rights. OHCHR. (also available at: https://bit.ly/3wgybl4).

United Nations. 2013. UN World Youth Report 2013: Youth and Migration. New York, US. UN. (also available at: https://www.un.org/development/desa/youth/world-youth-report/2013-2.html).

United States Department of Agriculture Foreign Agricultural Service. 2019. United States Wins WTO Dispute Finding China Provides Excessive Government Support to Its Grain Producers [online]. Washington DC, US. [Cited 20 October 2020] https://www.usda.gov/media/pressreleases/2019/02/28/united-states-wins-wto-dispute-finding-china-provides-excessive.

University of Arkansas. 2021. Program Evaluation [online]. Fayetteville, US. University of Arkansas System Division of Agriculture: Research \& Extension, University of Arkansas. https:// www.uaex.edu/support-units/program-staff-development/program-evaluation/steps.aspx. 
UNMICO. 2020. Données Clées Sur Le Réseau (situation juin 2016) [online]. Nouakcott, Mauritanie. [Cited 20 October 2020]. http://unmico.net/?q=node/33.

USAID. 2019. Data Collection Methods and Tools for Performance Monitoring. In: USAID Learning Lab. Washington DC, US. USAID. (also available at: https://bit.ly/3dkCsBC).

van Es, M., Guijt, I. \& Vogel, I. 2015. Theory of Change Thinking in Practice. The Hague, Netherlands, Hivos. (also available at: https://bit.ly/3mir1P6).

Villamor, G.B., van Noordwijk, M,. Djanibekov, U., Chiong-Javier, M.E. \& Catacutan, D. 2014. Gender Differences in Land-Use Decisions: Shaping Multifunctional Landscapes? Current Opinion in Environmental Sustainability 6. (also available at: https://bit.ly/3sIOTWy).

Vogel, I. 2012. Review of the Use of "Theory of Change" in International Development, London, UK. UK Department of International Development (DFID). (also available at: https://bit. (y/3dnXSOJ).

Vorley, B., Cotula, L. \& Chan, M.K. 2012. Tipping the Balance: Policies to Shape Agricultural Investments and Markets in Favour of Small-Scale Farmers. International Institute for Environment and Development and Oxfam. December 2012.

Webb Yackee, J. 2010. Do Bilateral Investment Treaties Promote Foreign Direct Investment? Some Hints from Alternative Evidence. Va. J. Int'l L. 51, no. 397.

Webb, J. A., Watts, R.J., Allan, C. \& Warner, A.T. 2017. Principles for Monitoring, Evaluation, and Adaptive Management of Environmental Water Regimes. In Policy and Science to Implementation and Management, 559-623. Cambridge, MA: Academic Press.

Webb, J.A., Watts, R.J., Allan, C. \& Conallin, J.C. 2018. Adaptive Management of Environmental Flows. Environmental Management No. 61. (also available at: https://bit.ly/3wsgm9c).

Wells, L. 1986. Investment Incentives: An Unnecessary Debate. The CTC Reporter 22: 58-60.

Whitley, S., Granoff, I., Chiofalo, E,. Halimanjaya, A. \& Pickard, S. 2014. Private Climate Finance in Sub-Saharan Africa: Mapping Incentives and Investment. ODI Working and Discussion Papers. (also available at: https://bit.ly/2PKXRMn).

Williams, B.K. \& Brown, E.D. 2014. Adaptive Management: From More Talk to Real Action. Environmental Management 53.

Woodward, J.D., Sherrick, B.J. \& Schnitkey, G.D. 2010. Revenue Risk Reduction Impacts of Crop Insurance in a Multi-Crop Framework. Applied Economic Perspectives and Policy 32, No. 3.

World Bank Group. 2017. Technical Discussion Paper on Concessional Insurance. Disaster Risk Financing \& Insurance Program. (also available at: https://elibrary.worldbank.org/doi/ abs/10.1596/31217). 
World Bank. 2016. A Year in the Lives of Smallholder Farmers [online]. Washington DC, World Bank. [Cited 20 October 2020]. https://bit.ly/3mbtSto.

World Bank. 2020. Agriculture Finance \& Agriculture Insurance [online]. Washington DC, World Bank. [Cited 20 October 2020]. https://bit.ly/3wdgmtD.

World Trade Organization. 2020. Agriculture: Explanation - Domestic Support [online]. Geneva, Switzerland. World Trade Organization. [Cited 21 October 2020]. https://bit.ly/39AkTMZ.

World Wildlife Fund. 2021. When Infrastructure Goes Wrong for Nature and People [online]. Gland, Switzerland. WWF. https://www.worldwildlife.org/stories/when-infrastructure-goeswrong-for-nature-and-people. 



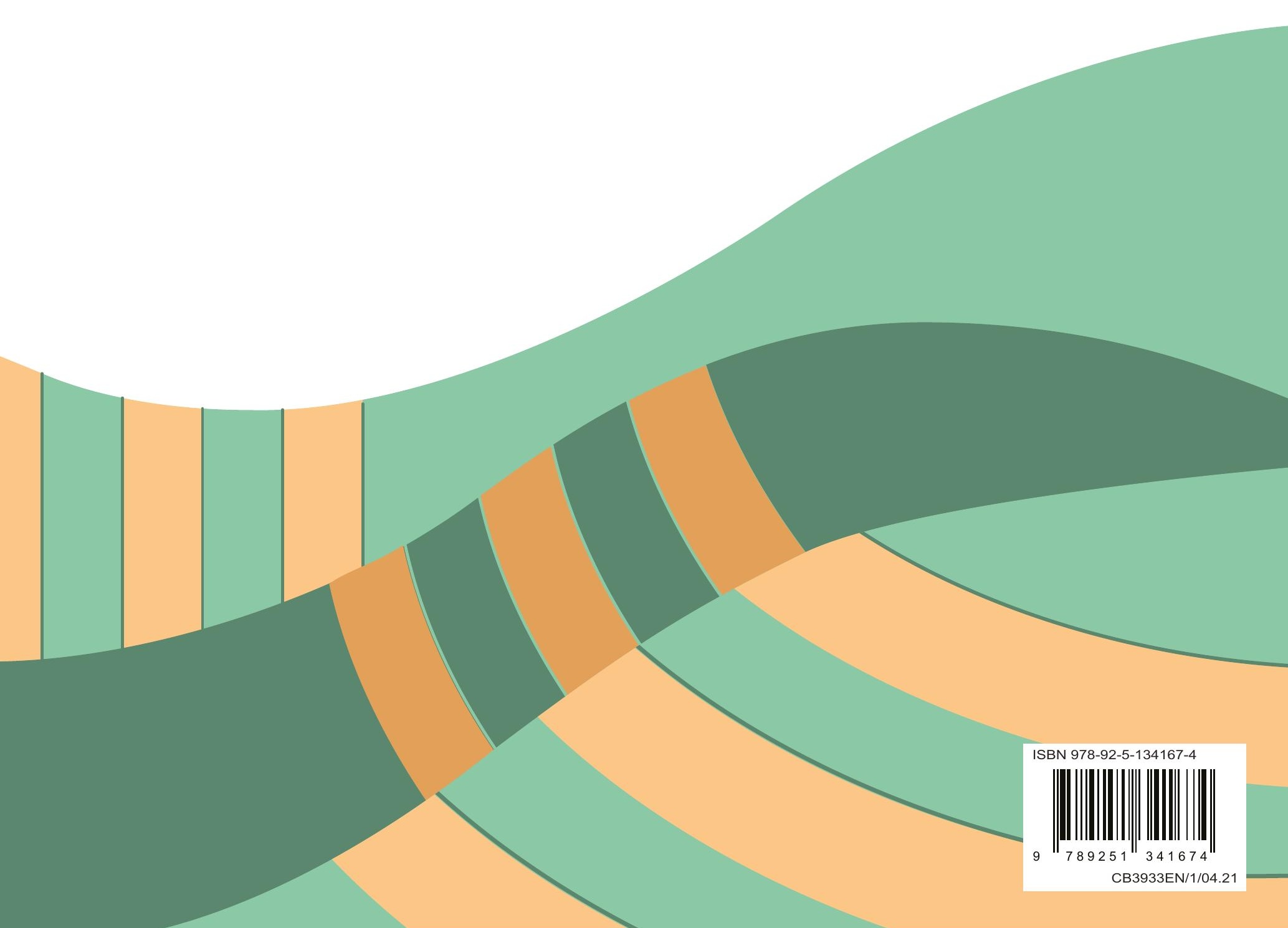

